\title{
THE ROLE OF ASTROCYTES IN MURINE MODELS OF TOXIC DEMYELINATION
}

\section{Doctoral Thesis}

In partial fulfillment of the requirements for the degree

"Doctor rerum naturalium (Dr. rer. nat.)"

in the Molecular Medicine Study Program

at the Georg-August University Göttingen

\author{
submitted by \\ Lena Menken \\ born in Achim
}

Göttingen, April 2016 


\section{Members of the thesis committee:}

\section{Supervisor (Reviewer)}

Prof. Dr. Wolfgang Brück

Department of Neuropathology

University Medical Center, Georg-August University Göttingen

Second Member of the thesis committee (Reviewer)

Prof. Dr. Mikael Simons

Department of Cellular Neuroscience

Max-Planck-Institute for Experimental Medicine, Göttingen

Department of Neurology

University Medical Center, Georg-August University Göttingen

Third member of the thesis committee

Prof. Dr. Alexander Flügel

Institute for Multiple Sclerosis Research, Dept. of Neuroimmunology

University Medical University Medical Center, Georg-August University Göttingen

Date of disputation: 


\section{Affidavit}

Here I declare that my doctoral thesis entitled "The role of astrocytes in murine models of toxic demyelination" has been written independently with no other sources and aids than quoted.

\section{Lena Menken}

Göttingen, April 2016 


\section{List of publications}

\section{Original article}

Kramann N, Neid K, Menken L, Schlumbohm C, Stadelmann C, Fuchs E, Brück W, Wegner C, (2015). Increased Meningeal T and Plasma Cell Infiltration is Associated with Early Subpial Cortical Demyelination in Common Marmosets with Experimental Autoimmune Encephalomyelitis. Brain pathology (Zurich, Switzerland) 25: 276-86

Kramann $\mathrm{N}^{*}$, Menken L*, Hayardeny L, Hanisch UK, Brück W, (2016). Laquinimod prevents cuprizone-induced demyelination independent of Toll-like receptor signalling. Neurology: Neuroimmunology \& Neuroinflammation MS (in press)

${ }^{*}=$ equal contribution

\section{Abstract}

Menken L, Swiniarski A, Ott M, Brück W, Wegner C

Glial changes in normal-appearing white matter in inflammatory demyelinating diseases

$58^{\text {th }}$ Annual Meeting of the German Society for Neuropathology and Neuroanatomy, 11-14 September 2013, Göttingen, Germany 


\section{Table of contents}

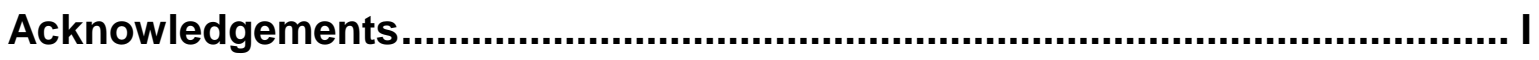

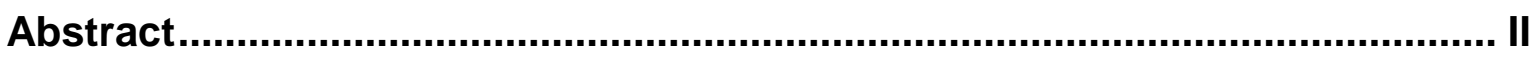

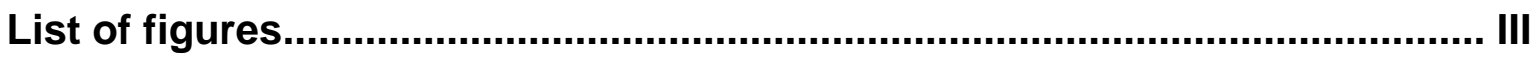

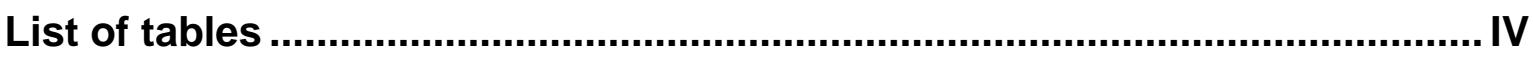

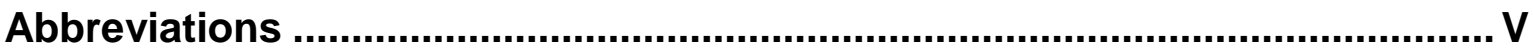

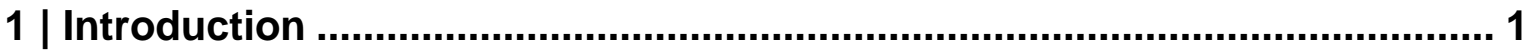

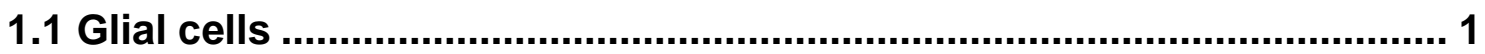

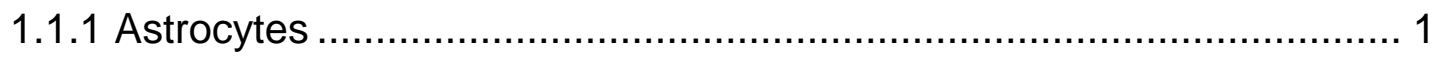

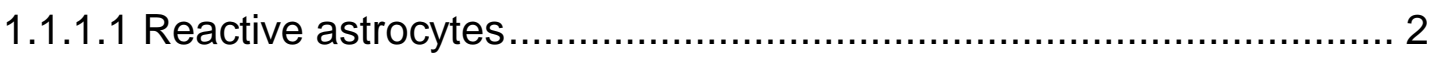

1.1.1.2 The NF-kB signalling pathway .................................................. 3

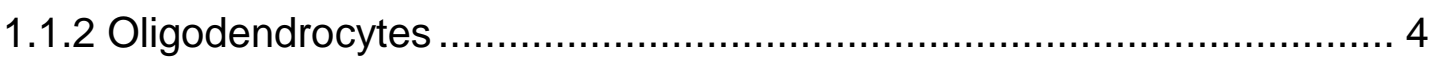

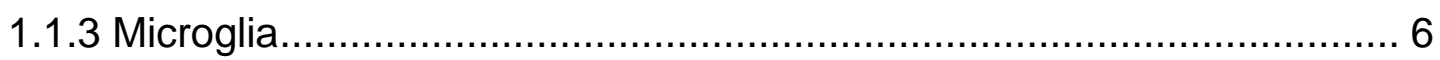

1.2 Toxic demyelination - murine models of multiple sclerosis .................. 7

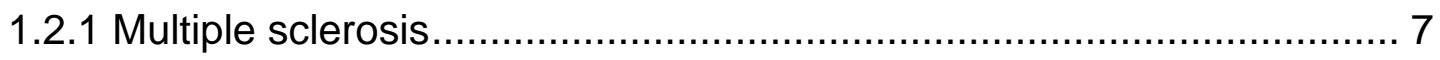

1.2.2 Animal models of toxic demyelination ............................................. 8

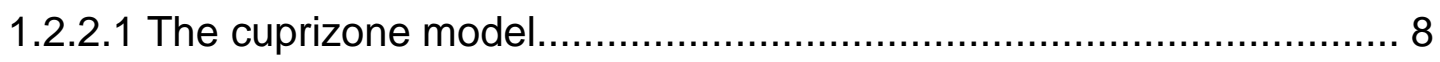

1.2.2.2 The focal lesion model ........................................................... 9

1.3 The GFAP Tg73.7 transgenic mice with elevated hGFAP expression . 10

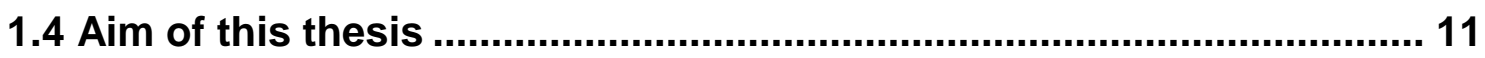

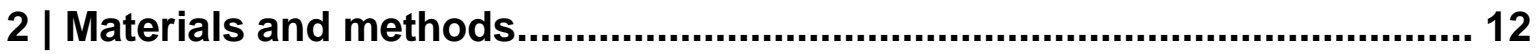

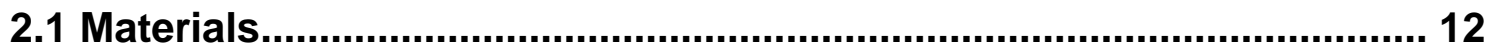

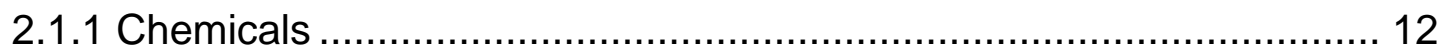

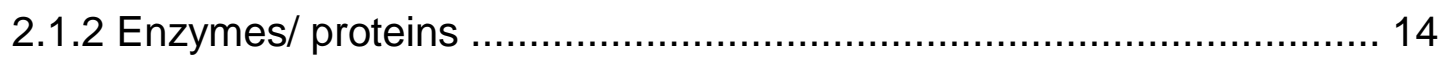

2.1.3 Applied kits and gene expression assays ...................................... 15 


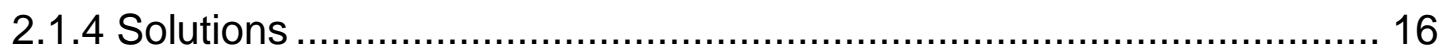

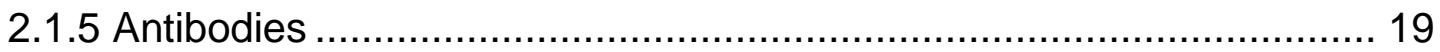

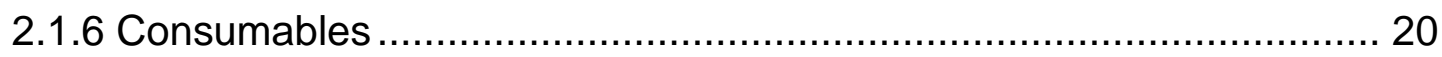

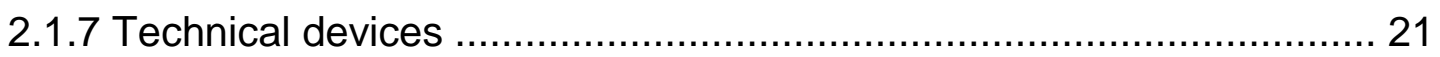

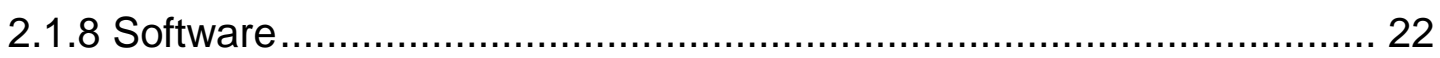

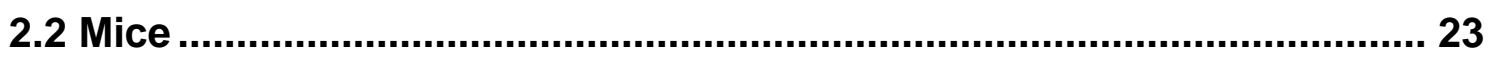

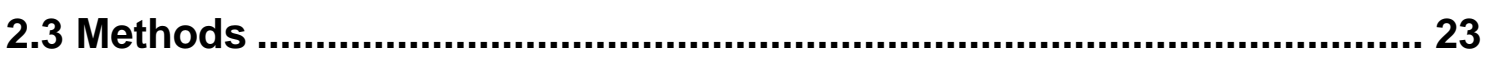

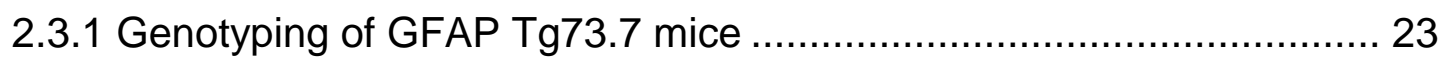

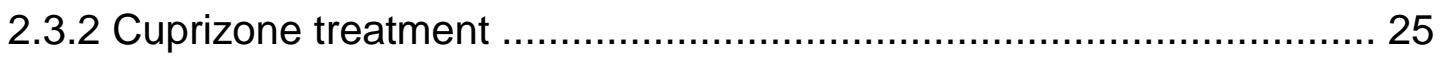

2.3.3 Intracerebral stereotactic injection with lysolecithin........................... 25

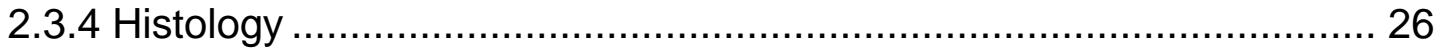

2.3.4.1 Luxol fast blue-periodic acid-Schiff staining ................................. 27

2.3.4.2 Bielschowsky silver impregnation ............................................ 28

2.3.4.3 Immunohistochemistry and fluorescence staining.......................... 28

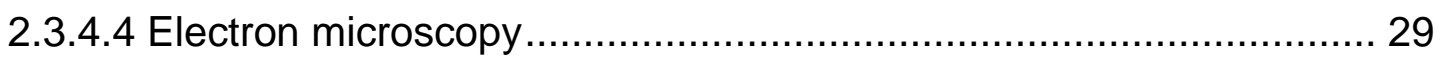

2.3.5 Astrocyte isolation from newborn mice ........................................ 30

2.3.6 Analysis of NF-KB activation in isolated astrocytes ........................... 31

2.3.7 Analysis of myelin phagocytosis in co-cultures of microglia with

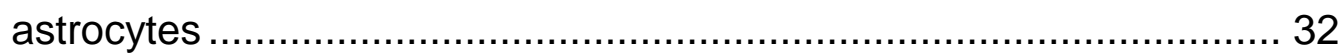

2.3.8 Measurement of cytokine and chemokine expression ...................... 33

2.3.8.1 RNA isolation from corpus callosum and primary astrocytes .......... 33

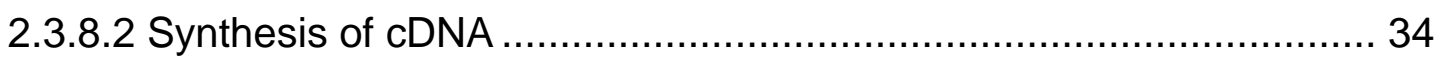

2.3.8.3 Measurement of gene expression by quantitative real-time PCR .... 35

2.3.8.4 Quantification of relative gene expression .................................... 36

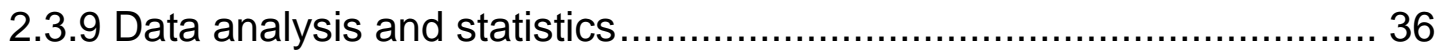

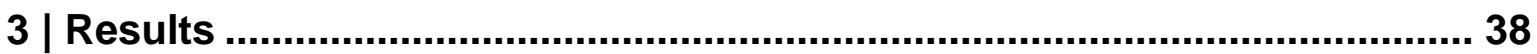

\subsection{Evaluating the effect of enhanced astrocytic human GFAP expression} on oligodendrocytes and microglia during toxic demyelination ............ 38

3.1.1 Regular myelin density and oligodendrocyte numbers but increased astrogliosis in naïve GFAP Tg73.7 mice ....................................... 38

3.1.2 Reduced cuprizone-induced weight loss and apoptosis in GFAP Tg73.7 mice after one week 
3.1.3 Reduced cuprizone-induced demyelination in GFAP Tg73.7 mice ..... 40 3.1.4 Reduced cuprizone-induced oligodendrocyte loss in GFAP Tg737 mice

3.1.5 Reduced cuprizone-induced acute axonal damage in GFAP Tg73.7 mice. 43

3.1.6 Less cuprizone-induced microglia infiltration in GFAP Tg73.7 mice ... 44

3.1.7 Less cuprizone-induced demyelination and oligodendrocyte loss, but similar microglia infiltration in GFAP Tg73.7 after 12 weeks of cuprizone treatment 45

3.1.8 Less efficient lysolecithin-induced focal demyelination, but similar microglia infiltration and oligodendrocyte numbers in GFAP Tg73.7 mice

3.1.9 Reduced NF-KB-activity in lysolecithin-induced focal demyelinated lesions in GFAP Tg73.7 mice 49

\subsection{Evaluating the effect of enhanced astrocytic hGFAP expression in} astrocytes on myelin and cytokine mRNA expression

3.2.1 Increased cuprizone-induced myelin mRNA expression in GFAP

Tg73.7 mice in vivo. 50

3.2.2 Less cuprizone-induced CCL2 and CXCL10 mRNA expression in GFAP Tg73.7 mice in vivo.

3.2.3 CXCL10 is expressed in astrocytes after 6 weeks of cuprizone-induced demyelination 53

3.2.4 Unaltered CCL2 and CXCL10 mRNA expression in GFAP Tg73.7 astrocytes after cytokine stimulation in vitro 55

3.2.5 Lower NF-KB activity in GFAP Tg73.7 astrocytes after cytokine stimulation in vitro.

\subsection{Reduced phagocytosis activity of microglia in co-cultures with} astrocytes in vitro.

4 | Discussion 


\subsection{Astrocytes with enhanced hGFAP expression protect from}

oligodendrocyte loss during cuprizone-induced demyelination

4.3.1 Beneficial effects of reactive astrocytes due to enhanced hGFAP expression during toxic demyelination

4.3.2 Astrocytes with enhanced hGFAP expression lead to oligodendrocyte preservation during cuprizone-induced demyelination but not in focal lesions 66

4.3.3 Altered chemokine expression of astrocytes may be beneficial for oligodendrocytes during cuprizone-induced demyelination 69

\subsection{Astrocytes with enhanced hGFAP expression regulate microglia} recruitment during cuprizone treatment.

4.4.1 Reduced cuprizone-induced oligodendrocyte death and less myelin degeneration is associated with less microglia infiltration but not in focal lesions

4.4.2 Reduced CCL2 and CXCL10 mRNA expression decreases microglia recruitment during cuprizone-induced demyelination

4.5 Reduced NF-KB activity in reactive astrocytes protects from exacerbated toxic demyelination 76

4.6 Summary and conclusions 78

5 | Outlook 80

6| References. 


\section{Acknowledgements}

First and foremost I would like to thank my supervisors Dr. Dr. Christiane Theodossiou-Wegner and Dr. Nadine Kramann for the guidance and the support during the years of my $\mathrm{PhD}$ thesis and for sharing their scientific expertise with me.

I would like to also express gratitude to Prof. Dr. Wolfgang Brück for giving me the opportunity to join his lab. I would also acknowledge him for supervising my project and for his scientific input and discussions. In addition, I want to thank Prof. Dr. Christine Stadelmann-Nessler for her scientific expertise and her helpful advices.

I want to thank my thesis committee members Prof. Dr. Mikael Simons and Prof. Dr. Alexander Flügel for their interest in my project and their supportive contributions during my progress reports. Additionally, I want to thank Prof. Dr. Mikael Simons for agreeing to act as second reviewer.

Many thanks to our laboratory assistants Mareike, Brigitte, Katja, Heidi, Olga and Sarah for their excellent technical and theoretical support in histology, immunohistochemistry and electron microscopy as well as for the nice conversations and the enjoyable atmosphere in the lab. Additionally, I am thankful to Elke and Susanne for their great technical and theoretical help with the microglia co-culture experiments. Furthermore, I want to thank Linda and Christin for their great help with the flow cytometry experiments and analysis. Also, I am grateful to Anne for her helpful comments on this manuscript and our scientific discussions.

I want to thank Insa, Nielsen, Claudia, Franziska, Alonso, Patrik, Linda, Sarah, Anne, Christin and all other colleagues and friends for the enjoyable working atmosphere, scientific discussions, and also the nice time we spent outside the lab.

I want to acknowledge our secretaries Cynthia and Heidi for administrative support and the Molecular Medicine PhD program.

Also I want to thank my friends Jana and Tina for their limitless practical and emotional support. And I am grateful to my parents for supporting me over all these years.

Finally, I would like to thank Thomas for believing in me, his patience and for always being there. 


\section{Abstract}

In demyelinating diseases such as multiple sclerosis (MS) activated astrocytes, characterised by up-regulation of the intermediate filament glial fibrillary acidic protein (GFAP), were shown to have beneficial as well as detrimental effects on demyelination. Therefore, this study aims to investigate the effect of enhanced GFAP expression in astrocytes on the interaction with oligodendrocytes and microglia during demyelination. To address this question, toxic demyelination was induced in transgenic mice with human (h)GFAP overexpression using two different approaches: the cuprizone model and intracerebral injection of lysolecithin.

The results demonstrated that an enhanced hGFAP expression in astrocytes has protective effects in both models, resulting in reduced demyelination and decreased oligodendrocyte loss during cuprizone treatment. Furthermore, this study demonstrated that enhanced hGFAP expression in astrocytes reduced microglia infiltration during cuprizone treatment. This observation might be explained by decreased mRNA expression of the chemokines CCL2 and CXCL10 in transgenic mice. Both chemokines were demonstrated to regulate microglia recruitment. Additionally, this study demonstrated that NF-KB activity was reduced in vitro and in vivo in astrocytes of transgenic mice with enhanced GFAP expression. The nuclear transcription factor (NF)-KB signalling pathway was shown to regulate the expression of CCL2 and CXCL10 in reactive astrocytes.

This study confirms that reactive astrocytes have protective effects in models of toxic demyelination in vivo. Enhanced hGFAP expression seems to modulate astrocytic chemokine expression, presumably via a reduced activation of the NF-KB pathway. The reduction of CCL2 and CXCL10 expression levels results in reduced microglia recruitment which may lead to reduced demyelination. 


\section{List of figures}

Figure 1: The three glial cell types in the CNS. ……...................................... 5

Figure 2: Reactive astrocytes in naïve GFAP Tg73.7 mice. ............................. 38

Figure 3: No alterations in microglia and oligodendrocyte density in naïve GFAP Tg73.7 mice.

Figure 4: Decreased apoptosis in GFAP Tg73.7 mice after 1 week of cuprizoneinduced demyelination and higher body weights during 6 weeks of cuprizone treatment.

Figure 5: Decreased cuprizone-induced demyelination in GFAP Tg73.7 mice. ... 41

Figure 6: Less demyelinated axons in GFAP Tg73.7 mice after 6 weeks of cuprizone-induced demyelination. 42

Figure 7: Reduced oligodendrocyte loss in GFAP Tg73.7 mice. ........................ 43

Figure 8: Less acute axonal damage in GFAP Tg73.7 mice. ............................ 44

Figure 9: Less microglia infiltration in GFAP Tg73.7 mice. 45

Figure 10: After 12 weeks of cuprizone treatment, cuprizone-induced demyelination and oligodendrocyte loss is less, whereas microglia infiltration is not altered in GFAP Tg73.7 mice.

Figure 11: Smaller demyelinated lesions in GFAP Tg73.7 mice and no differences in microglia infiltration and oligodendrocyte numbers compared to wild type mice.

Figure 12: Reduced astrocytic NF-KB activity in lysolecithin-induced lesions in GFAP Tg73.7 mice.

Figure 13: Higher myelin mRNA levels in GFAP Tg73.7 mice after 3 weeks of cuprizone-induced demyelination.

Figure 14: Cytokine and chemokine mRNA expression in vivo after 3 and 6 weeks of cuprizone-induced demyelination. 53

Figure 15: Astrocytes express CXCL10 after six weeks of cuprizone-induced demyelination.

Figure 16: Microglia and oligodendrocytes do not express CXCL10 during cuprizone-induced demyelination.

Figure 17: Similar expression levels of CCL2 and CXCL10 mRNA in GFAP Tg73.7 and wild type astrocytes in vitro.

Figure 18: Diminished increase in NF-kB activity in stimulated primary astrocytes of GFAP Tg73.7 mice. 
Figure 19: Astrocytes inhibit myelin phagocytosis activity of microglia in vitro. .... 58

Figure 20: Summary of the effects of enhanced hGFAP expression in astrocytes on demyelination, mature oligodendrocyte numbers and microglia infiltration during cuprizone-induced demyelination.

Figure 21: Schematic overview of the effects of enhanced hGFAP expression in astrocytes during cuprizone-induced demyelination resulting in preserved oligodendrocytes, myelin and reduced microglia recruitment in GFAP Tg73.7 mice.

\section{List of tables}

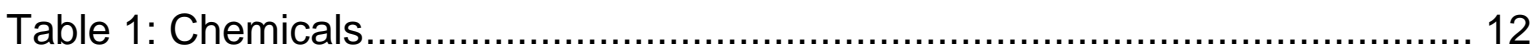

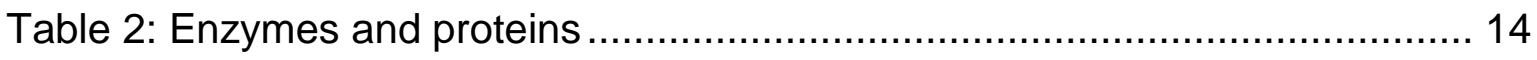

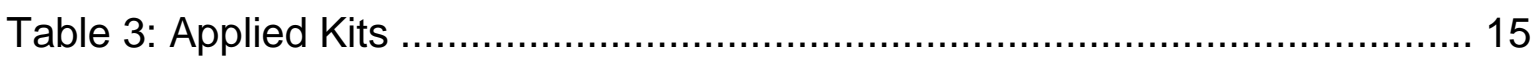

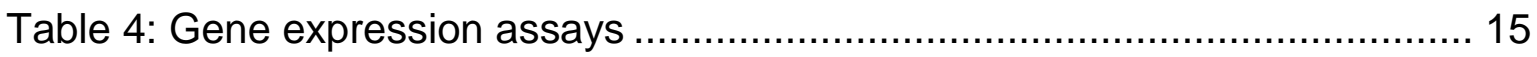

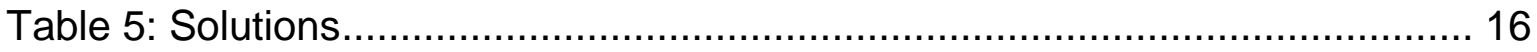

Table 6: Solutions for electron microscopy ............................................. 17

Table 7: Solutions for (immuno-) histochemistry ......................................... 17

Table 8: Solution for cell culture ............................................................ 18

Table 9: Primary antibodies for immunohistochemical staining ........................ 19

Table 10: Secondary antibodies for immunohistochemical staining ................... 20

Table 11: Flow cytometry antibodies ........................................................... 20

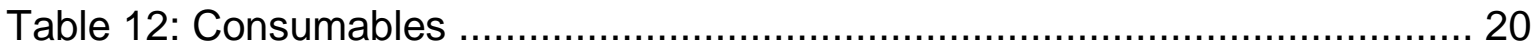

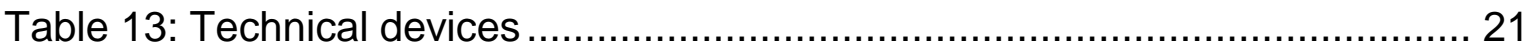

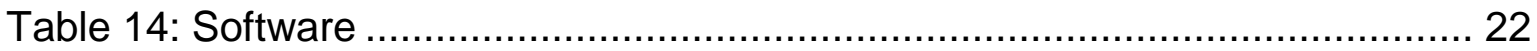

Table 15: Primers sequences for genotyping PCR of GFAP Tg73.7 mice. .......... 24

Table 16: Cycle parameters for genotyping PCR ...................................... 24

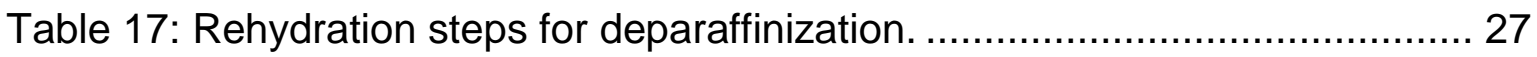

Table 18: Dehydration steps for EM. ........................................................ 30

Table 19: Cycle parameters for cDNA synthesis........................................... 34

Table 20: Cycle parameters for qPCR ....................................................... 36 


\section{Abbreviations}

\begin{tabular}{|c|c|}
\hline${ }^{\circ} \mathbf{C}$ & Degree Celsius \\
\hline$\mu \mathrm{l}$ & Microliter \\
\hline$\mu \mathrm{m}$ & Micrometre \\
\hline$\infty$ & Infinity \\
\hline $\mathrm{AgNO}_{3}$ & Silver nitrate \\
\hline Aldh1l1 & aldehyde dehydrogenase family 1 member L1 \\
\hline ANOVA & Analysis of variance \\
\hline APP & Amyloid precursor protein \\
\hline ATP & Adenosine-5triphosphat \\
\hline BBB & Blood brain barrier \\
\hline BDNF & Brain-derived neurotrophic factor \\
\hline bp & Base pairs \\
\hline CCL2/5 & C-C motif chemokine ligand $2 / 5$ \\
\hline CCR2/5 & C-C motif chemokine receptor $2 / 5$ \\
\hline cDNA & Complementary DNA \\
\hline cm & Centimeter \\
\hline CNPase & cyclic nucleotide phosphodiesterase \\
\hline CNS & Central nervous system \\
\hline Ctrl & Control \\
\hline $\mathrm{CuSO}_{4}$ & Copper sulphate \\
\hline CXCL10/12 & C-X-C motif chemokine 10/12 \\
\hline Cy2/3 & Cyanine 2/3 \\
\hline DAB & 3,3`-diaminobenzidine tetrachloride \\
\hline DAPI & 4',6-diamidino-2-phenylindole \\
\hline DMEM & Dulbecco's modified Eagle's medium \\
\hline DNA & Desoxyribonucleic acid \\
\hline dNTP & Desoxynucleotide triphosphate \\
\hline EAAT1/2 & Excitatory amino acid transporter $1 / 2$ \\
\hline EAE & Experimental autoimmune encephalomyelitis \\
\hline EM & Electron microscopy \\
\hline ERK & The extracellular-signal-regulated protein kinase \\
\hline FACS & Fluorescent-activated cell sorting \\
\hline FCS & Fetal calf serum \\
\hline g & Gram \\
\hline GLAST & Glutamate aspartate transporter \\
\hline GFAP & Glial fibrillary acidic protein \\
\hline $\mathbf{h}$ & Hour \\
\hline HBSS & Hank`s buffered salt solution \\
\hline $\mathrm{HCl}$ & Hydrogen chloride \\
\hline
\end{tabular}




\begin{tabular}{|c|c|}
\hline hGFAP & Human GFAP \\
\hline i.p. & Intraperitoneal \\
\hline HSV-TK & Herpes simplex virus thymidine kinase \\
\hline $\lg G$ & Immunoglobulin G \\
\hline IL & Interleukin \\
\hline $\mathrm{IL}-1 \beta$ & Interleukin 1 beta \\
\hline INFy & Interferon-gamma \\
\hline IKB & Inhibitor of kappa B \\
\hline $\mathbf{k b}$ & Kilo base pairs \\
\hline kg & Kilogram \\
\hline LFB-PAS & Luxol fast blue/ periodic acid-Schiff \\
\hline LPS & Lipopylsaccharide \\
\hline $\mathbf{M}$ & Molar \\
\hline MAG & Myelin-associated glycoprotein \\
\hline MAPKs & Mitogen-activated protein kinases \\
\hline MBP & Myelin basic protein \\
\hline mg & Milligram \\
\hline $\min$ & Minute \\
\hline ml & Millilitre \\
\hline mm & Millimetre \\
\hline $\mathrm{mM}$ & Millimolar \\
\hline $\mathrm{mm}^{2}$ & Square millimetre \\
\hline MOG & Myelin oligodendrocyte glycoprotein \\
\hline mRNA & Messenger RNA \\
\hline MS & Multiple sclerosis \\
\hline MRP14 & Marker myeloid-related protein 14 \\
\hline NAPDH & Nicotinamide adenine dinucleotide phosphate \\
\hline NF-kB & Nuclear factor kappa B \\
\hline NO & Nitric oxide \\
\hline OPC & Oligodendrocyte precursor cells \\
\hline PBS & Phosphate buffered saline \\
\hline PCR & Polymerase chain reaction \\
\hline PDGF & Platelet derived growth factor \\
\hline PFA & Paraformaldehyde \\
\hline PLP & Proteolipid protein \\
\hline qPCR & Quantitative real time PCR \\
\hline RNA & Ribonucleic acid \\
\hline ROS & Reactive oxygen species \\
\hline rpm & Rounds per minute \\
\hline $\mathbf{s}$ & Second \\
\hline SEM & Standard error of the mean \\
\hline
\end{tabular}




\begin{tabular}{l|l} 
TBE & Tris/Borate/EDTA \\
Tg & Transgenic (GFAP Tg73.7 mouse) \\
TNFa & Tumor necrosis factor alpha \\
Tris & Tris(hydroxymethyl)aminomethane \\
$\mathbf{W T}$ & Wild type mouse \\
$\mathbf{V}$ & Volt \\
\hline
\end{tabular}




\section{1 | Introduction}

\subsection{Glial cells}

There are four main glial cell types in the central nervous system (CNS): astrocytes, oligodendrocytes, microglia and ependymal cells, which support neurons by providing growth factors, maintain the brain homeostasis and regulate the CNS immunity. This work focusses on astrocytes and their interaction with microglia and oligodendrocytes during demyelination.

\subsubsection{Astrocytes}

Astrocytes have many regulatory functions in the CNS. They are primary responsible for maintaining brain homeostasis in several ways, including potassium/ sodium balance (Hertz 1965, Hertz et al 2015), copper (Scheiber \& Dringen 2013), water (Hubbard et al 2015, Nielsen et al 1997) and the reuptake of the neurotransmitter glutamate (Danbolt 2001). They orchestrate the homeostasis with several channels and transporters, for example the water channel aquaporin-4, which regulates the water homeostasis in the brain (Hubbard et al 2015, Nielsen et al 1997). Astrocytes reuptake extracellular glutamate via the glutamate transporter GLAST (glutamate aspartate transporter) and GLT-1 which is then converted to glutamine and released to the extracellular fluid to be taken up by neurons and reconverted to glutamate inside neurons (Bergles \& Jahr 1997, Martinez-Hernandez et al 1977, Van Den Berg \& Garfinkel 1971). Additionally, astrocytes are part of the blood brain barrier (BBB), which separates the brain from the blood and regulates the molecular exchange (Abbott et al 2006). Moreover, astrocytes are involved in synaptic transmission and synaptogenesis by the secretion of factors like glypicans that induce the formation of functional excitatory synapses between neurons (Allen et al 2012, Ullian et al 2001).

Classically, astrocytes are identified by the expression of their main intermediate filament glial fibrillary acidic protein (GFAP) and star-like morphology (Bignami et al 1972, Eng 1985, Eng et al 1971, Uyeda et al 1972). Together with vimentin and nestin GFAP builds the intermediate filament network in astrocytes and maintains the mechanical integrity of astrocytes and tissue (Eliasson et al 1999, Eng \& 
Ghirnikar 1994). But astrocytes are a heterogeneous cell population and gene expression of astrocytes depends among others on the brain region and developmental stage. Therefore, GFAP as classic astrocyte marker does not mark all astrocytes. Astrocytes from the brainstem, neocortex and cerebellum contain more than $98 \%$ GFAP-positive astrocytes, but cells from the optic nerve contain fewer than 30\% GFAP-positive astrocytes (Yeh et al 2009). Cortical astrocytes were shown to express increased levels of Foxg1, Nr2el mRNA and astrocytes from the cerebellum express En2, Pax and Scn7 in vitro (Yeh et al 2009). Additionally, astrocytes from different brain regions show unique biological properties. Thus, astrocyte coupling via gap-junctions is stronger in astrocytes in the cerebellum and optic nerve than spinal cord or cortical astrocytes (Lee et al 1994). Furthermore, it was recently demonstrated that gene expression of human astrocytes changes during the different stages of astrocyte maturation and it was confirmed that mature human astrocytes express genes for synapse-induction, gap-junctions and neural transmitter recycling in vitro (Zhang et al 2016). However, to differentiate astrocytes from other glia cells, the expression of cell surface proteins and proteins integral in the plasma membrane are the most cell type-specific ones and the most specific protein molecules for astrocytes includes GFAP and the glutamate transporter GLAST, the enzyme aldehyde dehydrogenase family 1 member L1 (Aldh1l1) and the water channel aquaporin-4 (Sharma et al 2015). More than $80 \%$ of the astrocytes from brainstem, neocortex and cerebellum express GLAST (Yeh et al 2009). Additionally, glutamine synthetase might be a marker for mature and immature astrocytes ( $\mathrm{He}$ et al 2007) and is highly co-expressed with GFAP (Ståhlberg et al 2011).

\subsubsection{Reactive astrocytes}

As consequence to CNS injuries, demyelinating disease like multiple sclerosis (MS) and trauma astrocytes become activated and form the so called reactive astrocytes or reactive astrogliosis (Dahl \& Bignami 1974, Eddleston \& Mucke 1993, Eng 1985, Roessmann \& Gambetti 1986). The formation of reactive astrocytes induces a complex shift in the astrocytes cell states including morphological alterations with increased thickness of their extended processes (Wilhelmsson et al 2006), alterations of the cytoskeleton with GFAP up-regulation (Dahl \& Bignami 1974, Eddleston \& Mucke 1993, Eng 1985, Sofroniew 2009) and alterations in gene 
expression (Eddleston \& Mucke 1993). These alterations have detrimental as well as beneficial effects during demyelination. For instance, the glial scar, which is formed by reactive astrocytes, on the one hand barriers the infiltration of inflammatory cells (Brambilla et al 2014, Sofroniew 2009, Voskuhl et al 2009) and on the other hand prevents regeneration by secreting inhibitory factors like chondroitin sulphate proteoglycans (Davies et al 1999). The former has a beneficial effect during demyelination and the latter is detrimental. Thus, the heterogeneity of reactive astrocytes is thought to produce different types of outcomes, one being inhibitory and others not (Liddelow \& Barres 2016).

Furthermore, reactive astrocytes modulate their environment by secreting a specific subset of inflammatory cytokines and chemokines. Chemokines induce chemotaxis in microglia and attract them to the lesion area. In vitro and in vivo studies have shown that reactive astrocytes change their expression profile during activation (Choi et al 2014, Dong \& Benveniste 2001, Hibbits et al 2012, Kang et al 2014, Meeuwsen et al 2003, Pekny \& Nilsson 2005, Pekny \& Pekna 2014, Pekny et al 2014, Skripuletz et al 2012, Zamanian et al 2012). Reactive human astrocytes newly secrete the cytokines and chemokines like CD45, interleukin $1 \beta$ (IL-1 $\beta$ ), C-X-C motif ligand 10 (CXCL10), C-C motif ligand 3 (CCL3), CCL5 and tumour necrosis factor a (TNFa) upon cytokine stimulation in vitro (Choi et al 2014). Another study demonstrated that human astrocytes isolated from postmortem brain tissue show increased mRNA levels of CCL2, CCL5, CXCL8 and growth factors in vitro (Meeuwsen et al 2003). Remarkably, different types of injury cause different changes in gene expression in vivo including cytokines corresponding to the heterogeneity of astrocytes (Zamanian et al 2012). Many cytokines and chemokines expressed by astrocytes are involved in controlling and interacting with immune cells like the microglia chemoattractant CCL2 (Zamanian et al 2012). Overall, the broad range of regulated genes demonstrate the complexity of reactive astrocytes.

\subsubsection{The NF-kB signalling pathway}

Numerous inflammatory cytokines and chemokines expressed by reactive astrocytes are regulated by the transcription factor nuclear-factor (NF)-KB (Choi et al 2014, Kaltschmidt \& Kaltschmidt 2009). In the healthy CNS NF-KB is not activated in astrocytes or other glial cells (Schmidt-Ullrich et al 1996). The rapid regulation of 
gene transcription by activation of NF-KB allows cells to rapidly response to extracellular stimuli. Furthermore, the inhibition of astrocytic NF-KB was shown to decrease demyelination (Raasch et al 2011) and the anti-inflammatory effect of the immunomodulatory drug laquinimod in MS is mediated through an inhibition of astrocytic NF-KB activity (Brück et al 2012). NF-KB activation can be induced by TNFa, IL $1 \beta$ or TLR and is the main signalling in the initiation of innate immunity and inflammation (Mc Guire et al 2013). When not activated NF-KB dimers are inhibited in the cytoplasm by binding to the inhibitor of KB (IKB) (Baeuerle \& Baltimore 1988). After activation, the signal is transduced through receptors, adaptor proteins and kinases to activate the IKB kinas (IKK) complex. The IKK complex than phosphorylates IKBs (Ghosh \& Baltimore 1990). The phosphorylated IKB is than polyubiquinated and subsequently degradated by the $26 \mathrm{~S}$ proteosom. After that NF$\mathrm{KB}$ dimers can accumulate and translocate into the nucleus where they activate transcription (Wong \& Tergaonkar 2009).

\subsubsection{Oligodendrocytes}

Oligodendrocytes are the myelin forming cells of the CNS and interact closely with neurons and their axons. By wrapping multi-layered sheaths of their extended cell membrane around the axon oligodendrocytes form the myelin sheaths. One oligodendrocyte forms myelin for several neighbouring axons (Figure 1). The myelination of axons is essential for rapid nerve conduction in vertebrates (Moore et al 1978, Rushton 1951). Thus, myelination increases signal speed and the development of complex and compact neural circuits (Saab et al 2013). Beyond signalling, compact myelin sheaths are essential for neuronal functions (Griffiths et al 1998). The long axons of neurons are vulnerable and the ensheathing by oligodendrocytes therefore protects axonal integrity (Simons \& Nave 2015). Furthermore, oligodendrocytes have a metabolic supportive function for axons (Funfschilling et al 2012). The three myelin proteins myelin-associated glycoprotein (MAG), protein proteolipid protein (PLP) and myelin basic protein (MBP) are expressed by oligodendrocytes and important for compact myelin formation. The two main proteins in compact myelin are PLP and MBP and the absence of MBP leads to dysmyelinated axons (Brady et al 1999). The lack of PLP causes altered oligodendrocyte function and leads to axonal swelling and degeneration (Griffiths et al 1998) and MAG is suggested to modulate myelination (Quarles 2007). 


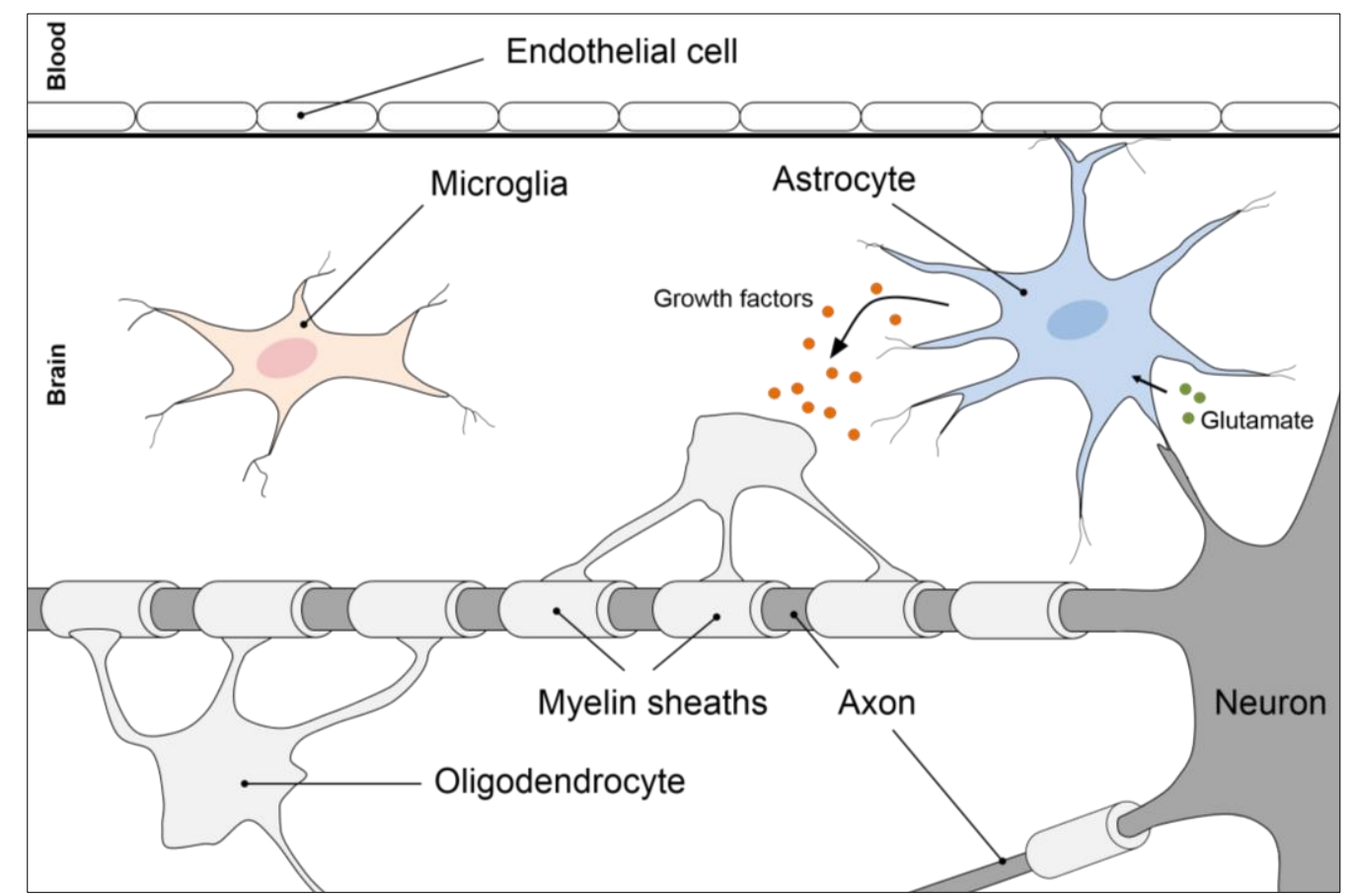

Figure 1: The three glial cell types in the CNS.

Astrocytes have many regulatory functions. They maintain the brains homeostasis, build the blood brain barrier with endothelial cells, recycle glutamate and provide growth factors for oligodendrocytes. Oligodendrocytes form the myelin sheaths around the axons and microglia are the phagocytic and immune cells of the CNS.

In MS, demyelination and oligodendrocyte death are among the earliest pathological changes (Brück \& Stadelmann 2005) but with heterogeneity between different MS patients (Brück et al 1994). The loss or damage of oligodendrocytes during demyelination leads to unprotected axons. The unprotected axons are more vulnerable to neurotoxic factors which are produced during inflammation, including reactive oxygen species (ROS), nitric oxide or glutamate (Saab et al 2013). This causes axonal damage and degeneration, subsequently leading to persistent disability in patients (Bjartmar et al 2003). Cytokines which were released during inflammation and demyelination can act on oligodendrocytes due to a broad range of immune receptors like CXCR1, CXCR2, CXCR3 (receptor for chemokines) and TNF-R1/R2 (receptor for TNFa) (Omari et al 2005). Thereby oligodendrocytes are sensitive to changes in cytokine concentrations during demyelination (Peferoen et al 2014). Moreover, in vitro data suggests that oligodendrocytes itself can produce chemokines including CXCL10, CCL2, CCL3 and CCL5 and thereby contribute active to the inflammatory process (Balabanov et al 2007). 


\subsubsection{Microglia}

Microglia are the resident immune cells of the CNS which regulate the immune responses. In the healthy CNS microglia actively scan their environment, being ready to rapidly transform to activated stages (Gomez-Nicola \& Perry 2015, Hanisch \& Kettenmann 2007). Resting microglia furthermore are involved in maintaining brain homeostasis (Hanisch \& Kettenmann 2007). Microglia become activated due to cytokines or the presence of pathogens, which are recognized by their cell-surface molecules acting as immunostimulants. One immunostimulant is lipopylsaccharide (LPS) on bacteria or other surface structures of viral, bacterial or fungal origin. Furthermore, microglia are the phagocytes of the CNS and remove death cell debris and myelin debris during demyelination (Brück et al 1995, Voß et al 2012). Thereby phagocytosis exacerbates demyelination but on the other hand removal of myelin debris is thought to be required for subsequent repair mechanisms and remyelination (Skripuletz et al 2012, Voß et al 2012).

During demyelination an increased and persistent activation of microglia is thought to contribute to oligodendrocyte and neuronal damage. Here, microglia become activated due to cytokines like IL-1, interferon y (INFy), IL-6 or TNFa and are recruited to the lesion (Hanisch 2002). Activated microglia itself secrete immunomodulatory factors like free radicals (ROS, nitric oxide) and inflammatory cytokines, which are toxic to neurons and oligodendrocytes. Additionally, this leads to the recruitment of inflammatory cells like T-cells (Hanisch 2002, Merrill et al 1993, Peferoen et al 2014). Microglia express a wide variety of receptors (CXCR2, CXCR3, CXCR4, CCR3, CCR5) for many different chemokines (Hanisch 2002). The chemokine ligand binds to the complementary chemokine seven transmembrane domain receptor which causes the release of intracellular second messenger via Gprotein complexes (Kuang et al 1996, Wu et al 1993). For cell migration, receptor binding initiates intracellular alterations such as the reorganization of the cytoskeleton, formation of focal adhesion and pseudopodia extension leading to movement of the cell (Premack \& Schall 1996). To convert the extracellular signal a family of serine/ threonine protein kinases called mitogen-activated protein kinases (MAPKs) including the Jun N-terminus kinase, p38 and the extracellular-signalregulated protein kinase (ERK) is activated. MAPKs are activated through a kinase signalling cascade which in turn active MAPKs by phosphorylation (Huang et al 2004, Seger \& Krebs 1995). 


\subsection{Toxic demyelination - murine models of multiple sclerosis}

Myelin loss is the pathological hallmark of demyelinating diseases like MS. To investigate underlying mechanisms of demyelination different animal models with toxin-induced demyelination have been established. The cuprizone model and the lysolecithin-induced focal lesion models serve as model in this thesis.

\subsubsection{Multiple sclerosis}

MS is a chronic inflammatory demyelinating disease predominantly affecting young adults leading to substantial disability in a proportion of patients. Active demyelination occurs due to inflammation (Brück et al 1995, Hemmer et al 2002, Kornek \& Lassmann 1999). Based on evidence derived from the animal model of experimental autoimmune encephalomyelitis (EAE) and histopathological evaluation of MS brain tissue, MS is considered to be a T-cell mediated autoimmune disease. Myelin-reactive T-cells enter the CNS, become reactivated by myelinspecific autoantibodies released by local antigen presenting cells and initiate the autoimmune process (Hemmer et al 2002, Sospedra \& Martin 2005). B-cells can serve as antigen presenting cells (Flach et al 2016) and also endogenous CNS autoantigens are considered to reactivate T-cells (Kinzel et al 2016).

MS patients typically show multifocal lesions anywhere in the CNS but predominantly in the optic nerve, periventricular and subcortical cerebral regions, the cerebellum, the brainstem and the spinal cord (Brück \& Stadelmann 2005). Histopathological hallmarks are demyelination with oligodendrocyte loss during the chronic disease stage with variable degree of regeneration, inflammatory infiltration of immune cells of the adaptive and innate immune system (T-cells, B-cells, macrophages and microglia), axonal loss and reactive astrocytes (Brück \& Stadelmann 2005).

Demyelinating white matter lesions can be further classified into early active, late active and inactive lesions according to the presence and distribution of myelindegradation products within macrophages/ microglia and inflammatory macrophage/ microglia-activation markers (Brück et al 1995). Early active lesions are indicated by macrophages expressing the marker myeloid-related protein 14 (MRP14) and contain myelin degradation products positive for MBP, PLP, myelin 
oligodendrocyte glycoprotein (MOG) and cyclic nucleotide phosphodiesterase (CNPase). Macrophages in late active lesions contain myelin degradation products positive for MBP and PLP, but not for MOG or CNPase. Inactive demyelinated lesions are classified by macrophages containing either empty vacuoles or periodic acid-Schiff (PAS)-positive degradation products (Brück et al 1995).

Reactive astrocytes are located mainly in active lesions (Brück \& Stadelmann 2005, Schönrock et al 1998). As mentioned previously, reactive astrocytes were shown to expression increased levels of cytokines and chemokines (Choi et al 2014, Meeuwsen et al 2003). In MS lesions, reactive astrocytes were shown to express CXCL10 and CCL2 and thereby might induce microglia activation and recruitment (Balashov et al 1999) and could contribute to regulate inflammation. Additionally, astrocytes seem to restrict leukocyte entry by glial scar formation (Voskuhl et al 2009) and decrease inflammation. However, their concrete role during demyelination in MS is not yet clear.

\subsubsection{Animal models of toxic demyelination}

Both models used in this thesis of toxic demyelination mimic pathological hallmarks of MS lesions like myelin loss, oligodendrocyte loss, microglia infiltration and reactive astrocytes. Cuprizone induces demyelination by acting toxic to oligodendrocytes whereas the lysolecithin is a detergent lysing myelin cell membranes. Thus, both models together can provide comprehensive information about glia cells during toxic demyelination.

\subsubsection{The cuprizone model}

Cuprizone-induced demyelination is commonly used to investigate glial functions during demyelination. Robust and consistent demyelination in the corpus callosum is induced by feeding mice the copper chelator cuprizone (Hiremath et al 1998). On a cellular level, severe oligodendrocyte loss is the first observed effect of cuprizone treatment (Goldberg et al 2013, Hesse et al 2010). During treatment oligodendrocyte loss increases (Buschmann et al 2012, Hiremath et al 1998, Komoly et al 1987). Oligodendrocyte apoptosis is paralleled by microglia activation. Actually, microglia become activated during the first two weeks and severe demyelination is observed at week three (Gudi et al 2009, Hiremath et al 1998). Other immune cells are not 
involved in cuprizone-induced demyelination as the BBB remains intact and prevents immune cell infiltration in the CNS (Bakker \& Ludwin 1987, Kondo et al 1987, McMahon et al 2002). Pronounced demyelination starts around week three and reaches its maximum at week five or six and is concomitant with astrocyte activation (Gudi et al 2009, Hiremath et al 1998). Moreover, reactive astrocytes are caused by cuprizone-treatment with increased GFAP mRNA expression (Hibbits et al 2012, Hiremath et al 1998, Werner et al 2010).

The exact mechanism of cuprizone-induced demyelination is not clear. However, it was assumed that cuprizone as a copper-chelating agent induces copper deficiency in the CNS of mice (Hiremath et al 1998). As other chelators fail to induce similar clinical signs and substituting copper on top of the cuprizone diet failed to reduce toxicity another mechanism of cuprizone action was suggested (Carlton 1966). Enlarged mitochondria in oligodendrocytes were identified and related to cuprizoneinduced oligodendrocyte damage (Blakemore 1972). Mitochondria provide cells with adenosine-5-triphosphate (ATP) and are the source for cellular energy. It has been postulated that cuprizone-induced oligodendrocyte apoptosis could be a result from the inhibition of enzymes of the mitochondrial respiration chain (Goldberg et al 2013, Kipp et al 2009). Data of in vitro studies are controversial. One study showed no affected cell viability in rat primary oligodendrocytes when treated with cuprizone alone, but in combination with INFY and/ or TNFa cell viability was decreased (Pasquini et al 2007). In contrast, other studies showed in vitro reduced differentiation in rat oligodendrocytes treated with cuprizone (Bénardais et al 2013, Cammer 1999). However, all studies show altered mitochondrial function in oligodendrocytes. In vivo and in vitro results demonstrate a decrease in activities of complex I and III of the respiratory chain (Bénardais et al 2013, Pasquini et al 2007). Even if the underlying mechanism is not completely understood the well-studied robust and predictable course of demyelination during cuprizone treatment makes it a valid model to investigate glia function and cell interaction during demyelination.

\subsubsection{The focal lesion model}

The focal lesion model provides a model were the effects of demyelination can be investigated locally in the brain and rapidly after induction. Stereotactic injection of lysolecithin induces focal areas of demyelination. Lysolecithin is a potent detergent 
lysing cell membranes, including myelin and results in focal areas of demyelination (Gregson 1989, Hall \& Gregson 1971). It is assumed that lysolecithin primarily attacks myelin sheaths rather than oligodendrocytes because it starts to disrupt myelin within 30 minutes after injection (Hall 1972). In the white matter of the spinal cord lysolecithin leads to demyelination of axons, increased oligodendrocyte precursor cell densities and activated astrocytes (Hall 1972, Woodruff et al 2004). Lysolecithin induce lesions with axonal loss only around the injection side (Keough et al 2015, Woodruff \& Franklin 1999). Demyelination of axons starts two days after lesion induction and is complete after 10 days. After that an endogenous remyelination process starts around day 14. At day 21 nearly all axons are remyelinated (Hinks \& Franklin 1999). In contrast to the cuprizone model leukocyte involvement cannot be excluded in the focal lesion model. The injection needle induces at least partial leakage of the BBB. In focal lesions infiltrated T-cells, neutrophils and monocytes were found 6 until 12 hours after lesion induction (Ousman \& David 2000). The lysolecithin-induced demyelination is a highly reproducible model with a known mode of action. Therefore, it is suitable to investigate glia function and cell interaction during demyelination.

\subsection{The GFAP Tg73.7 transgenic mice with elevated hGFAP expression}

The GFAP Tg73.7 mice were used in this thesis to investigate the function of astrocytes with enhanced hGFAP expression. GFAP is commonly expressed in mature astrocytes and strongly up-regulated in response to CNS damage (Dahl \& Bignami 1974, Eddleston \& Mucke 1993, Eng \& Ghirnikar 1994, Eng et al 1971). The transcriptional regulation of GFAP allows to investigate manipulated astrocyte function. To generate this model, genomic clones were isolated of the human (h)GFAP gene (Brenner et al 1990). A promotor (gfa2) consisting of 2.2 kilo base pairs (kb) of 5'-flanking DNA of the hGFAP gene has been found to drive astrocyticspecific expression in vitro (Besnard et al 1991). To generate transgenic mice a gfa2-lac $Z$ (an Escherichia coli $\beta$-galactosidase reporter gen) construct was generated with the $2.2 \mathrm{~kb}$ fragment of the hGFAP gene and injected into male pronucleus of fertilized mouse eggs. The gfa2-lac $Z$ transgene was almost exclusively expressed in astrocytes throughout the CNS and up-regulated after CNS stab injury in the immediate area around the wound. Thus, the gfa2 region provides 
a critical regulator element for directing expression of other genes of interest in astrocytes (Brenner et al 1994). Accordingly, numerous GFAP knockout mice were generated by disrupting the first exon of the GFAP gene in embryonic stem cells. These mice do not develop anatomical abnormalities and astrocytes are present (Gomi et al 1995, McCall et al 1996, Pekny et al 1995). The 448 bp gfa28 GFAP promoter is expressed in only restricted CNS regions confirming the heterogeneity of astrocytes (Lee et al 2008, Lee et al 2006). This suggests that astrocytes in different regions have different regulatory mechanisms for controlling GFAP expression.

In this study the transgenic mouse line GFAP Tg73.7 was used carrying multiple copies of the hGFAP gene (Messing 1998). These mice show a moderate hGFAP up-regulation and were originally generated to investigate the neurodegenerative Alexander's disease (Messing 1998). Alexander's disease is a rare disorder of the CNS, mostly manifesting in children and leading to leukoencephalopathy and premature death (Alexander 1949, Brenner et al 2001). Alexander's disease is primary caused by mutations in the GFAP gene (Brenner et al 2001, Messing 1998). With the GFAP Tg73.7 mice it was formerly demonstrated that overexpression of hGFAP causes reactive astrocytes but no alterations in myelination (Messing 1998).

\subsection{Aim of this thesis}

The main aim of this study is to investigate the role of astrocytes with enhanced expression of hGFAP in the animal models of cuprizone-induced demyelination and lysolecithin-induced focal demyelination. The investigation will consider two major aspects:

I. Investigation of the effect of enhanced hGFAP expression in astrocytes on the cellular pathology of demyelination. How does enhanced astrocytic hGFAP expression change the interaction of astrocytes with other glial cells (oligodendrocytes and microglia) during demyelination?

II. Investigation of the effect of enhanced hGFAP expression in astrocytes on cytokine expression and cell signalling in vivo and in vitro. Does enhanced astrocytic hGFAP expression induce changes in cytokine expression and NF-kB signalling in astrocytes during demyelination? 


\section{2 | Materials and methods}

\subsection{Materials}

\subsubsection{Chemicals}

Table 1: Chemicals

\section{Chemicals}

Acetic acid, $10 \%$ solution

Agarose

$\mathrm{AgNO}_{3}$ (silver nitrate)

Ammonium chloride (10x)

Ammonium solution, $32 \%$

AquaTex

Azure II, powder

Boric acid

Chloral hydrate

Citric acid

Cuprizone Bis(cyclohexanone)oxaldihydrazone)

DAB (3,3'-diaminobenzidine)

DAPI (4',6-diamidino-2-phenylindole)

DDSA (dodecenyl succinic anhydride)

DePeX mounting medium

dNTP (deoxynucleoside triphosphate) mix

DMEM (Dulbecco`s Modified Eagle Medium) high glucose

$4.5 \mathrm{~g} / \mathrm{l}$

\section{Provider}

Merck Millipore, Germany

StarLab GmbH, Germany

Carl Roth, Germany

BD Bioscience, Germany

Merck Millipore, Germany

Merck Millipore, Germany

Merck Millipore, Germany

Carl Roth, Germany

Fagron GmbH\&Co. KG, Germany

Merck, Millipore

Sigma Aldrich, USA

Sigma Aldrich, USA

Sigma Aldrich, USA

Serva Electrophoresis, Germany

Serva Electrophoresis, Germany

Thermo Scientific, USA

Gibco life technologies ${ }^{\mathrm{TM}}$ Thermo

Scientific, USA 


\section{Chemicals}

Eosin $G$

Ethanol $96 \%$

Ethidium bromide

EDTA (ethylenediamine tetraacetic acid disodiumsalt dehydrate)

FCS (fetal calf serum)

Fluorescence mounting medium

Formalin (37\% formaldehyde solution, free from acid)

GeneRuler ${ }^{\mathrm{TM}}$, 100 base pairs (bp) DNA ladder Plus

Glutaraldehyde, $25 \%$ aqueous solution

Go-Taq $^{\circledR}$ DNA polymerase buffer, $5 x$

Ground mouse chow (complete feed for rats \& micemaintenance, ground)

HBSS (Hank's Buffered Salt Solution)

$\mathrm{HCl}$ (hydrochloride acid)

Hydrogen peroxide, $30 \%$ solution

Isopropyl alcohol

Ketamine, $10 \%$

Lysolecithin (L-a-lysophosphatidyl choline)

Myers Hämalaun

Metapyrin, $500 \mathrm{mg} / \mathrm{ml}$

Monastral blue

$\mathrm{NaCl}$ (sodium chloride)

$\mathrm{NaOH}$ (sodium hydroxide solution), $1 \mathrm{M}$

\section{Provider}

Merck Millipore, Germany

Merck Millipore, Germany

Sigma Aldrich, USA

Carl Roth, Germany

Sigma Aldrich, USA

Dako, Germany

Merck Millipore, Germany

Thermo Scientific, USA

Merck Millipore, Germany

Promega, USA

Ssniff Spezialdiäten $\mathrm{GmbH}$

Germany

Sigma Aldrich, USA

Merck Millipore, Germany

Merck Millipore, Germany

Merck Millipore, Germany

Medistar $^{\circledR}$, Germany

Sigma Aldrich, USA

Merck Millipore, Germany

Serumwerk Bernburg AG, Germany

Sigma Aldrich, USA

Carl Roth, Germany

Merck Millipore, Germany 


\section{Chemicals}

Nitric acid, $65 \%$ solution

Osmium tetraoxide, powder

Paraffin, (paraplast plus)

PBS (phosphate buffered salt solution)

Penicillin, 10,000 units/ streptomycin, 10 mg/ml

Periodic acid

PFA (paraformaldehyde), powder

PLL (poly-L-lysine hydrobromide), powder

Schiff's reagent

SDS (sodium dodecyl sulfate), $10 \%$ solution

Sodium thiosulfate pentahydrate

Tris

Triton X-100

Trizma Base

Xylazine solution, $20 \mathrm{mg} / \mathrm{ml}$

Xylol

\section{Provider}

Merck Millipore, Germany

Carl Roth, Germany

Tyco Healthcare, Germany

Sigma Aldrich, USA

Sigma Aldrich, USA

Merck Millipore, Germany

Merck Millipore, Germany

Sigma Aldrich, USA

Sigma Aldrich, USA

Sigma Aldrich, USA

Merck Millipore

Carl Roth, Germany

MP Biomedicals, Germany

Sigma Aldrich, USA

Ecuphar, Berlgium

Merck Millipore, Germany

\subsubsection{Enzymes/ proteins}

Table 2: Enzymes and proteins

Enzymes/ proteins

Collagenase D

DNase I

IFNY, recombinant

\section{Provider}

Roche, Switzerland

Roche, Switzerland

R\&D Systems, USA 
Enzymes/ proteins

IL-1 $\beta$, recombinant

TNFa, recombinant

Trypsin-EDTA, $0.25 \%$ and $0.05 \%$ solution

\section{Provider}

R\&D Systems, USA

R\&D Systems, USA

Gibco/Invitrogen, USA

\subsubsection{Applied kits and gene expression assays}

Table 3: Applied Kits

\begin{tabular}{|c|c|}
\hline Kits & Provider \\
\hline Cignal Lenti NF-kB Reporter (luc) Kit & SABioscience/ Qiagen, USA \\
\hline High capacity cDNA, Reverse Transcription Kit & AB applied biosystems ${ }^{\mathrm{TM}}, \mathrm{USA}$ \\
\hline miRNeasy Mini Kit & Qiagen, Germany \\
\hline RNase-Free DNase Set (50) & Qiagen, Germany \\
\hline RNeasy Microarray Tissue Kit & Qiagen, Germany \\
\hline $\mathrm{RT}^{2}$ PreAMP cDNA Synthesis Kit & Qiagen, Germany \\
\hline $\begin{array}{l}\mathrm{RT}^{2} \text { PreAMP cDNA Synthesis Primer Mix for Mouse } \\
\text { Multiple Sclerosis PCR }\end{array}$ & Qiagen, Germany \\
\hline $\mathrm{RT}^{2}$ Profiler ${ }^{\mathrm{TM}}$ PCR Array Mouse Multiple Sclerosis & Qiagen, Germany \\
\hline RT-QP73-05 qPCR core kit & Eurogenetec, Belgium \\
\hline
\end{tabular}

Table 4: Gene expression assays

TaqMan® Gene Expression Assays

B2m, Mm00437762_m1, 20x

CCL2, Mm00441242_m1, 20x

CCL5, Mm01302428_m1, 20x

\section{Provider}

Thermo Fisher, USA

Thermo Fisher, USA

Thermo Fisher, USA 
TaqMan® Gene Expression Assays

CXCL10, Mm00445235_m1, 20x

CXCL12, Mm00445553_m1, 20x

HPRT, Mm01545399_m1, 20x

IL-6, Mm00446190_m1, 20x

TNFa, Mm00443258_m1, 20x

\section{Provider}

Thermo Fisher, USA

Thermo Fisher, USA

Thermo Fisher, USA

Thermo Fisher, USA

Thermo Fisher, USA

\subsubsection{Solutions}

Table 5: Solutions

\section{Solution}

Chloral hydrate, $14 \%$ solution

DAPI

FACS (fluorescent-activated cell sorting) buffer

Ketamine/ xylazine mixture

Lysolecithin, $1 \%$ solution

Metapyrin

Monastral blue, $3 \%$ solution

PFA, $4 \%$ solution

\section{Composition}

$14 \mathrm{~g}$ chloral hydrate

$100 \mathrm{ml}$ bidistilled water

$1 \mu \mathrm{I}$ DAPI

$10,000 \mu \mathrm{PBS}$

$490 \mathrm{ml}$ PBS, sterile

$10 \mathrm{ml}$ FCS

$1.2 \mathrm{ml}$ ketamine

$1 \mathrm{ml}$ xylazine

$7.8 \mathrm{ml} \mathrm{NaCl}$

$10 \mathrm{mg}$ lysolecithin

$1 \mathrm{ml}$ sterile PBS

$3 \mathrm{ml} \mathrm{metapyrin}{ }^{\circledR}$

1 l water

$0.3 \mathrm{~g}$ monastral blue

$10 \mathrm{ml}$ sterile PBS

Filtration

40 g PFA

1,000 ml 1-fold PBS 
Solution

Tail lysis buffer

TBE buffer

\section{Composition}

$50 \mu \mathrm{l} \mathrm{NaOH}$, adjust to $\mathrm{pH} 7.4$

filtration

$6.057 \mathrm{~g}$ Tris

$400 \mathrm{ml}$ bidistilled water

$\mathrm{HCl}$, adjust to $\mathrm{pH} 8.5$

$5 \mathrm{ml} 5 \mathrm{mM}$ EDTA

$20 \mathrm{ml} 200 \mathrm{mM} \mathrm{NaCl}$

$10 \mathrm{ml} 0.2 \%$ SDS

$10.8 \mathrm{~g}$ Tris

$5.5 \mathrm{~g}$ boric acid

$4 \mathrm{ml} 0.5 \mathrm{M}$ EDTA

$1,000 \mathrm{ml}$ water

Table 6: Solutions for electron microscopy

\section{Solution}

Glutaraldehyde, 3\% solution

Richardson's Stain (Richardson et al 1960)

Synthetic resine

\section{Composition}

$12 \mathrm{ml} 25 \%$ glutaraldehyde

$88 \mathrm{ml}$ PBS

$2 \mathrm{ml} 1 \%$ azure II

$1 \mathrm{ml} \%$ methylene blue

$1 \mathrm{ml} 1 \%$ borax

$27 \mathrm{ml}$ renlam $\mathrm{M}-1$

$23 \mathrm{mI}$ DDSA

0.75-1 ml DMP-30

Table 7: Solutions for (immuno-) histochemistry

\section{Solution}

$\mathrm{AgNO}_{3}, 20 \%$ solution

Citric acid buffer, $10 \mathrm{nM}$

\section{Composition}

$10 \mathrm{~g} \mathrm{AgNO}_{3}$

$50 \mathrm{ml}$ distilled water

$2.1 \mathrm{~g}$ citric acid

$1,000 \mathrm{ml}$ distilled water 
Solution

$\mathrm{CuSO}_{4}$ working solution

DAB working solution

Developer stock solution

Eosin, $1 \%$ solution

LFB working solution

Sodium thiosulfate, $2 \%$ solution

Tris-EDTA, $1 \mathrm{mM}$

Triton, $1 \%$ solution

\section{Composition}

$\mathrm{NaOH}$, adjust to $\mathrm{pH} 6$

$1 \mathrm{ml} 2 \% \mathrm{CuSO}_{4}$

$50 \mathrm{ml} \mathrm{NaCL}$

$49 \mathrm{ml}$ PBS

$1 \mathrm{ml} \mathrm{DAB}$

$20 \mu$ l hydrogen peroxide

$20 \mathrm{ml}$ formalin

$0.5 \mathrm{~g}$ citric acid

$500 \mathrm{ml}$ distilled water

$2 \mathrm{ml}$ eosin

$198 \mathrm{ml} 70 \%$ isopropyl alcohol

Filtration

$1 \mathrm{~g} \mathrm{LFB}$

1 I ethanol

$5 \mathrm{ml}$ acetic acid (add after complete

solution of LFB)

Filtration

$10 \mathrm{~g}$ sodium thiosulfate

pentahydrate

$500 \mathrm{ml}$ distilled water

$1.21 \mathrm{~g}$ Trizma base

$1 \mathrm{ml} 0.1 \mathrm{M}$ EDTA

$1,000 \mathrm{ml}$ distilled water

Adjust to $\mathrm{pH} 8$

$100 \mu \mathrm{l}$ Triton X-100

$10 \mathrm{ml}$ PBS

Table 8: Solution for cell culture

Solution

Composition

DMEM+

500 ml DMEM 


\subsubsection{Antibodies}

Table 9: Primary antibodies for immunohistochemical staining

\begin{tabular}{|c|c|c|c|c|}
\hline Antigen & Marker for & Species/clone & Dilution & Provider \\
\hline APP & $\begin{array}{l}\text { Amyloid } \\
\text { precursor protein }\end{array}$ & Mouse/ 22c11 & $1: 2,000$ & Chemicon, Germany \\
\hline Caspase-3 & $\begin{array}{l}\text { Activated } \\
\text { caspase-3 }\end{array}$ & Rabbit/ C92-605 & $1: 150$ & $\begin{array}{l}\text { BD-Pharmingen }{ }^{\mathrm{TM}} \text {, } \\
\text { USA }\end{array}$ \\
\hline CXCL10/IP-10 & $\begin{array}{l}\text { C-X-C motif } \\
\text { chemokine } 10\end{array}$ & Goat & $1: 100$ & R\&D Systems, USA \\
\hline GFAP & $\begin{array}{l}\text { Glial fibrillary } \\
\text { acidic protein }\end{array}$ & Rabbit & $1: 1,000$ & Dako, Germany \\
\hline lba1 & $\begin{array}{l}\text { Microglia/ } \\
\text { macrophages }\end{array}$ & Rabbit & $1: 100$ & $\begin{array}{l}\text { Wako Pure } \\
\text { Chemicals } \\
\text { Industries, Japan }\end{array}$ \\
\hline Mac-3 & $\begin{array}{l}\text { Microglia/ } \\
\text { macrophages }\end{array}$ & Rat/ M37/84 & $1: 200$ & $\begin{array}{l}\text { BD-Pharmingen }{ }^{\mathrm{TM}} \text {, } \\
\text { USA }\end{array}$ \\
\hline MBP & $\begin{array}{l}\text { Myelin basic } \\
\text { protein }\end{array}$ & rabbit & $1: 1,000$ & Dako, Germany \\
\hline NF-kB p65 & $\begin{array}{l}\text { Subunit of NF-KB } \\
\text { transcription } \\
\text { complex }\end{array}$ & Rabbit/ C-20 & $1: 1,000$ & Santa Cruz, USA \\
\hline Olig2 & $\begin{array}{l}\text { Oligodendrocyte } \\
\text { precursor cells/ } \\
\text { mature } \\
\text { oligodendrocytes }\end{array}$ & Rabbit/ 18953 & $1: 300$ & $\begin{array}{l}\text { IBL international, } \\
\text { Germany }\end{array}$ \\
\hline P25/ TPPP & $\begin{array}{l}\text { Mature } \\
\text { oligodendrocytes }\end{array}$ & Rabbit/ 92305 & $1: 500$ & Abcam, Great Britain \\
\hline
\end{tabular}


Table 10: Secondary antibodies for immunohistochemical staining

\begin{tabular}{lllll} 
Antibody & Host & Directed against & Dilution & Provider \\
\hline Goat anti rabbit & Goat & Anti-rabbit IgG & $1: 500$ & Dianova, Germany \\
Streptavidin Cy3 & Sheep & Anti-goat IgG & $1: 100$ & $\begin{array}{l}\text { Jackson Immuno- } \\
\text { Research, USA }\end{array}$ \\
Streptavidin Cy2 & Goat & Anti-rabbit IgG & $1: 100$ & $\begin{array}{l}\text { Jackson Immuno- } \\
\text { Research, USA }\end{array}$ \\
\hline
\end{tabular}

Table 11: Flow cytometry antibodies

\begin{tabular}{lllll} 
Antibody & Fluorochrome & Clone & Dilution & Provider \\
\hline CD11b & APC & M1/70 & $1: 200$ & eBioscience, USA \\
CD16/CD32 & - & 93 & $1: 200$ & BioLegend, USA \\
\hline
\end{tabular}

\subsubsection{Consumables}

Table 12: Consumables

\section{Consumables}

24-well culture plate

Bottle top filter, $0.2 \mu \mathrm{m}$

Cell culture flask, $25 \mathrm{~m}^{2}$

Cell culture flask, $75 \mathrm{~m}^{2}$

Cell culture dish, $60 \times 15 \mathrm{~mm}$

FACS tubes, $5 \mathrm{ml}$

Glass capillary, Micropipettes 1-5 $\mu \mathrm{l}$

Neubauer counting chamber (surface $0.0025 \mathrm{~mm}^{2}$ )

\section{Provider}

Greiner Bio-One GmbH, Germany

Sarstedt, Germany

Sarstedt, Germany

Sarstedt, Germany

Sarstedt, Germany

BD Bioscience, USA

B. Braun Melsungen AG, Germany

Brand GmbH, Germany 
Consumables

Ocular counting grid, WHSZ 10x-H

Petri dish

$\mathrm{RT}^{2}$ PCR Array Loading Reservoir (12)

Falcon tubes $(50 \mathrm{ml}, 15 \mathrm{ml})$

\section{Provider}

Olympus, Germany

Greiner Bio-One GmbH, Germany

Qiagen, Germany

Sarstedt, Germany

\subsubsection{Technical devices}

Table 13: Technical devices

\section{Technical devices}

BD LSRFortessa ${ }^{\mathrm{TM}}$ cell analyzer

Camera for light microscope DP71

Camera for fluorescence microscope XM10

Centrifuge $5415 \mathrm{R}$

Centrifuge $5810 \mathrm{R}$

Dental drill control tool K44974

Dental drill 4912

Fluorescence microscope BX51

iQ5 Multicolor Real-Time PCR Detection System

Light microscope BX41

Mastercycler gradient

Microtome SM2000R

Microwave

Mithras LB 940 Multimode Reader

\section{Provider}

BD Bioscience, USA

Olympus, Germany

Olympus, Germany

Eppendorf, Germany

Eppendorf, Germany

Kavo, Dental Excellence, Germany

Kavo, Dental Excellence, Germany

Olympus, Germany

BioRad Laboratories, Germany

Olympus, Germany

Eppendorf, Germany

Leica, Germany

Panasonic, Japan

Berthold Technologies, Germany 
Technical devices

NanoDrop $^{\text {TM }}$ Spectrophotometer ND-1000

Sliding microtome SM2000 R

TissueRuptor

Thermomixer comfort

Speed vacuum Concentrator 5301

Stereotactic device STO-51730

\section{Provider}

PEQLAB, Biotechnologie GmbH,

Germany

Leica, Germany

Qiagen, Germany

Eppendorf, Germany

Eppendorf, Germany

FMI GmbH-Stoelting, Germany

\subsubsection{Software}

Table 14: Software

\section{Software}

FlowJo 7.6.1 (Tree Star Inc., Ashland, USA)

GraphPad Prism Version 5.01

(GraphPad, California, USA)

ImageJ 64 (http://imagej.nih.gov/ij/)

Adobe $^{\circledR}$ Illustrator ${ }^{\circledR}$ CS4 (Adobe Systems Incorporated,

California, USA)

\section{Utilization}

Data analysis flow cytometry

Statistical analysis

Measurement of demyelinated

areas/ lesion size

Figures 


\subsection{Mice}

Transgenic mice carrying a copy of the human GFAP gene TgN(GFAP)Mes10 (from now referred to as GFAP Tg73.7) were generated and first described by Messing (Messing 1998). Mice were obtained on FVB/ N genetic background and backcrossed to C57BL/ 6N. For the present studies, heterozygous mice were used and wild type littermates served as controls. Animals were derived from in house colonies at the animal facility of the University Medical Centre Göttingen, Germany. C57BL/ 6 mice were purchased from Charles River Laboratories (Germany).

All mice were kept under standardized conditions with a 12/ 12 hour (h) light/ dark cycle and food and water ad libitum in the animal facility of the University Medical Center in Göttingen, Germany. All animal experimentation was carried out in accordance with the European Communities Council Directive of 24 November 1986 (86/EEC) and were approved by the Lower Saxony Federal State Office for Consumer Protection and Food Safety, Germany. Experiments contained at least 4 animals per group and were performed at least twice.

\subsection{Methods}

\subsubsection{Genotyping of GFAP Tg73.7 mice}

Polymerase chain reaction (PCR) was used to analyse the genotype of GFAP Tg73.7 mice. During PCR small fragments of a DNA template were amplified. Specific nucleic acid sequences (primers) serve as starting point for the amplification. Both primers flank the region of interest and ensure correct amplification of the target. The DNA polymerase builds a new complementary DNA strand to the template DNA (DNA target). The new DNA strands work as template for further amplification. Basing on this principle the DNA target is multiplied. The PCR cycle consist of three steps. During the first phase (denaturation) the DNA, polymerase and nucleotides are heated to $95^{\circ} \mathrm{C}$ to separate DNA strands. In the annealing phase the primers bind to the DNA single strands and the polymerase starts to synthesize DNA in $5^{\prime} \rightarrow 3^{\prime}$-direction (elongation).

For genotyping, DNA was extracted from tail biopsies of GFAP Tg73.7 mice. To achieve that, the tissue was digested in $350 \mu$ tail lysis buffer containing 
$20 \mu \mathrm{l}$ proteinase $\mathrm{K}$ overnight in a thermomixer at 350 rounds per minute (rpm) and $56^{\circ} \mathrm{C}$. Digested tissue was centrifuged by $13,200 \mathrm{rpm}$ at RT for $5 \mathrm{~min}$. Supernatant was transferred to a new tube containing $350 \mu \mathrm{l}$ isopropyl alcohol and was centrifuged again for $5 \mathrm{~min}$ at 13,200 rpm at RT. Supernatant was disposed and the pellet was washed with $350 \mu \mathrm{l} 70 \%$ ethanol. After another centrifugation the supernatant was disposed and the pellet was dried for $10 \mathrm{~min}$ in a speed vacuum concentrator and resuspended in $100 \mu$ l bidistilled water.

The extracted DNA served as template for DNA amplification. Additionally, each reaction contained $2 \mu \mathrm{l}$ genomic DNA, $1 \mu \mathrm{l} 10 \mathrm{mM}$ dNTP Mix, $2 \mu$ loligonucleotide primers (MB-114, Pr. 35, each $1 \mu \mathrm{l}$ ), $0.2 \mu \mathrm{l} \mathrm{Go-Taq} \mathrm{polymerase,} 5 \mu \mathrm{l}$ of the supplied buffer (5x PCR buffer) and $14.8 \mu$ l bidistilled water.

Table 15: Primers sequences for genotyping PCR of GFAP Tg73.7 mice.

\begin{tabular}{lll} 
Primers for GFAP Tg73.7 & Sequence & Provider \\
\hline MB-114 & 5'-CTC ATA CTC ATG ATG GGG AG-3' & $\begin{array}{l}\text { Promega, } \\
\text { Germany }\end{array}$ \\
Pr. 35 & 5'-AAC AGC CTA TGG AGG GAC TG-3' & $\begin{array}{l}\text { Promega, } \\
\text { Germany }\end{array}$ \\
\hline
\end{tabular}

All PCR reactions were run in a T3 Thermocycler with the following cycle parameters:

Table 16: Cycle parameters for genotyping PCR.

\begin{tabular}{lll} 
Temperature & Time & Step \\
\hline $95^{\circ} \mathrm{C}$ & $180 \mathrm{sec}$ & Pre-denaturation \\
$95^{\circ} \mathrm{C}$ & $40 \mathrm{sec}^{*}$ & Denaturation \\
$62^{\circ} \mathrm{C}$ & $30 \mathrm{sec}^{*}$ & Annealing \\
$72^{\circ} \mathrm{C}$ & $1 \mathrm{~min}$ & Elongation \\
$72^{\circ} \mathrm{C}$ & $10 \mathrm{~min}$ & Final elongation \\
$4^{\circ} \mathrm{C}$ & $\infty$ & Storage \\
${ }^{*} 35 \mathrm{cycles}$ & &
\end{tabular}


To visualize PCR products, $10 \mu \mathrm{l}$ of the sample were loaded on agarose gel $(1.8 \%$ in TBE buffer) containing $3 \mu$ l ethidium bromide. A 100 bp DNA ladder (5 $\mu$ l) was used to estimate PCR-product length. Electrophoresis was performed at 100 volt (V) for 60 min. One single PCR band of 381 bp marks hemizygous GFAP Tg73.7 transgenic mice.

\subsubsection{Cuprizone treatment}

Cuprizone is a commonly used model to study different aspects of demyelination. In this study, GFAP Tg73.7 mice at the age of 8 to 10 weeks received a $0.25 \%$ cuprizone (Sigma-Aldrich, Germany) diet at libitum. Cuprizone (2.5 g) was mixed with normal ground chow (1,000 g; ssniff Spezialdiäten $\mathrm{GmbH}$, Germany). The control group received normal chow and are further referred to as naïve mice. Body weight was controlled once weekly. The measured weight was converted into percentage because GFAP Tg73.7 mice were smaller than their wild type littermates. The mean of the initial body weight was set to $100 \%$ and the measured body weight during cuprizone treatment was then converted in relation to the body weight at the beginning of the experiment.

To analyse demyelination, apoptosis, acute axonal damage, oligodendrocyte precursor cell (OPC) numbers, oligodendrocyte numbers and macrophage infiltration GFAP Tg73.7 mice and wild type littermates were fed for either 1, 2, 3, 4, 5 or 6 weeks with $0.25 \%$ cuprizone. To asses long-term effects, GFAP Tg73.7 mice and wild type littermates received $0.25 \%$ cuprizone for 12 weeks. To investigate gene expression of CCL2, CCL5, CXCL10, CXCL12, IL-6 and TNFa, GFAP Tg73.7 mice and wild type littermates were treated for 3 or 6 weeks with $0.25 \%$ cuprizone.

\subsubsection{Intracerebral stereotactic injection with lysolecithin}

Lysolecithin is a cell membrane-solubilizing agent and a model to study different parts of focal demyelinated. GFAP Tg73.7 mice and wild type mice at the age of 8 to 10 weeks were injected with $1 \mu \mathrm{l}$ of $1 \%$ lysolecithin into the corpus callosum to induce focal demyelination. Lysolecithin was diluted in sterile PBS. Animals were perfused 7 days after injection. For that purpose, mice were anaesthetized with intraperitoneal injection (i.p.) of ketamine/ xylazine mixture $(100 \mu \mathrm{l} / 10 \mathrm{~g}$ body weight). After surgical tolerance was reached, tested via loss of pedal reflex, a 
rostro-caudal cut at the top of the head was made to expose the skull. Mice were fixed in a stereotactic device to ensure precise injection. At $1 \mathrm{~mm}$ caudal to the bregma and $2 \mathrm{~mm}$ sagittal to the bregma a small hole was drilled with a dental drill. To avoid brain damage, drilling was stopped when one thin bone layer was still intact. The layer was carefully removed with a fine scraper until the brain was visible. Lysolecithin was combined with monastral blue to mark the point of injection. $1 \mu \mathrm{l}$ lysolecithin was injected stereotactically with a thin finely calibrated glass capillary (diameter $0.05-0.10 \mathrm{~mm}$ ) into the corpus callosum. To prevent disruptive lesions, lysolecithin was administered very slowly. Afterwards, the capillary was carefully removed and the skin was stitched. For pain therapy mice receive Metapyrin ${ }^{\circledR}$ from 2 days before injection until 3 days afterwards.

\subsubsection{Histology}

After experiments were completed, mice were injected i.p. with a lethal doses of $14 \%$ chloral hydrate solution. After loss of protective reflexes and loss of consciousness, mice were transcardially perfused through the left ventricle with cold PBS followed by cold 4\% paraformaldehyde (PFA). Brain, liver and spleen were taken and stored in $4 \%$ PFA at $4^{\circ} \mathrm{C}$ for 2 days post-fixation and afterwards were transferred into PBS. For the histological analysis of cuprizone experiments, brains were dissected in $2 \mathrm{~mm}$ thick coronal sections using a brain matrix (mouse acrylic matrices, Braintree scientific Inc., USA). To analyse stereotactic injection experiments histologically, one coronal brain section including the injection side was cut. The injection was localized by Monastral blue trace.

For paraffin embedding, tissue was washed in water and gradually dehydrated over night by performing a graded alcohol/ xylene/ paraffin series with an automated tissue processor and embedded in paraffin. Embedded tissue was cut in $1 \mu \mathrm{m}$ thick sections using a sliding microtome (Leica SM2000R, Leica, Germany) and tissue sections were mounted on microscope slides.

Before the staining procedure, tissue sections were deparaffinized for at least 30 $\min$ at $54^{\circ} \mathrm{C}$ and rehydrated. The rehydration series was done as follows: 
Table 17: Rehydration steps for deparaffinization.

\begin{tabular}{ll} 
Time & Solution \\
\hline $4 \times 10 \mathrm{~min}$ & xylol \\
$1 \times 5 \mathrm{~min}$ & isoxylol \\
$2 \times 5 \mathrm{~min}$ & $100 \%$ isopropyl alcohol \\
$1 \times 5 \mathrm{~min}$ & $90 \%$ isopropyl alcohol \\
$1 \times 5 \mathrm{~min}$ & $70 \%$ isopropyl alcohol \\
$1 \times 5$ min & $50 \%$ isopropyl alcohol \\
distilled water &
\end{tabular}

After the staining procedure, stained sections were dehydrated by performing the procedure described above in reverse order. Finally, stained sections were mounted in DePeX medium or were embedded without dehydration in AquaTex mounting medium.

\subsubsection{Luxol fast blue-periodic acid-Schiff staining}

To analyse the degree of demyelination after cuprizone treatment, Luxol fast blueperiodic acid-Schiff (LFB-PAS) staining was performed. LFB-PAS stains myelin in the central nervous system in dark blue (LFB) and demyelinated areas in pink (PAS). After rehydration in $90 \%$ isopropyl alcohol, tissue sections were transferred into LFB working solution and incubated at $60^{\circ} \mathrm{C}$ over night. Afterwards, sections were washed with $90 \%$ isopropyl alcohol and differentiated, first with $0.05 \%$ lithium carbonate (diluted in water), followed by short incubation in 70\% isopropyl alcohol. Differentiation was stopped when only myelin was stained deep blue. To stop the reaction, stained sections were rinsed extensively with distilled water. For PAS reaction, stained sections were incubated for $5 \mathrm{~min}$ in 1\% periodic acid (diluted in water), followed by 5 min washing with running tab water and 5 min thoroughly washing with distilled water. Afterwards, sections were stained for 20 min with Schiff's reagent and washed again for $10 \mathrm{~min}$ with running tab water. Counterstaining with Mayers Hämalaun was performed to stain cell nuclei. Sections were incubated 3 min with Mayers Hämalaun, washed with distilled water and 
shortly differentiated in $1 \% \mathrm{HCl}$. After washing with distilled water, bluing was achieved by rinsing stained sections for 10 min under running tab water.

The grade of demyelination in the corpus callosum after cuprizone treatment was analysed using a semi-quantitative scoring system, as previously published in Brück et al (2012): no (0), minimal (0.5), <33\% (1), 33-66\% (2) and >66\% (3) demyelination. The size of focal lesions in the corpus callosum after lysolecithin injection was measured with the ImageJ software and pictures were taken at $4 x$ original magnification using a light microscope (Light microscope BX41) connected with a digital camera.

\subsubsection{Bielschowsky silver impregnation}

To investigate axonal integrity and loss, tissue slices were stained with Bielschowsky silver impregnation. First, tissue sections were rehydrated as described above. After washing with distilled water sections were transferred for 20 min in $20 \% \mathrm{AgNO}_{3}$ solution and washed at least twice with distilled water. To clear the $\mathrm{AgNO}_{3}$ solution, ammonia solution was added drop by drop. Sections were incubated in cleared $\mathrm{AgNO}_{3}$ for $15 \mathrm{~min}$ in the dark. For washing, 3 drops ammonia were added to distilled water to rinse slices. 10 drops developer were added and slices were developed for 3-5 min until tissue turns ochre. Reaction was stopped by rinsing with bidistilled water and stained sections were transferred in $2 \%$ sodium thiosulfate solution for 2 min.

\subsubsection{Immunohistochemistry and fluorescence staining}

Immunohistochemistry was performed with primary antibodies against acutely damaged axons (amyloid precursor protein, APP), apoptotic cells (activated caspase-3), astrocytes (glial fibrillary protein; GFAP), activated microglia/macrophages (Mac-3), myelin basic protein (MBP), oligodendrocyte lineage cells (olig2) and mature oligodendrocytes (p25). For immunofluorescence staining primary antibodies against the chemokine CXCL10, GFAP, p25 and microglia (Iba1) and the nuclear factor (NF)-KB-subunit p65 were used. Prior to immunohistochemistry, epitope retrieval was performed by heating the slides 5 times in $10 \mathrm{mM}$ citric acid buffer (APP, CXCL10, Iba1, Mac-3) or $1 \mathrm{mM}$ Tris-EDTA solution (activated caspase-3, olig2, p25) in a microwave for $3 \mathrm{~min}$. To achieve that, 
tissue sections were transferred in glass cuvettes filled with the corresponding buffer. Between the steps, the cuvettes were refilled alternating with distilled water or corresponding buffer. To block endogenous peroxidase, sections were first washed in PBS followed by 20 min incubation in $3 \%$ hydrogen peroxide solution at $4^{\circ} \mathrm{C}$. After washing with PBS for 3 times to inhibit unspecific binding, sections were incubated with 10\% FCS (diluted in PBS) for $20 \mathrm{~min}$ at RT. Activated caspase-3 immunohistochemistry requires blocking with $1 \%$ Triton-X 100 solution for $1 \mathrm{~h}$ and CXCL10 requires blocking in 10\% donkey serum diluted in PBS. Primary antibodies (see Table 9 see table in section 2.1.5) were diluted in 10\% FCS in PBS, CXCL10 in 10\% donkey serum in PBS and incubated overnight in wet chambers. Control sections were incubated in the absence of primary antibodies or with isotype control antibodies. Then sections were washed 3 times with PBS. Biotin-conjugated secondary antibody binding was visualized with peroxidase and 3,3'-diaminobenzidine tetrachloride (DAB). Biotinylated secondary antibodies were diluted in 10\% FCS in PBS and incubated for $1 \mathrm{~h}$ at RT. Unbound antibody was removed by washing with PBS. Fluorescence secondary antibody was visualized with cyanine (Cy) 2-conjugated goat-anti-rabbit IgG and biotinylated goat-anti-sheep Cy3 Streptavidin. Nuclei were counterstained with DAPI.

APP-positive axons, activated caspase3-positive apoptotic cells, Mac-3-positive microglia, p25-positive and olig2-positive oligodendrocytes were light microscopically evaluated in the corpus callosum at $400 x$ original magnification using an ocular counting grid. The cell numbers were quantified per square $\mathrm{mm}$. Fluorescent double-stainings of CXCL10 either with p25, Iba1 or GFAP were assessed using a magnification of 400x (Light microscope Olympus BX41).

\subsubsection{Electron microscopy}

To evaluate myelin integrity of axons in the corpus callosum, electron microscopic (EM) analysis was performed. A subset of GFAP Tg73.7 mice and wild type mice ( $n=3$ per group) received cuprizone treatment for 0,6 or 12 weeks. Mice were sacrificed and perfused with cold PBS (see section 2.3.4). Triangle pieces of the corpora callosa were removed and stored in $3 \%$ glutaraldehyde at $4^{\circ} \mathrm{C}$ for at least 7 days for post-fixation. Para-sagittal slices of $1 \mathrm{~mm}$ were prepared and sections were 
processed through $1 \%$ osmium tetroxide for $1 \mathrm{~h}$ at $4^{\circ} \mathrm{C}$. After two washing steps with PBS the slices were dehydrated as followed:

Table 18: Dehydration steps for EM.

\begin{tabular}{ll} 
Time & Solution \\
\hline $1 \mathrm{~h}$ at $4^{\circ} \mathrm{C}$ & $\begin{array}{l}\text { uranyl acetate (in } 70 \% \\
\text { alcohol) }\end{array}$ \\
$10 \mathrm{~min}$ & $\begin{array}{l}50 \% \text { alcohol } \\
10 \mathrm{~min}\end{array}$ \\
$10 \mathrm{~min}$ & $80 \%$ alcohol \\
$2 \times 15 \mathrm{~min}$ & $100 \%$ alcohol \\
$2 \times 20 \mathrm{~min}$ & propylene oxide
\end{tabular}

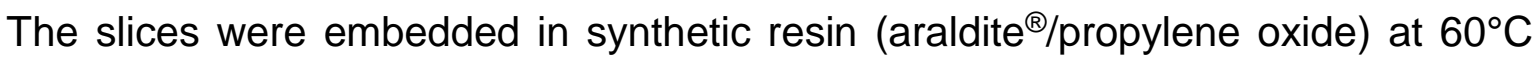
overnight. Ultrathin sections were cut for EM. Semi thin sections were stained with Richardson's Stain to select regions for EM evaluation. The number of myelinated axons was counted in non-overlapping fields with results expressed as a percentage of myelinated axons (number of myelinated axons/ total axons $x 100$ ).

\subsubsection{Astrocyte isolation from newborn mice}

To investigate astrocyte changes due to hGFAP overexpression in vitro, primary astrocytes were isolated. To achieve that, newborn (postnatal day 0-3) GFAP Tg73.7 mice and wild type mice were decapitated. Afterwards, heads were transferred into a petri dish with cold HBSS to rinse of the blood. The scull was opened and brains were carefully removed and transferred into a new petri dish with cold HBSS. Olfactory bulbs and cerebella were removed. Fibroblast growing would inhibit astrocyte growing. For that purpose, the meninges were neatly removed from all over the brain to prevent growing of meningeal fibroblasts. Then isolated brains were transferred into $15 \mathrm{ml}$ Falcons ${ }^{\mathrm{TM}}$ with cold HBSS and stored on ice. Before further proceeding, Falcons ${ }^{\mathrm{TM}}$ were incubated in a waterbath for $3 \mathrm{~min}$ at $37^{\circ} \mathrm{C}$. To achieve a single cell solution, brain tissue was digested and afterwards mechanically dissociated. First, HBSS was removed and brains were digested in $0.25 \%$ Trypsin-EDTA ( $3 \mathrm{ml} /$ brain) with DNase $\left(33.33 \mu \mathrm{l} /\right.$ brain) for $10 \mathrm{~min}$ at $37^{\circ} \mathrm{C}$. 
Digestion solution was removed and tissue was washed twice with $5 \mathrm{ml} 37^{\circ} \mathrm{C}$ warm HBSS. Brains were mechanically dissociated by pipetting with a 1,000 $\mu$ l pipet tip and $1 \mathrm{ml}$ DMEM+. The cell suspension plus $9 \mathrm{ml}$ DMEM+ was filled in PLL-coated $75 \mathrm{~mm}^{2}$ cell culture flasks. The primary cell culture containing astrocytes, oligodendrocytes and microglia were cultivated for 7 to 10 days in a tissue culture incubator at $37^{\circ} \mathrm{C}$ and $5 \% \mathrm{CO}_{2}$. Medium was changed every 3 to 4 days.

After 7 to 10 days of cultivation, cells were washed with $37^{\circ} \mathrm{C}$ PBS and shaken vigorously to remove oligodendrocytes and microglia. To detach astrocytes, cells were incubated with $3 \mathrm{ml}$ warm Trypsin-EDTA $(0.05 \%)$ for 3 min. Flasks were shaken and washed thoroughly to remove all astrocytes. To stop the reaction, Trypsin-EDTA-cell lysate was transferred into a $15 \mathrm{ml} \mathrm{Falcon}^{\mathrm{TM}}$ containing $5 \mathrm{ml}$ warm DMEM+. After centrifugation for $10 \mathrm{~min}$ at $900 \mathrm{rpm}$, the supernatant was discarded and the cell pellet was resuspended in warm DMEM+.

\subsubsection{Analysis of NF-KB activation in isolated astrocytes}

To assess the effect of hGFAP overexpression on astrocytic NF-KB activity an in vitro assay was performed. Astrocytic NF-KB signalling pathway activity was measured in primary astrocytes using the luciferase reporter assay (Cignal Lenti NF-kB Reporter (luc) kit). The experiments were done in cooperation with Dr. Nadine Kramann (Institut of Neuropathology, University Medical Center Göttingen, Germany).

The activities of firefly (Photinus pyralis) and Renilla (Renilla reniforms) luciferases were measured sequentially from the same sample. First, the firefly luciferase reporter is measured, then the reaction is quenched and the Renilla luciferase reaction is simultaneously initiated. To investigate changes of NF-KB activation in primary astrocytes of GFAP Tg73.7 mice compared to wild type astrocytes, isolated astrocytes were plated at a density of $1 \times 10^{5}$ astrocytes per well in a PLL-coated 96well-plate. When astrocytes were $60-80 \%$ confluent, they were transfected with the inducible NF-KB responsive firefly luciferase reporter and a Renilla luciferase normalization reporter for $24 \mathrm{~h}$ at $37^{\circ} \mathrm{C}$ and $5 \% \mathrm{CO}_{2}$. After $24 \mathrm{~h}$, astrocytes were stimulated with $10 \mathrm{ng} / \mathrm{ml}$ TNFa or $10 \mathrm{ng}$ INFY with IL-1 $1 \beta$ for $1 \mathrm{~h}$. The medium was removed and astrocytes were rinsed with PBS, followed by adding $100 \mu$ LAR II solution to generate stabilized luminescent signal. The firefly luciferase activity was 
measured luminometrically (Mithras LB 940 Multimode Reader, Berthold Technologies, Bad Wildbad, Germany). Then, the Stop \& Glo ${ }^{\circledR}$ reagent was added to quench firefly signal and Renilla luciferase activity was measured. The fold induction was calculated as quotient of relative light units (RLU) of induced cells divided by RLU of control cells.

\subsubsection{Analysis of myelin phagocytosis in co-cultures of microglia with astrocytes}

To measure whether astrocytes have an effect on myelin phagocytosis of microglia, co-cultures of astrocytes with microglia were established and phagocytosis of myelin was measured via flow cytometry. Isolated primary astrocytes of GFAP Tg73.7 mice and wild type mice were plated in a 24-well-plate, 100,000 per well. After 2 days of culturing at $37^{\circ} \mathrm{C}$ and $5 \% \mathrm{CO}_{2}, 200,000$ microglia per well were added. After $24 \mathrm{~h}$, fluorescently labelled myelin $(10 \mu \mathrm{g} / \mathrm{ml})$ was added and cells were incubated for $2 \mathrm{~h}$. Myelin was removed and cells were washed with warm DMEM+ and twice with warm PBS. Cells were detached with $0.05 \%$ Trypsin-0.02\% EDTA for 3 min at $37^{\circ} \mathrm{C}$. The reaction was stopped by adding $600 \mu \mathrm{L}$ DMEM+ per well and cells were carefully detached with a cell scraper and transferred into $2 \mathrm{ml}$ Eppendorf cups on ice. Remaining cells were transferred into the Eppendorf cups after washing the cells with $600 \mu \mathrm{l}$ DMEM+. After centrifugation at $800 \mathrm{xg}$ for $10 \mathrm{~min}$ at $4^{\circ} \mathrm{C}$ supernatant was decanted, cells were resuspended in $1 \mathrm{ml}$ FACS buffer and again centrifuged. The supernatant was decanted and cells were resuspended in FC-block solution (anti-CD16/32 antibody, 1:200), diluted with FACS buffer and incubated for $10 \mathrm{~min}$ at $4^{\circ} \mathrm{C}$. The fluorochrome-labelled antibody against CD11b (CD11b-APC, 1:200) was prepared in FACS buffer and added to the cells. After 25 min incubation at $4^{\circ} \mathrm{C}$ in the dark $1 \mathrm{ml}$ FACS buffer was added and cells were centrifuged at $800 \mathrm{x} \mathrm{g}$ for 10 min. The supernatant was decanted and cells were resuspended in $200-500 \mu \mathrm{l}$ FACS buffer and transferred to FACS tubes. Flow cytometry was performed using the BD LSRFortessa ${ }^{\mathrm{TM}}$ (BD Bioscience, USA). The results were analysed using FlowJo 7.6.1 (Tree Star Inc., USA). For analysis, 10.000 CD11b-positive cells were included and myelin incorporation was measured. The phagocytosis ratio of microglia was calculated (CD11b+ cells with myelin incorporation/ total CD11b+ cells $\times 100)$. 


\subsubsection{Measurement of cytokine and chemokine expression}

To analyse effects of hGFAP overexpression on cytokine and chemokine expression in vitro and in vivo, RNA from the corpus callosum of mice after cuprizone treatment and from stimulated astrocytes was isolated, cDNA synthesised and gene expression measured.

\subsubsection{RNA isolation from corpus callosum and primary astrocytes}

For in vivo studies, total RNA was isolated from the corpus callosum of GFAP Tg73.7 mice and wild type mice after 3 and 6 weeks of cuprizone treatment using the RNeasy ${ }^{\circledR}$ Microarray kit (Qiagen) according to the manufacturer protocol. Mice were sacrificed with a lethal dose of chloral hydrate solution (i.p.) after 3 or 6 weeks of cuprizone treatment. Age matched naïve mice served as controls. After mice were perfused with PBS, the brains were dissected and the corpora callosa carefully isolated. Prior to further procedure, dissected tissue was frozen in liquid nitrogen with 1,000 $\mu \mathrm{l}$ Qiazo ${ }^{\circledR}$ lysis buffer. For RNA isolation, tissue was homogenized using the TissueRuptor (Qiagen, Germany). For in vitro studies, total RNA was isolated from GFAP Tg73.7 and wild type primary astrocytes using the miRNeasy Mini Kit (Qiagen) according to the manufacturer's instructions. Astrocytes were plated in $25 \mathrm{~cm}^{2}$ culture flasks and cultured for 3 days. Than primary astrocytes were once washed with PBS and stimulated with either TNFa $(10 \mathrm{ng} / \mathrm{ml}$ in $2 \mathrm{ml}$ DMEM+) or INFY with IL-1 $\beta$ (10 $\mathrm{ng} / \mathrm{ml}$ in $2 \mathrm{ml}$ DMEM+) for $3 \mathrm{~h}$. Unstimulated astrocytes served as controls. After incubation, cells were washed with DMEM+, followed by washing with cold PBS. Astrocytes were carefully detached using a cell scraper and transferred into $1.5 \mathrm{ml}$ Eppendorf cups. Remaining liquid was removed by centrifugation for $10 \mathrm{~min}$ at $12,000 \mathrm{rpm}$ and $4^{\circ} \mathrm{C}$. Cell pellet was resuspended with $500 \mu \mathrm{l}$ Qiazol ${ }^{\mathrm{TM}}$ lysis buffer and frozen in liquid nitrogen. For RNA isolation, cells were homogenized using a syringe.

Homogenized tissue or astrocytes was incubated for $5 \mathrm{~min}$ at RT. To segregate RNA from other proteins, $200 \mu \mathrm{l}$ chloroform was added and the samples were shaken vigorously for $15 \mathrm{sec}$ and centrifuged for $15 \mathrm{~min}$ with $12,000 \mathrm{xg}$ at $4^{\circ} \mathrm{C}$. The samples separate into 3 phases: an upper, clear, aquatic phase containing RNA, a white interphase and a red lower, organic phase. The upper phase was transferred in a new $1.5 \mathrm{ml}$ Eppendorf cup. One volume of $70 \%$ ethanol was added and mixed 
by pipetting up and down to perform ethanol precipitation. Without delay, the mixture was directly transferred into RNeasy Mini columns and centrifuged with 10,000 rpm for $15 \mathrm{sec}$ at $21^{\circ} \mathrm{C}$. The RNeasy Mini columns contain a silica gel inside to bind nucleic acid. Several wash steps with the provided buffer followed by centrifugation (15 sec, $10,000 \mathrm{rpm}, 21^{\circ} \mathrm{C}$ ) remove impurities from the membrane. To cleave DNA, DNase1 was added and incubated for $15 \mathrm{~min}$. Then the membrane was washed with buffer and samples were centrifuged for $1 \mathrm{~min}$ with $13,000 \mathrm{rpm}$ and $21^{\circ} \mathrm{C}$ to remove possible carryover of buffer or ethanol. $30 \mu \mathrm{l}$ RNase free water was added to bind the RNA. After 1 min centrifugation at $10,000 \mathrm{rpm}$ and $21^{\circ} \mathrm{C}$ the RNA yield was determined with the NanoDrop ${ }^{\circledR}$. Nucleic acids have absorbance maxima at 260 and $280 \mathrm{~nm}$. Samples with a 260/280 absorbance ratio of $\sim 2 \pm 0.2$ contain pure RNA and were used for cDNA synthesis.

\subsubsection{Synthesis of cDNA}

To synthesize cDNA from total RNA, the high capacity cDNA reverse transcription kit (AB Applied Biosystem ${ }^{\mathrm{TM}}$, USA) was used. First, the reverse transcription master mix was prepared on ice containing 10x RT buffer ( $2 \mu$ per reaction), 25x dNTP mix $100 \mathrm{mM}$ (0.8 $\mu \mathrm{l}$ per reaction), 10x RT random primers $(2 \mu \mathrm{l}$ per reaction), MultiScribe $^{\mathrm{TM}}$ reverse transcriptase $(1 \mu \mathrm{l}$ per reaction), RNase inhibitor $(1 \mu \mathrm{l}$ per reaction) and nuclease-free water (3.2 $\mu \mathrm{l}$ per reaction). The RNA samples were prepared with $300 \mathrm{ng}$ RNA (brain tissue) and $500 \mathrm{ng}$ RNA (isolated primary astrocytes) and diluted in RNase-free water to reach a total volume of $10 \mu \mathrm{l}$. Next, $10 \mu \mathrm{l}$ RNA-sample and $10 \mu \mathrm{l}$ master mix were mixed in an 8-tube-strip. After mixing by pipetting up and down for 2 times, the tubes were sealed, briefly centrifuged and placed in a Thermocycler with cycle parameters listed below:

Table 19: Cycle parameters for cDNA synthesis.

\begin{tabular}{ll} 
Temperature & Time \\
\hline $25^{\circ} \mathrm{C}$ & $10 \mathrm{~min}$ \\
$37^{\circ} \mathrm{C}$ & $120 \mathrm{~min}$ \\
$85^{\circ} \mathrm{C}$ & $5 \mathrm{~min}$ \\
$4^{\circ} \mathrm{C}$ & $\infty$ Storage
\end{tabular}




\subsubsection{Measurement of gene expression by quantitative real-time PCR}

The expression of inflammatory cytokines and chemokines was analysed in vivo in the corpus callosum of GFAP Tg73.7 mice and wild type mice after 3 and 6 weeks of cuprizone treatment. Additionally, the expression was analysed in vitro in primary astrocytes after TNF $\alpha$ or INFY with IL-1 $1 \beta$ stimulation by quantitative real-time PCR (qPCR). With the qPCR technique the amplification product, indicated by fluorescence intensity, of a target DNA sequence is measured in real-time. Specific primers bind to the target DNA sequence to start amplification. To calculate the relative product quantity, the cycle number at which a sample begins to amplify exponentially, the cycle threshold (Ct), is used. The expression of the genes of interest is quantified in relation to the housekeeping genes.

Prior to single qPCRs, the $\mathrm{RT}^{2}$ Profiler ${ }^{\mathrm{TM}} \mathrm{PCR}$ Array mouse multiple sclerosis (Qiagen, Germany) was used to identify genes of interest. The $\mathrm{RT}^{2}$ Profiler ${ }^{\mathrm{TM}} \mathrm{PCR}$ Array was conducted following the company's instructions. Beforehand, the CDNA transcription was performed using the $\mathrm{RT}^{2}$ PreAMP Synthesis kit (Qiagen, Germany) and the $\mathrm{RT}^{2}$ PreAMP Pathway Primer Mix (Qiagen, Germany) following the manufacturer's instructions. Afterwards, the measured Ct-values were used to calculate relative gene expression (see next section).

The identified genes transcribe the cytokines and chemokines CXCL10, CXCL12, CCL2, CCL5, TNFa and IL-6 and were further analysed with single qPCRs using the RT-QP73-05 qPCR core kit (Eurogentec) and FAM labelled TaqMan ${ }^{\circledR}$ Gene Expression Assays (TaqMan ${ }^{\circledR}$ Gene Expression Assay Thermo Fisher, USA). B2m and HPRT were used as housekeeping genes. For the GPCR analysis the master mix of the GPCR core kit was prepared containing the specific primers $(1 \mu \mathrm{l}), 2 \mathrm{x}$ reaction buffer ( $2 \mu \mathrm{l}$ per sample), MgCL2 solution ( $50 \mathrm{mM}, 2 \mu$ l per sample), dNTP solution ( $5 \mathrm{mM}, 0.8 \mu \mathrm{l}$ per sample), HotGoldStar enzyme ( $0.1 \mu \mathrm{l}$ per sample) and nuclease-free water to reach a total volume of $20 \mu \mathrm{l}$. The master mix and $2 \mu \mathrm{l}$ sample-cDNA was pipetted into a 96-well-plate and sealed carefully. All samples were measured as duplicates. The plates were placed in an $\mathrm{iQ} 5^{\mathrm{TM}}$ real-time cycler with cycle parameters listed below. Data was collected at $60^{\circ} \mathrm{C}$. 
Table 20: Cycle parameters for qPCR.

\begin{tabular}{lll} 
Temperature & Time & Step \\
\hline $95^{\circ} \mathrm{C}$ & $10 \mathrm{~min}$ & HotGoldStar activation \\
$94^{\circ} \mathrm{C}$ & $15 \mathrm{~s}^{*}$ & Denaturation \\
$60^{\circ} \mathrm{C}$ & $1 \mathrm{~min}^{*}$ & Annealing and extension \\
$* 40 \mathrm{cycles}$ & &
\end{tabular}

\subsubsection{Quantification of relative gene expression}

To compare the expression levels of CXCL10, CXCL12, CCL2, CCL5, TNFa and IL-6 in GFAPTg73.7 mice or astrocytes to wild type controls the $\Delta \Delta$ Ct-method was applied. First, the expression of the target gene is normalized to the mean $\mathrm{Ct}$ of the housekeeping genes $(\Delta \mathrm{Ct})$, here B2m and HPRT

$$
\Delta \mathrm{Ct}=\mathrm{Ct} \text { target gene }-\mathrm{Ct} \text { mean [housekeeping genes] }
$$

Then the $\Delta \mathrm{Ct}$ of the control was subtracted from the $\Delta \mathrm{CT}$ of GFAP Tg73.7 to calculate the $\Delta \Delta \mathrm{Ct}$ :

$$
\Delta \Delta \mathrm{Ct}=\Delta \mathrm{Ct} \text { GFAP Tg73.7 mice }-\Delta \mathrm{Ct} \text { wild type mice }
$$

The fold change in expression was calculated with the formula:

$$
\text { Fold change }=2^{-\Delta \Delta C t}
$$

A fold change from 0.5 until 1.5 indicates no gene-expression regulation. A fold change greater than 1.5 indicates a gene expression up-regulation and less than 0.5 indicates a gene expression down-regulation compared to the normalisation control.

\subsubsection{Data analysis and statistics}

Statistical analysis was performed using GraphPadPrism Software (version 5.01 GraphPad Software, USA). All data is given as mean with standard error ( \pm SEM). Normal distribution was tested with D'Agostino-Pearson normality test or Kolmogorov-Smirnov test for smaller samples. Statistical significance was determined as $p \leq 0.05$. 
Histological differences of GFAP Tg73.7 mice compared to wild type mice after 0, 1, $2,3,4,5$ or 6 weeks of cuprizone treatment were analysed with two-way analysis of variance (ANOVA) followed by Bonferroni multiple comparison test. Histological differences after 12 weeks of cuprizone treatment were analysed with the MannWhitney $U$ test for non-parametric data. The differences in lesion size, microglia infiltration, p25-positive oligodendrocyte numbers and nuclear p65-translocation in GFAP-positive astrocytes in lysolecithin-induced lesions between GFAP Tg73.7 mice and wild type mice were analysed with the Student's $t$-test for parametric data. The differences in mRNA expression levels of MAG, MBP, PLP1, CCL5 and IL-6 between GFAP Tg73.7 mice and wild type mice were analysed using the one-way ANOVA followed by Dunn's multiple comparison test. The differences in mRNA expression levels of CCL2, CXCL12, TNFa and CXCL10 between GFAP Tg73.7 mice and wild type mice were analysed with one-way ANOVA followed by Tukey's multiple comparison test. The differences in NF-KB activity in GFAP Tg73.7 astrocytes compared to wild type astrocytes were analysed using one-way ANOVA followed by Bonferroni's multiple comparison test. The expression levels of CCL2 and CXCL10 in GFAP Tg73.7 astrocytes compared to wild type astrocytes were analysed with the Student's $t$-test. Myelin phagocytosis activity of microglia with astrocyte co-culture were compared to microglia single cultures using the MannWhitney $U$ test. 


\section{3 | Results}

\subsection{Evaluating the effect of enhanced astrocytic human GFAP expression on oligodendrocytes and microglia during toxic demyelination}

To investigate effects of enhanced astrocytic hGFAP expression on oligodendrocytes and microglia, the effects were analysed immunohistochemically in naïve GFAP Tg73.7 mice, after cuprizone treatment and in focally induced lesions.

\subsubsection{Regular myelin density and oligodendrocyte numbers but increased astrogliosis in naïve GFAP Tg73.7 mice}

To examine whether naïve GFAP Tg73.7 mice show alterations in astrocyte activation, myelination, microglia infiltration and oligodendrocyte numbers compared to wild type littermates histochemical and immunohistochemical analysis was performed.
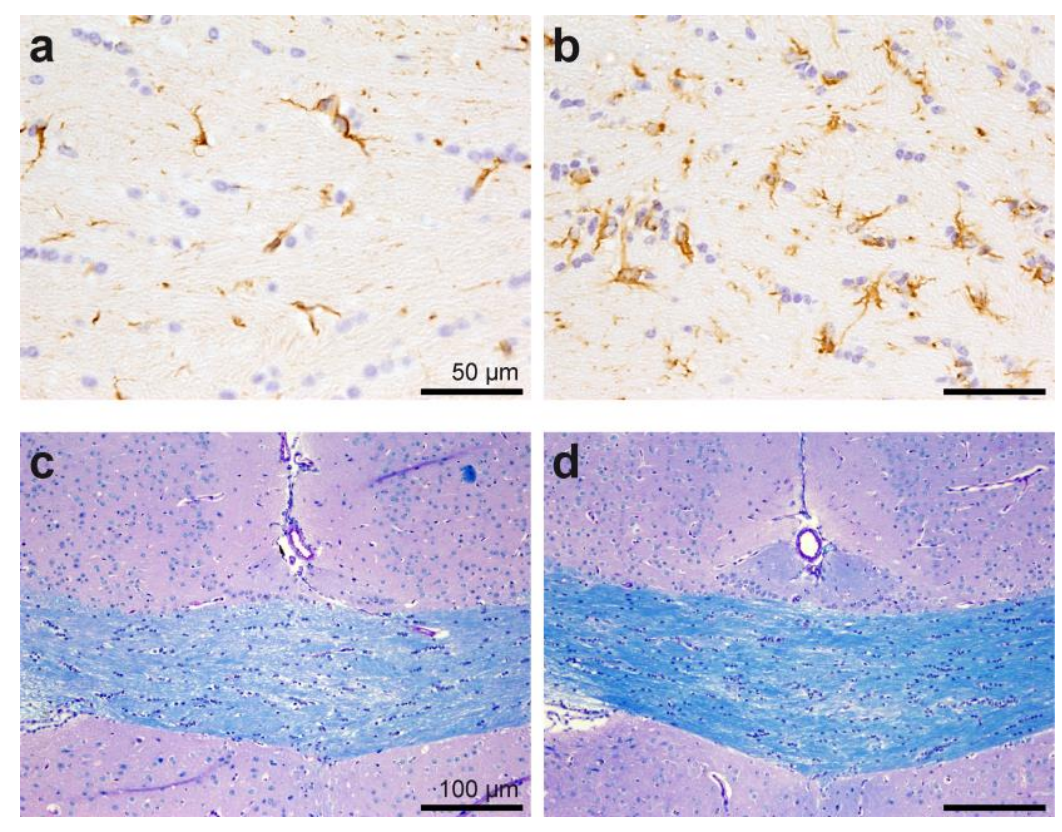

Figure 2: Reactive astrocytes in naïve GFAP Tg73.7 mice.

Naîve GFAP Tg73.7 mice (b) show GFAP-positive astrocytes with reactive morphology compared to wild type littermates. Myelination, shown with LFB-PAS staining, is dense in GFAP Tg73.7 mice (d) and wild type littermates (c). Representative pictures of the corpus callosum of naïve mice were taken at 400x original magnification (a, b; scale bars: $50 \mu \mathrm{m}$ ) and 100x original magnification (c, d; scale bars: $100 \mu \mathrm{m})$. 
Astrocytes immunostained for GFAP did not show reactive morphology in naïve wild type mice (Figure 2a) whereas naïve GFAP Tg73.7 mice showed reactive GFAPpositive astrocytes (Figure 2b). Luxol fast blue-periodic acid-Schiff (LFB-PAS)stained brain sections revealed no alterations in myelination in GFAP Tg73.7 mice (Figure 2d) compared to wild type mice (Figure 2c).

Mac-3-positive microglia were not altered in naïve GFAP Tg73.7 mice (Tg) compared to wild type mice (WT) (Tg: $1.3 \pm 1.27$ cells $/ \mathrm{mm}^{2}$ vs. WT: $3.9 \pm 2.72$ cells $/ \mathrm{mm}^{2}$; Figure 3c). Additionally, oligodendrocyte numbers were not altered in naïve GFAP Tg73.7 mice compared to wild type littermates, counted on p25immunostained brain sections (Tg: $1142.0 \pm 84.79$ cells $/ \mathrm{mm}^{2}$ vs. WT: $1059.0 \pm 32.08$ cells/mm²; Figure 3f).

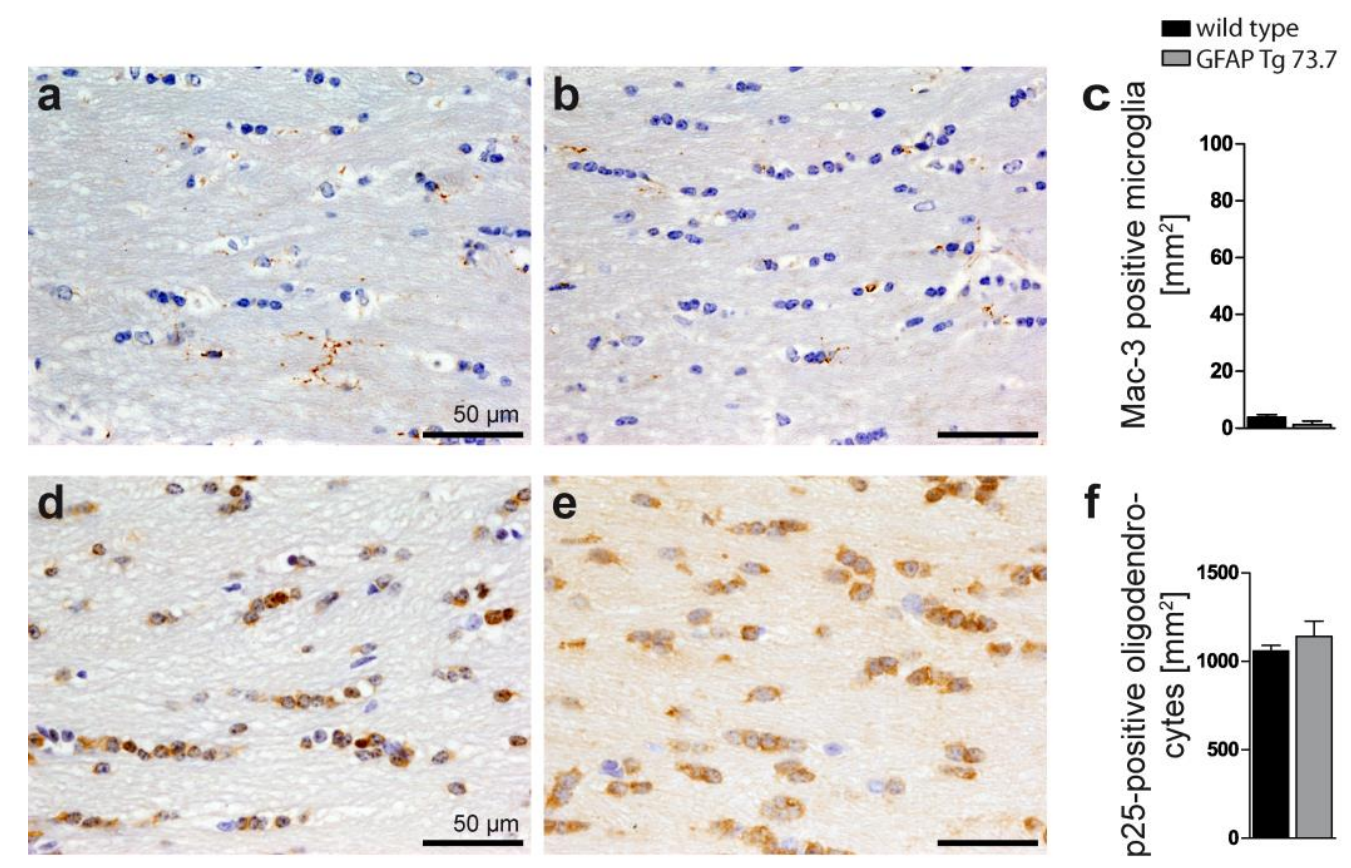

Figure 3: No alterations in microglia and oligodendrocyte density in naïve GFAP Tg73.7 mice. Immunohistochemical staining with Mac-3 for microglia (a, b) and p25 for mature oligodendrocytes (d, e) showed no alterations in naïve GFAP Tg73.7 mice (b, e) compared to wild type littermates (a, d). Representative pictures of the corpus callosum after 1 week of cuprizone treatment were taken at $400 x$ original magnification (scale bars: $50 \mu \mathrm{m}$ ). Data are presented as mean $\pm S E M$.

\subsubsection{Reduced cuprizone-induced weight loss and apoptosis in GFAP Tg73.7 mice after one week}

To assess the clinical effects of cuprizone feeding, body weight was measured once weekly during 6 weeks of cuprizone treatment (Figure 4d). During 6 weeks of 
cuprizone treatment GFAP Tg73.7 mice showed significantly higher body weight than their wild type littermates $(p<0.01 ; \mathrm{Tg}: 105.10 \% \pm 2.94$ vs. WT: $92.18 \% \pm 1.39$; Figure 4).

To analyse the effect of enhanced astrocytic hGFAP expression on cell death during the first week of cuprizone treatment, brain slices of GFAP Tg73.7 mice and wild type littermates were stained with antibodies against activated caspase-3. The evaluation of caspase-3-positive apoptotic cells revealed significantly less numbers of apoptotic cells in GFAP Tg73.7 mice (Figure 4b) compared to wild type littermates (Figure $4 \mathrm{a})$ after 1 week of cuprizone treatment $\left(p<0.001 ; \mathrm{Tg}: 24.21\right.$ cells $/ \mathrm{mm}^{2} \pm 5.10$ vs. WT: 121.8 cells $/ \mathrm{mm}^{2} \pm 10.70$; Figure $4 \mathrm{c}$ ).
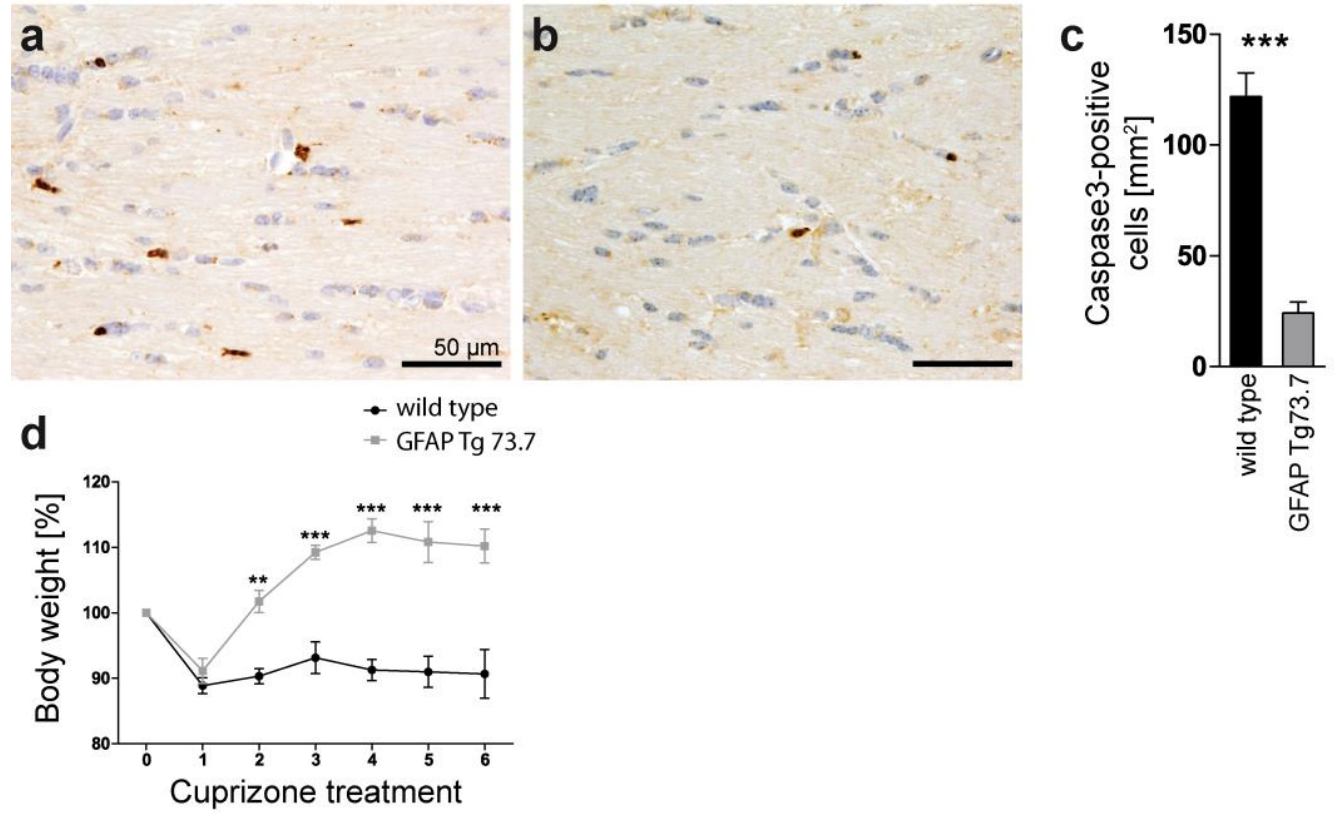

Figure 4: Decreased apoptosis in GFAP Tg73.7 mice after 1 week of cuprizone-induced demyelination and higher body weights during 6 weeks of cuprizone treatment.

Immunohistochemistry for activated caspase-3 revealed significantly reduced apoptotic cells in GFAP Tg73.7 mice (b) compared to wild type littermates (a) after 1 week of cuprizone treatment (c). Body weight was controlled once weekly. GFAP Tg73.7 mice show significantly higher body weights [\%] compared to wild type littermates during 6 weeks of cuprizone treatment (d). Representative pictures of the corpus callosum after 1 week of cuprizone treatment were taken at $400 \mathrm{x}$ original magnification (scale bars: $50 \mu \mathrm{m})\left({ }^{* *} \mathrm{p}<0.01,{ }^{* * *} \mathrm{p}<0.001\right)$. Data are presented as mean $\pm \mathrm{SEM}$.

\subsubsection{Reduced cuprizone-induced demyelination in GFAP Tg73.7 mice}

To evaluate the effect of enhanced astrocytic hGFAP expression on cuprizoneinduced demyelination, myelin loss was analysed on LFB-PAS stained sections in 
GFAP Tg73.7 mice (Figure 5b) and wild type littermates (Figure 5a) after 3, 4, 5 and 6 weeks of cuprizone treatment. Demyelination was evaluated using a semiquantitative scoring system, previously published in Brück et al (2012): no (0), minimal (0.5), <33\% (1), 33-66\% (2) and >66\% (3) demyelination.

The evaluation revealed a significant reduction of cuprizone-induced demyelination in the corpus callosum of GFAP Tg73.7 mice compared to wild type littermates after 4 weeks of cuprizone treatment ( $p<0.05$; Tg: $0.80 \pm 0.33$ vs. WT: $1.90 \pm 0.36)$, after 5 weeks of cuprizone treatment ( $p<0.001$; Tg: $0.42 \pm 0.20$ vs. WT: $1.88 \pm 0.23)$ and after 6 weeks of cuprizone treatment $(p<0.001$; Tg: $0.90 \pm 0.33 v s$. WT: $3.00 \pm 0.00$; Figure 5c).
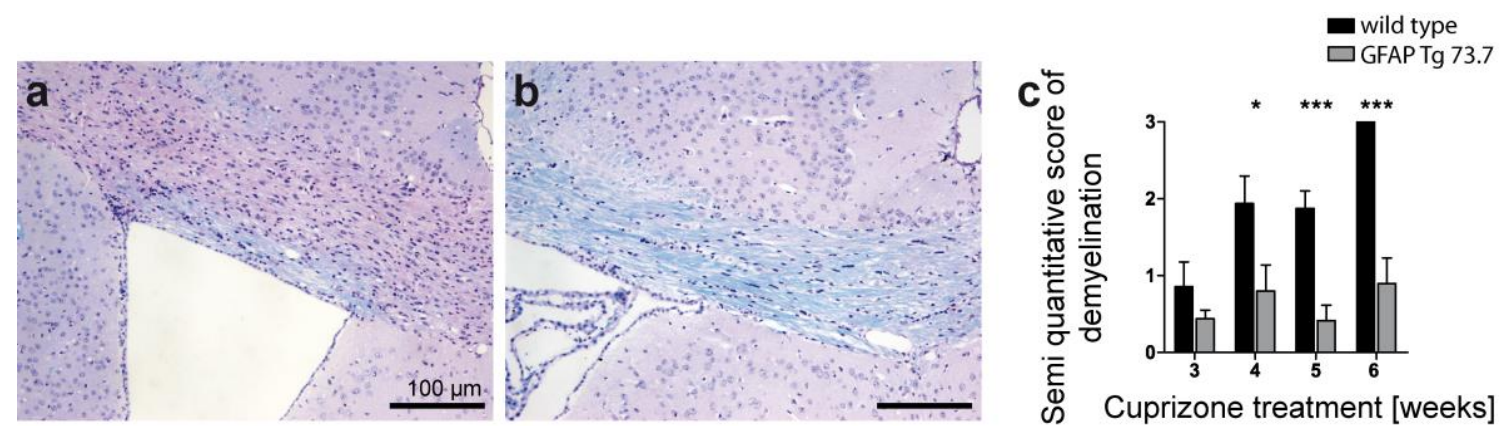

Figure 5: Decreased cuprizone-induced demyelination in GFAP Tg73.7 mice.

Demyelination is extensive in the corpus callosum of wild type littermates (a) compared to moderate demyelination in GFAP Tg73.7 mice (b) after 6 weeks of cuprizone treatment. Evaluation of LFBPAS stained sections revealed demyelination in GFAP Tg73.7 mice (b) is significantly reduced after 4, 5 and 6 weeks of cuprizone treatment compared to wild type littermates. Representative pictures of the corpus callosum after 6 weeks of cuprizone treatment were taken at 100x original magnification (scale bars: $100 \mu \mathrm{m})\left({ }^{*} \mathrm{p}<0.05 ;{ }^{* * *} \mathrm{p}<0.001\right)$. Data are presented as mean $\pm \mathrm{SEM}$.

To evaluate myelination of axons on the ultrastructural level, electron microscopic (EM) pictures of the corpus callosum were taken. EM analysis revealed a significantly higher percentage of myelinated axons in GFAP Tg73.7 mice compared to wild type littermates after 6 weeks of cuprizone treatment $(p<0.01 ; \mathrm{Tg}: 92.00 \%$ \pm 7.65 vs. WT: $81.48 \% \pm 18.52$; Figure 6c). In naïve GFAP Tg73.7 mice (Figure 6b) and wild type littermates (Figure 6a) $100 \% \pm 0.00$ axons were myelinated. 

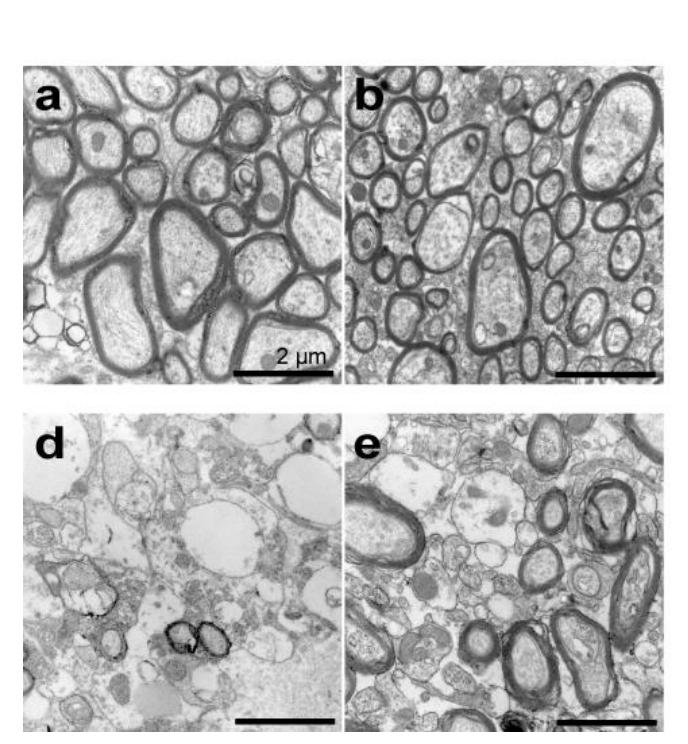

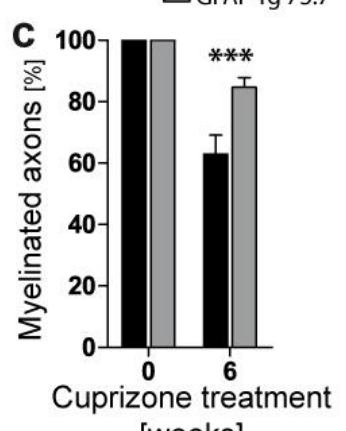

[weeks]

Figure 6: Less demyelinated axons in GFAP Tg73.7 mice after 6 weeks of cuprizone-induced demyelination.

Naïve wild type mice (a) and GFAP Tg73.7 mice (b) show intact myelin sheaths of callosal axons (c). After 6 weeks of cuprizone treatment the percentage of myelinated axons is significantly higher in GFAP Tg73.7 mice (e, c) compared to wild type littermates (d, c) (scale bars: $2 \mu \mathrm{m})\left({ }^{* *} \mathrm{p}<0.01\right)$. Data are presented as mean \pm SEM.

\subsubsection{Reduced cuprizone-induced oligodendrocyte loss in GFAP Tg737 mice}

To assess the effect of enhanced astrocytic hGFAP expression on oligodendrocytes during cuprizone-induced demyelination, GFAP Tg73.7 mice and wild type littermates were treated for 1, 2, 3, 4, 5 and 6 weeks with cuprizone. The analysis of brain slices stained with $\mathrm{p} 25$, a protein expressed in mature oligodendrocytes (Höftberger et al 2010), revealed significantly higher numbers of mature oligodendrocytes in GFAP Tg73.7 mice (Figure 7c) compared to wild type littermates after 4 weeks of cuprizone treatment $\left(p<0.001\right.$; Tg: 936.2 cells $/ \mathrm{mm}^{2}$ \pm 95.39 vs. WT: 434.90 cells $/ \mathrm{mm}^{2} \pm 95.45$; Figure $7 \mathrm{c}$ ), after 5 weeks of cuprizone treatment ( $p<0.001$; Tg: 1020.0 cells $/ \mathrm{mm}^{2} \pm 98.28$ vs. WT: 495.0 cells $/ \mathrm{mm}^{2} \pm 70.43$; Figure 7c) and after 6 weeks of cuprizone treatment $(p<0.001 ; \mathrm{Tg}: 1087.0$ \pm 21.22 cells $/ \mathrm{mm}^{2}$; vs. WT: $406.5 \pm 88.81$ cells $/ \mathrm{mm}^{2}$; Figure $7 \mathrm{c}$ ). P25-positive oligodendrocyte numbers were not altered in GFAP Tg73.7 mice compared to wild type littermates after 1, 2 and 3 weeks of cuprizone treatment (Figure 7c).

To analyse oligodendrocyte precursor cells (OPC), brain slices were immunostained with antibodies against olig2, an oligodendrocyte transcription factor. Olig2 detects mainly immature oligodendrocytes, but also binds to mature oligodendrocytes, 
however, with a weaker staining signal. Analysis of olig2 staining revealed significant higher numbers of olig2-positive oligodendrocytes in GFAP Tg73.7 mice compared to wild type littermates only after 1 week of cuprizone treatment $(p<0.05$; Tg: 707.2 cells $/ \mathrm{mm}^{2} \pm 34.21$ vs. WT: 282.3 cells $/ \mathrm{mm}^{2} \pm 42.85$; Figure $7 f$ ). Olig2positve oligodendrocytes were not altered in GFAP Tg73.7 mice compared to wild type littermates after 2, 3, 4, 5 and 6 weeks of cuprizone treatment (Figure 7f).
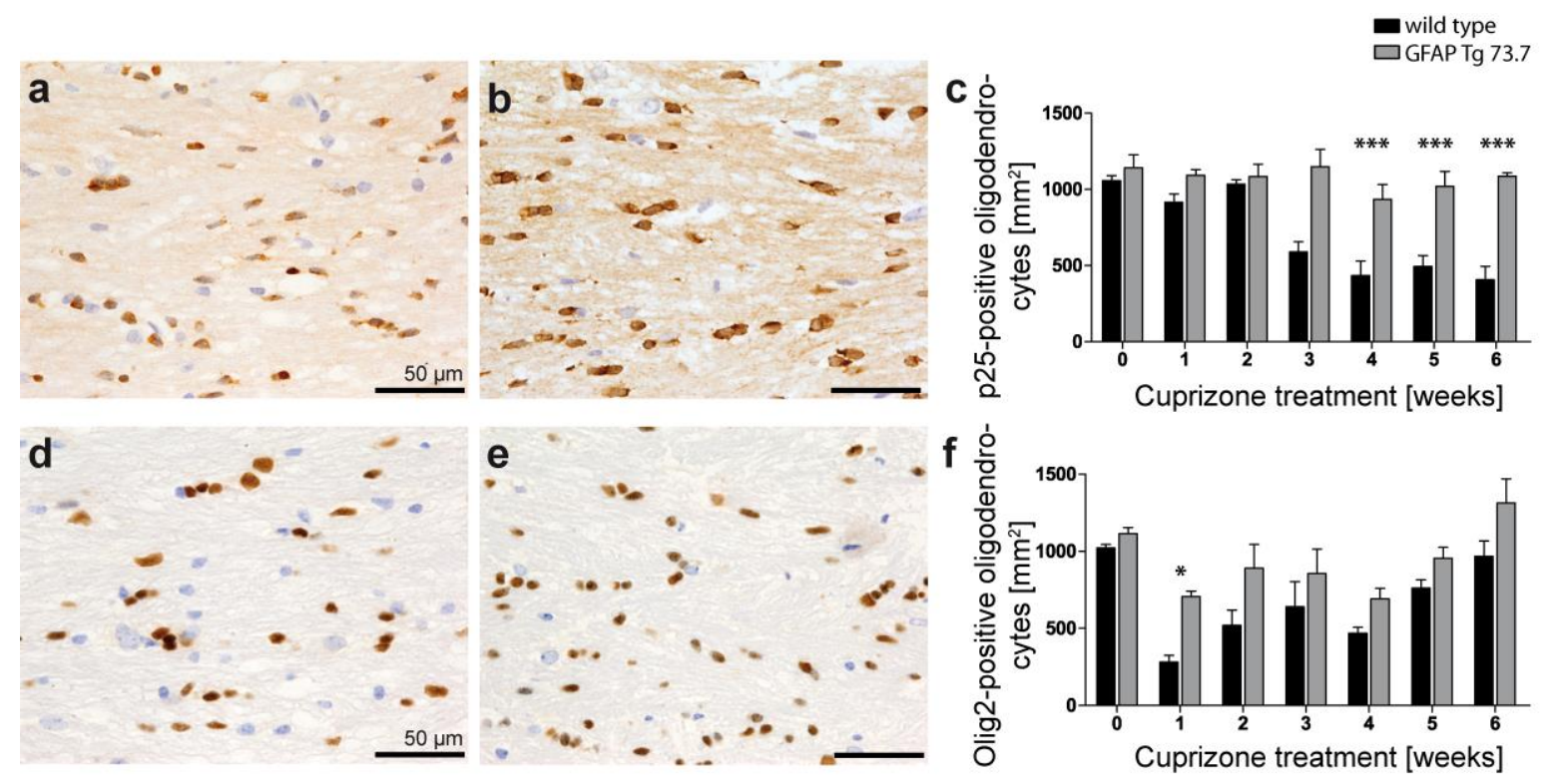

Figure 7: Reduced oligodendrocyte loss in GFAP Tg73.7 mice.

Analysis of p25-positive mature oligodendrocytes displays significantly reduced oligodendrocyte loss in GFAP Tg73.7 mice (b) compared to decreased oligodendrocyte numbers in wild type littermates (a) after 5 and 6 weeks of cuprizone treatment. Immunostaining against olig2 showed significant more olig2-positive oligodendrocytes in GFAP Tg73.7 mice (e) compared to wild type littermates (d) only after 1 week of cuprizone treatment. Representative pictures of the corpus callosum after 6 weeks of cuprizone treatment were taken at $400 x$ original magnification (scale bars: $50 \mu \mathrm{m})\left({ }^{*} p<0.05\right.$; $\left.{ }^{* * *} p<0.001\right)$. Data are presented as mean \pm SEM.

\subsubsection{Reduced cuprizone-induced acute axonal damage in GFAP Tg73.7 mice}

Cuprizone-induced demyelination is paralleled by axonal damage. To determine the effect of enhanced astrocytic hGFAP expression on acute axonal damage during cuprizone-induced demyelination, GFAP Tg73.7 mice and wild type littermates were fed with cuprizone for 3, 4, 5 and 6 weeks. Acute axonal damage was analysed on brain sections stained with an antibody against the amyloid precursor protein (APP). Acute axonal damage causes disrupted APP transport and leads to the formation of APP-positive spheroids. The quantification of APP-positive spheroids in the corpus 
callosum revealed significantly lower numbers in GFAP Tg73.7 mice (Figure 8b) compared to wild type littermates (Figure 8a) after 4 weeks of cuprizone treatment ( $p<0.001$; Tg: 60.04 cells $/ \mathrm{mm}^{2} \pm 34.66$ vs. WT: 696.8 cells $/ \mathrm{mm}^{2} \pm 95.26$; Figure $8 \mathrm{c}$ ). The number of APP-positive spheroids was also significantly lower in GFAP Tg73.7 mice compared to wild type littermates after 5 weeks of cuprizone treatment $(p<0.01$; $\mathrm{Tg}$ : 5.75 cells $/ \mathrm{mm}^{2} \pm 3.56$ vs. wild type littermates: 313.30 cells $/ \mathrm{mm}^{2} \pm 53.68$; Figure $8 \mathrm{c})$ as well as after 6 weeks of cuprizone treatment $\left(\mathrm{p}<0.05 ; \mathrm{Tg}: 14.78 \mathrm{cells} / \mathrm{mm}^{2}\right.$ \pm 6.84 vs. WT: 288.90 cells $/ \mathrm{mm}^{2} \pm 43.24$; Figure $8 \mathrm{c}$ ).
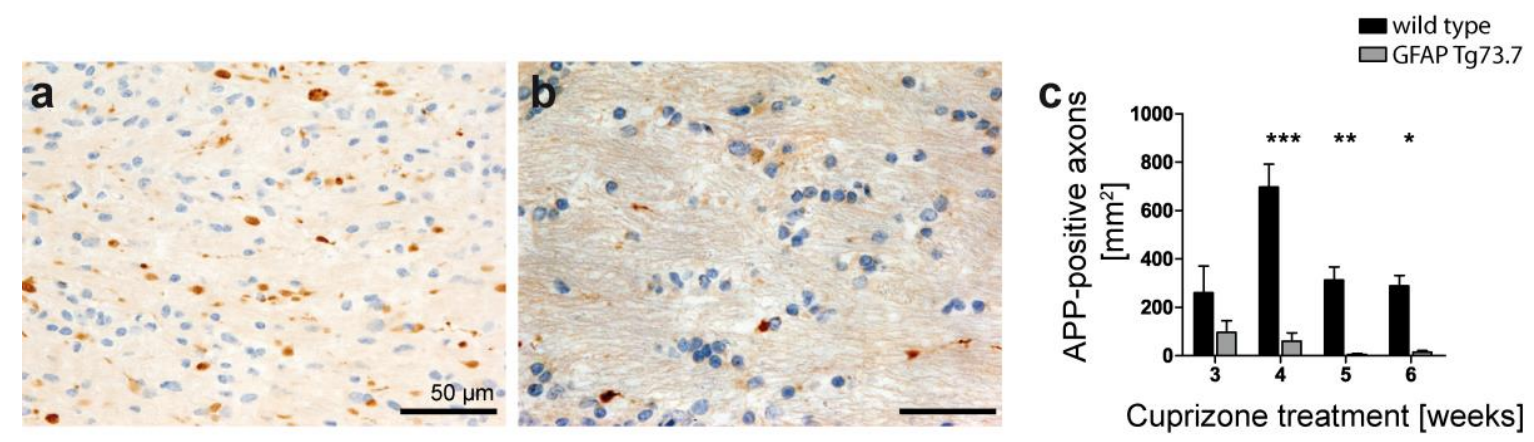

Figure 8: Less acute axonal damage in GFAP Tg73.7 mice.

Evaluation of APP-positive axonal spheroids reveals significantly less spheroids in GFAP Tg73.7 mice (b) compared to wild type littermates (a) after 4, 5 and 6 weeks of cuprizone treatment. Representative pictures of the corpus callosum after 4 weeks of cuprizone treatment were taken at $400 x$ original magnification (scale bars: $50 \mu \mathrm{m})\left({ }^{*} \mathrm{p}<0.05 ;{ }^{* *} \mathrm{p}<0.01 ;{ }^{* * *} \mathrm{p}<0.001\right)$. Data are presented as mean $\pm S E M$.

\subsubsection{Less cuprizone-induced microglia infiltration in GFAP Tg73.7 mice}

To analyse the effect of enhanced hGFAP expression in astrocytes on microglia infiltration during cuprizone-induced demyelination, GFAP Tg73.7 mice and wild type littermates were treated with cuprizone for 1, 2, 3, 4, 5 and 6 weeks. Afterwards brain sections were immunostained with an antibody against Mac-3, which is an antigen on the surface of tissue macrophages. The evaluation of Mac-3 immunostained brain sections of GFAP Tg73.7 mice (Figure 9b) and wild type littermates (Figure 9a) revealed significantly less Mac-3-positive microglia in GFAP Tg73.7 mice compared to wild type littermates after 4 weeks of cuprizone treatment ( $p<0.01$; Tg: 371.3 cells $/ \mathrm{mm}^{2} \pm 75.36$ vs. WT: 947.8 cells $/ \mathrm{mm}^{2} \pm 154.60$; Figure $\left.9 \mathrm{c}\right)$. Mac-3-positive microglia were also significantly less in GFAP Tg73.7 mice compared to wild type littermates after 5 weeks ( $p<0.001 ; \mathrm{Tg}: 98.7 \pm 11.52 \mathrm{cells} / \mathrm{mm}^{2}$ vs. WT: $909.7 \pm 82.04$ cells $/ \mathrm{mm}^{2}$; Figure $9 \mathrm{c}$ ) and after 6 weeks of cuprizone treatment 
( $p<0.001 ; \mathrm{Tg}: 149.0 \pm 22.04$ cells $/ \mathrm{mm}^{2}$ vs. WT: $727.0 \pm 55.37 \mathrm{cells} / \mathrm{mm}^{2}$; Figure $\left.9 \mathrm{c}\right)$. Microglia infiltration was not altered in GFAP Tg73.7 mice compared to wild type littermates after 1, 2 and 3 weeks of cuprizone treatment (Figure 9c).
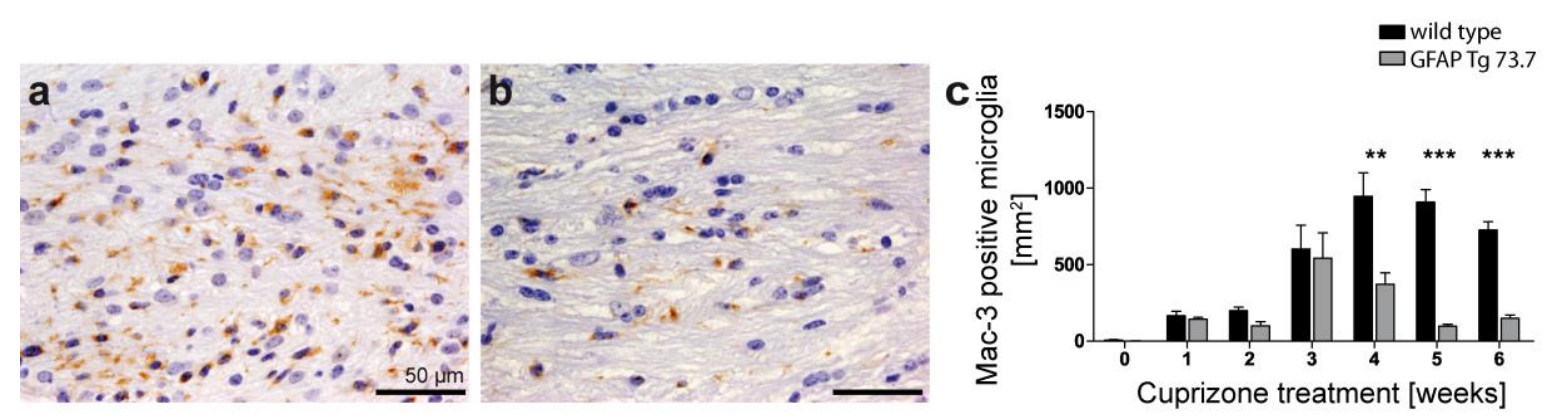

Figure 9: Less microglia infiltration in GFAP Tg73.7 mice.

Evaluation shows significantly less Mac-3-positive microglia in GFAP Tg73.7 mice (b) compared to wild type littermates (a) after 4, 5 and 6 weeks of cuprizone treatment (c). Representative pictures of the corpus callosum after 6 weeks of cuprizone treatment were taken at $400 \mathrm{x}$ original magnification (scale bars: $50 \mu \mathrm{m})\left({ }^{\star *} p<0.01 ;{ }^{* * *} p<0.001\right)$. Data are presented as mean $\pm S E M$.

\subsubsection{Less cuprizone-induced demyelination and oligodendrocyte loss, but similar microglia infiltration in GFAP Tg73.7 after 12 weeks of cuprizone treatment}

To analyse the effect of enhanced astrocytic hGFAP expression on cuprizoneinduced pathology after long-term cuprizone treatment, GFAP Tg.73.7 mice and wild type littermates were fed with cuprizone for 12 weeks. The semi-quantitative analysis of demyelination (see score in 3.1.3) on LFB-PAS stained sections revealed significant less demyelination in GFAP Tg73.7 mice compared to wild type littermates after 12 weeks of cuprizone treatment ( $p<0.05$; Tg: $1.8 \pm 0.20$ vs. WT: 2.9 \pm 0.03 ; Figure 10c). In contrast, Mac-3-positive microglia numbers were not altered in GFAP Tg73.7 mice compared to wild type littermates after 12 weeks of cuprizone treatment (Tg: 476.2 cells $/ \mathrm{mm}^{2} \pm 50.12$ vs. WT: 540.3 cells $/ \mathrm{mm}^{2} \pm 45$.90; Figure $10 f$ ). However, the number of p25-positive mature oligodendrocytes was significantly higher in GFAP Tg73.7 mice compared to wild type littermates ( $p<0.05$; Tg: 1019 cells $/ \mathrm{mm}^{2} \pm 106.0$ vs. WT: 447.2 cells $/ \mathrm{mm}^{2} \pm 80.71$; Figure $10 \mathrm{i}$ ), as well as the number of olig2-positive oligodendrocytes ( $p<0.05$; Tg: 1214 cells $/ \mathrm{mm}^{2} \pm 108.4$ vs. WT 860.4 cells $/ \mathrm{mm}^{2} \pm 45.02$; Figure $10 \mathrm{l}$ ). 


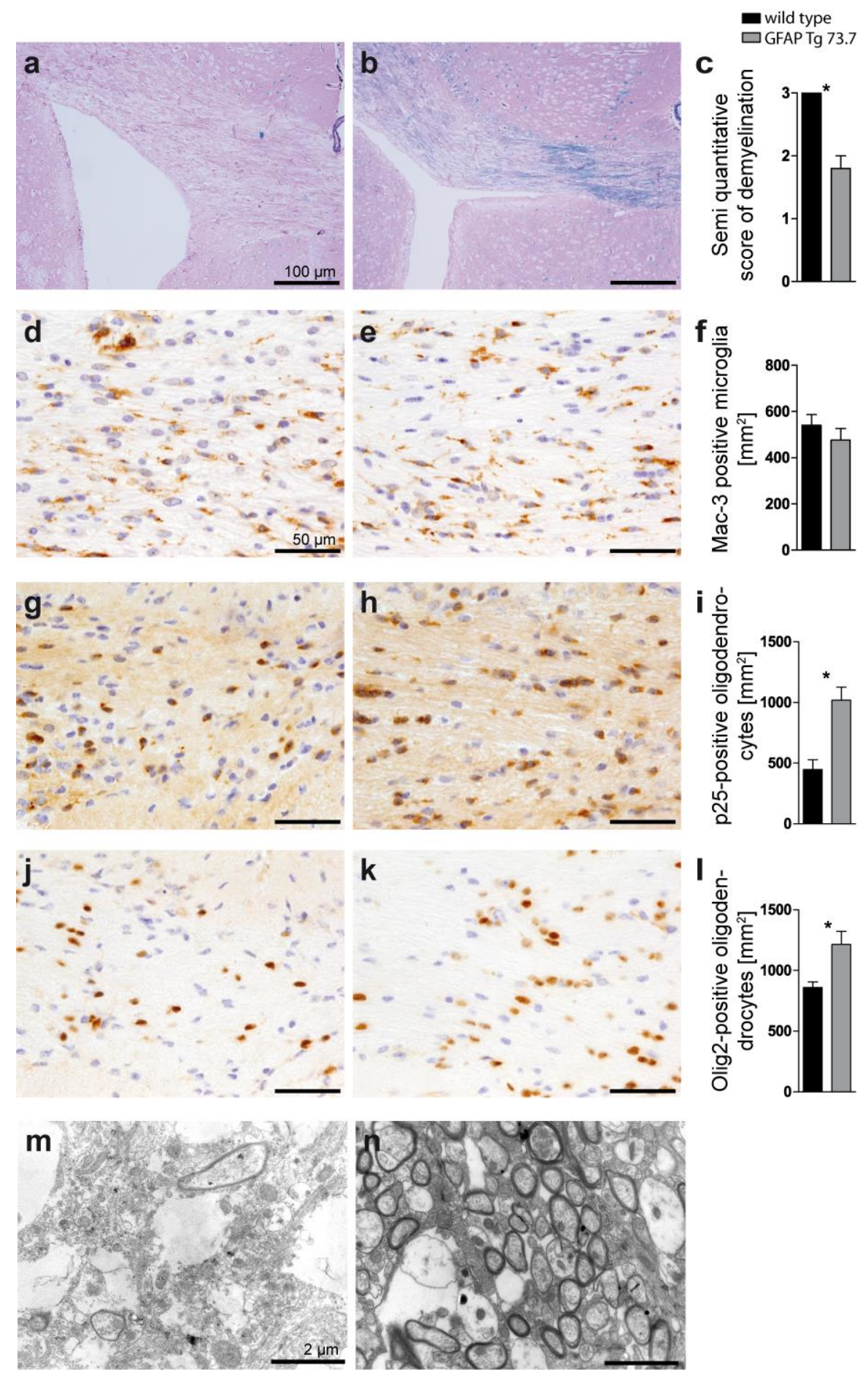

Figure 10: After 12 weeks of cuprizone treatment, cuprizone-induced demyelination and oligodendrocyte loss is less, whereas microglia infiltration is not altered in GFAP Tg73.7 mice. To analyse long-term effects, GFAP Tg73.7 mice (b, e, h, k, n) and wild type littermates (a, d, g, j, m) were treated for 12 weeks with cuprizone. Semi-quantitative evaluation of demyelination on LFBPAS stained sections revealed only minimal demyelination in GFAP Tg73.7 mice $(b, c)$ compared to extensive demyelination in wild type littermates $(a, c)$. Mac3-positive microglia numbers were not altered in GFAP Tg73.7 mice (e, f) compared to wild type littermates (d, f). P25-positive mature oligodendrocytes as well as olig2-positive oligodendrocytes were significantly higher in GFAP Tg73.7 mice ( $h, k$ ) compared to wild type littermates $(g, j)$. Representative electron microscopic pictures show axons without myelin sheaths in wild type littermates $(\mathrm{m})$ compared to myelinated axons in 
GFAP Tg73.7 mice (n). Representative pictures of the corpus callosum were taken at 100x original magnification (a, b; scale bar: $100 \mu \mathrm{m})$ and at $400 x$ original magnification (d-k; scale bars: $50 \mu \mathrm{m}$ ) $\left({ }^{*} p<0.05\right)$. Data are presented as mean \pm SEM.

\subsubsection{Less efficient lysolecithin-induced focal demyelination, but similar microglia infiltration and oligodendrocyte numbers in GFAP Tg73.7 mice}

To analyse the effect of enhanced astrocytic hGFAP expression on focal demyelination, lysolecithin was stereotactically injected into the lateral corpus callosum. The lesion size was assessed on LFB-PAS stained sections 7 days post injection. Measurement of demyelinated area revealed significantly smaller lesions in GFAP Tg73.7 compared to wild type controls ( $p \leq 0.001$; Tg: $75321 \mu \mathrm{m}^{2} \pm 12169$ vs. WT: $148982 \mu \mathrm{m}^{2} \pm 13340$; Figure 11c). To investigate Mac-3-positve microglia and p25-positive oligodendrocytes in the lesion area, brain sections were doublestained with an antibody against myelin basic protein (MBP) to identify the lesion area and either with Mac-3 or with p25. The evaluation did show similar high microglia numbers inside the lesion area in GFAP Tg73.7 mice compared to wild type controls (Tg: 1938 cells $/ \mathrm{mm}^{2} \pm 151.8$ vs. WT: 1864 cells $/ \mathrm{mm}^{2} \pm 139$.9; Figure $11 \mathrm{f})$, as well as similar low numbers of p25-positive oligodendrocytes compared to wild type mice (Tg: 117.4 cells $/ \mathrm{mm}^{2} \pm 42.54$ vs. WT: $48.72 \mathrm{cells} / \mathrm{mm}^{2} \pm 10.40$; Figure 11i). 

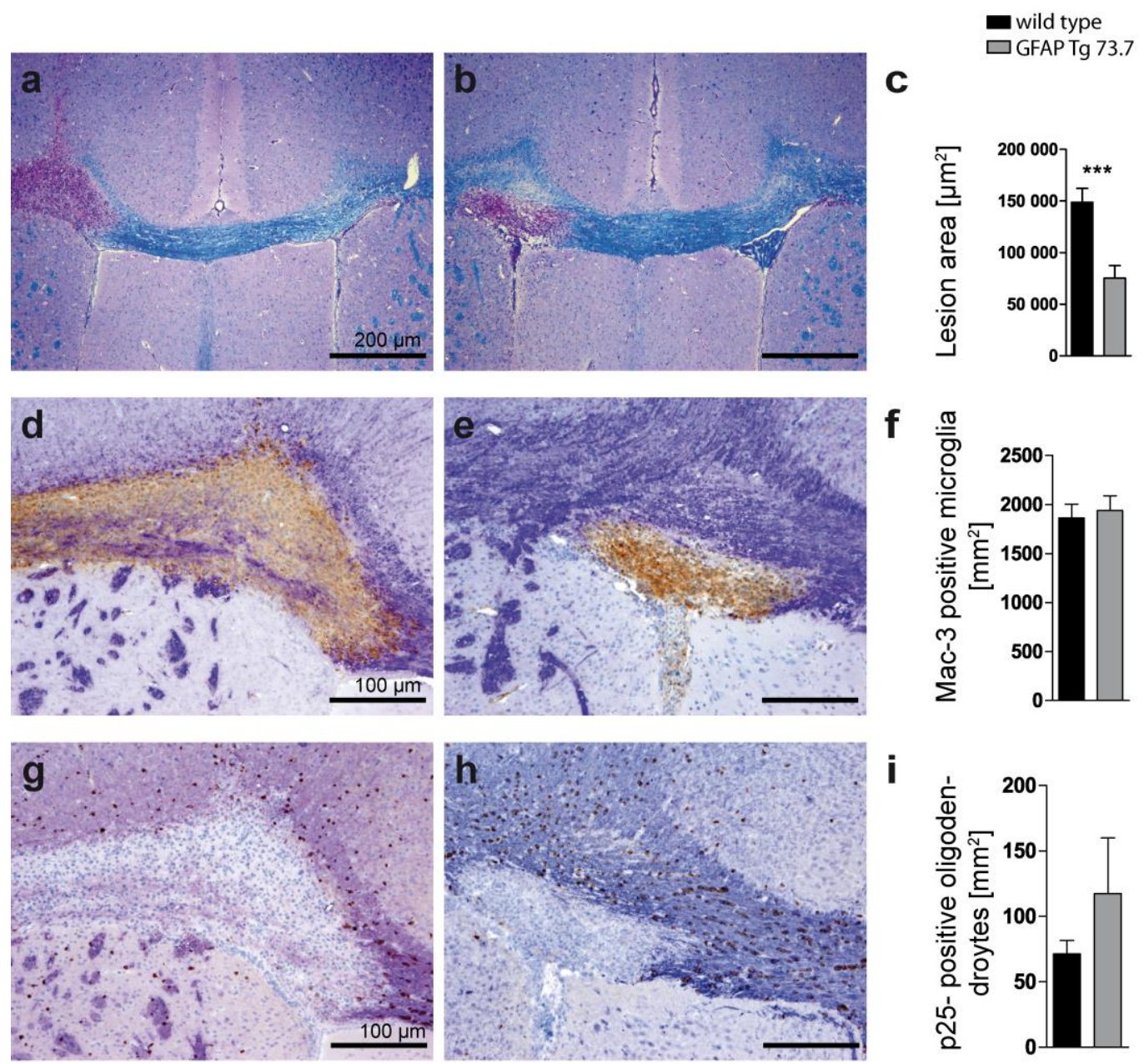

Figure 11: Smaller demyelinated lesions in GFAP Tg73.7 mice and no differences in microglia infiltration and oligodendrocyte numbers compared to wild type mice.

To evaluate focal demyelinated lesions, lysolecithin was injected into the corpus callosum of GFAP Tg73.7 mice and wild type littermates and evaluated after 7 days. The measurement of lesion area on LFB-PAS stained sections reveals significantly smaller lesions in GFAP Tg73.7 mice (b, c) compared to wild type controls $(\mathrm{a}, \mathrm{c})$. Double stained sections with antibodies against the myelin basic protein (MBP) and Mac-3 did not show any alteration in the density of Mac-3-positive microglia in GFAP Tg73.7 mice (e, f) compared to wild type controls (d, f), however, smaller lesion size was confirmed. Double stained sections with antibodies against MBP and p25, indicate no difference in p25-positive mature oligodendrocyte numbers between GFAP Tg73.7 mice ( $h$, i) and wild type controls $(g, i)$, but oligodendrocytes were almost depleted in comparison to normal white. Representative pictures of the corpus callosum were taken at 100x original magnification (a, b; scale bars: $100 \mu \mathrm{m})$ and at $400 x$ original magnification (d, e, g, h; scale bars: $50 \mu \mathrm{m})\left({ }^{* * *} p<0.001\right)$. Data are presented as mean \pm SEM. 


\subsubsection{Reduced NF-KB-activity in lysolecithin-induced focal demyelinated lesions in GFAP Tg73.7 mice}

The activity of the NF-KB pathway regulates gene transcription of several genes essential during demyelination (Raasch et al 2011). When NF-kB is activated it translocates into the nucleus to activate gene expression. To analyse the effect of enhanced astrocytic hGFAP on NF-kB activity in focal lesions, brain sections were doublestained with antibodies against the NF-kB-subunit p65 and GFAP. Nuclei were stained with DAPI. Seven days post lesion induction, GFAP-positive astrocytes with nuclear p65 were counted in the lesion area. The analysis revealed significantly less nuclear translocation of p65 in GFAP Tg73.7 astrocytes (Figure 12b) compared to wild type controls ( $p<0.01$; Tg: $27.22 \% \pm 1.99$ vs. WT: $55.93 \% \pm 8.65$; Figure $12 c$ ).
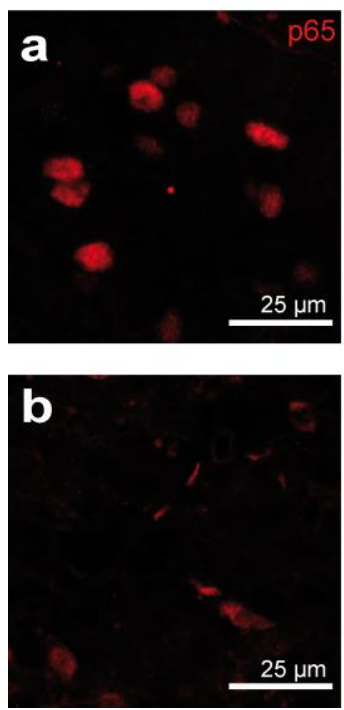
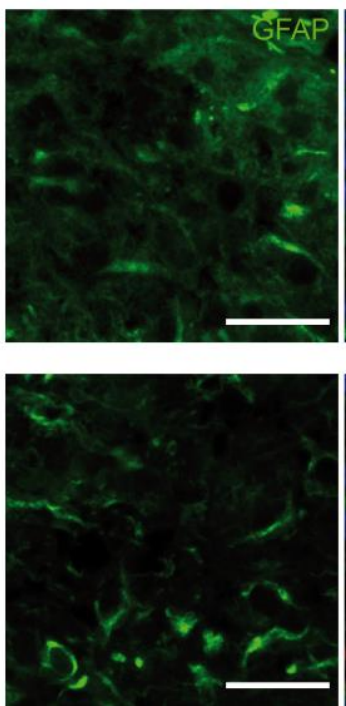
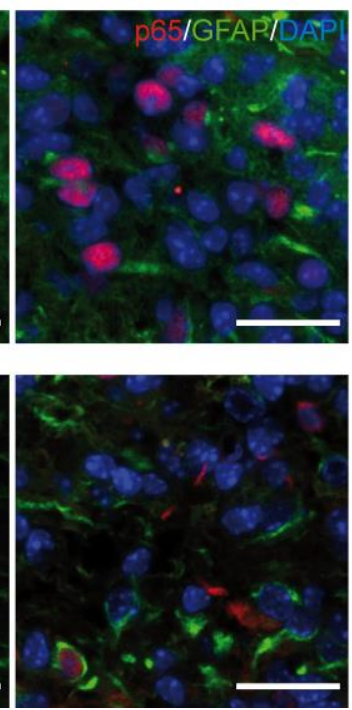

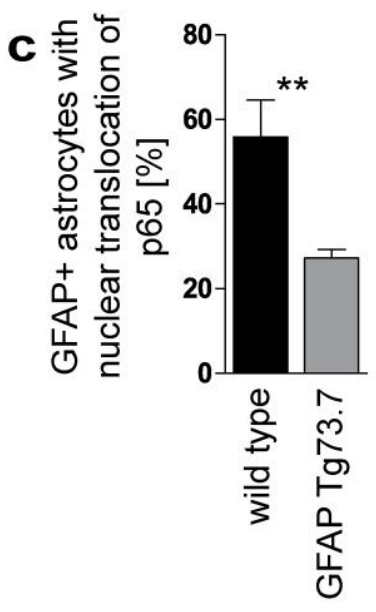

Figure 12: Reduced astrocytic NF-kB activity in lysolecithin-induced lesions in GFAP Tg73.7 mice.

Nuclear translocation of the NF-KB subunit p65 (red) in GFAP-positive astrocytes (green) indicates NF-kB activation. The evaluation in focal lesions shows less GFAP-positive astrocytes with nuclear p65 in GFAP Tg73.7 mice (b, c) compared to wild type mice (a, c). Representative pictures of the corpus callosum were taken at $400 x$ original magnification (scale bars: $25 \mu \mathrm{m})\left({ }^{* *} \mathrm{p}<0.01\right)$. Data are presented as mean \pm SEM.

\subsection{Evaluating the effect of enhanced astrocytic hGFAP expression in astrocytes on myelin and cytokine mRNA expression}

To investigate the effect of enhanced hGFAP in astrocytes expression on cytokine expression in vivo selected cytokines and chemokines were analysed by qPCR after 
cuprizone treatment. Afterwards identified chemokines were further analysed in stimulated astrocytes in vitro. Furthermore, myelin protein mRNA expression after cuprizone treatment was measured to further analyse effects of enhanced astrocytic hGFAP expression on demyelination.

\subsubsection{Increased cuprizone-induced myelin mRNA expression in GFAP Tg73.7 mice in vivo}

Myelin genes are downregulated prior to actual degradation of myelin during cuprizone-induced demyelination (Morell et al 1998). Thus, the analysis of myelin mRNA expression can reveal early effects of cuprizone-induced demyelination. To investigate the effect of enhanced astrocytic hGFAP expression on myelin mRNA expression during cuprizone treatment, GFAP Tg73.7 mice and wild type littermates were fed with cuprizone for 3 and 6 weeks. Myelin associated glycoprotein (MAG), proteolipid protein 1 (PLP1) and MBP mRNA expression in the corpus callosum was analysed with the $\mathrm{RT}^{2}$ Profiler ${ }^{\mathrm{TM}}$ PCR Array mouse multiple sclerosis (Qiagen, Germany). The fold change was normalised to wild type controls. The array analysis revealed higher mRNA levels of MAG (Figure 13a), MBP (Figure 13b) and PLP1 (Figure 13c) in GFAP Tg73.7 mice after 3 weeks of cuprizone treatment $(p<0.05$, MAG: $7.63 \pm 1.22$; $p<0.05$, MBP: $7.89 \pm 1.90 ; p<0.01$, PLP1: $8.12 \pm 1.21$ ) compared to naïve mice (MAG: $0.81 \pm 0.06$, MBP: $0.71 \pm 0.03$, PLP1: $0.81 \pm 0.06$ ). After 6 weeks of cuprizone treatment the myelin protein mRNA expression was reduced $(p<0.01$, MAG: $1.25 \pm 0.19$; $p<0.05$, PLP1: $1.42 \pm 0.17$ ) compared to 3 weeks (Figure 13). 


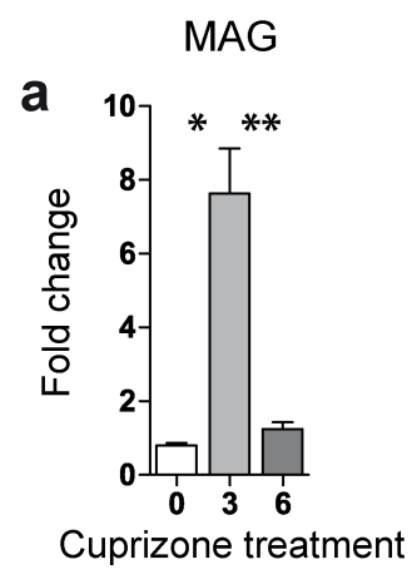

[weeks]

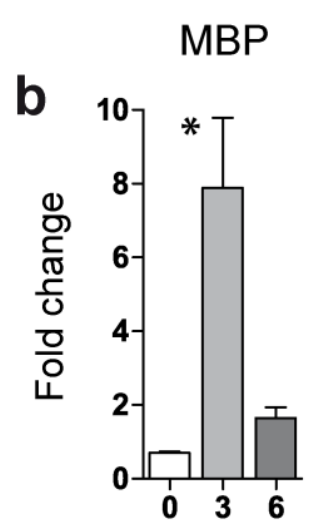

Cuprizone treatment [weeks]

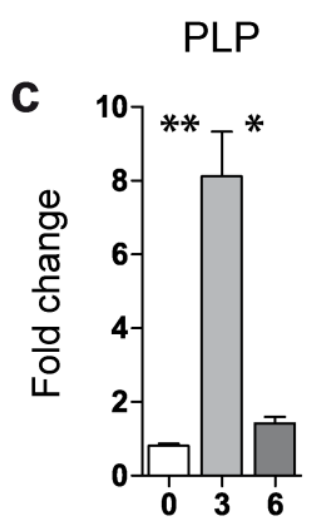

Cuprizone treatment [weeks]

Figure 13: Higher myelin mRNA levels in GFAP Tg73.7 mice after 3 weeks of cuprizoneinduced demyelination.

The mRNA expression of myelin proteins in the corpus callosum of GFAP Tg73.7 mice after 3 and 6 weeks of cuprizone treatment was analysed via GPCR. The fold changes were normalized to wild type littermates. Expression of myelin associated glycoprotein (MAG) (a), myelin basic protein (MBP) (b) and proteolipid protein 1 (PLP1) (c) mRNA is significantly higher in GFAP Tg73.7 mice after 3 weeks of cuprizone treatment compared to naïve GFAP Tg73.7 mice. The fold change of MAG and PLP1 is significant higher after 3 weeks compared to 6 weeks of cuprizone treatment $\left({ }^{*} \mathrm{p}<0.05\right.$; ${ }^{* *} \mathrm{p}<0.01$ ). Fold changes are presented as mean \pm SEM.

\subsubsection{Less cuprizone-induced CCL2 and CXCL10 mRNA expression in GFAP}

\section{Tg73.7 mice in vivo}

To analyse the effect of hGFAP overexpression on cytokine and chemokine expression during cuprizone-induced demyelination, the mRNA expression of $\mathrm{C}-\mathrm{C}$ motif ligand 2 (CCL2), CCL2, CCL5, C-X-C motif ligand 10 (CXCL10), CXCL12, interleukin-6 (IL-6) and tumour necrosis factor a (TNFa) were analysed with qPCR. It was previously shown that cytokine and chemokine mRNA are regulated during cuprizone-induced demyelination (Biancotti et al 2008, Buschmann et al 2012, Jurevics et al 2002, Skripuletz et al 2012). The fold change was normalised to naïve controls.

The qPCR analyses revealed significantly less up-regulated CCL2 mRNA expression in GFAP Tg73.7 mice compared to increased up-regulation in wild type littermates after 3 weeks ( $p<0.01$; Tg: $1.56 \pm 0.60$ vs. WT: $5.91 \pm 1.00$ ) and 6 weeks of cuprizone treatment ( $p<0.01, \mathrm{Tg}: 0.65 \pm 0.24$ vs. WT: $4.56 \pm 0.82$; Figure 14a). Additionally, the mRNA expression of CXCL10 was significantly less up-regulated in GFAP Tg73.7 mice compared to wild type littermates whereas it is substantially 
increased after 6 weeks of cuprizone treatment $(p<0.001, \mathrm{Tg}$ : $1.51 \pm 0.45$ vs. WT: $9.40 \pm 1.40$; Figure 14c). After 3 weeks of cuprizone treatment CXCL10 mRNA expression was similar not up-regulated in GFAP Tg73.7 mice and wild type littermates (Tg: $1.20 \pm 0.30$ vs. WT: $0.97 \pm 0.13$ ).

The mRNA levels of CCL5, CXCL12, IL- 6 and TNFa were similar up- or downregulated in GFAP Tg73.7 mice compared to wild type littermates after 3 or 6 weeks of cuprizone treatment (Figure 14). As normalised to naïve controls, CCL5 mRNA expression (Figure 14b) was up-regulated in GFAP Tg.73.7 mice and not in wild type mice (Tg: $1.79 \pm 0.42$ vs. WT: $0.98 \pm 0.29$ ) after 3 weeks of cuprizone treatment and comparable up-regulated in GFAP Tg73.7 mice and wild type mice after 6 weeks of cuprizone treatment (Tg: $3.12 \pm 0.58$ vs. WT: $2.65 \pm 0.68$ ). CXCL12 mRNA expression (Figure 14d) was down-regulated in wild type mice and not in GFAP Tg73.7 mice after 3 weeks of cuprizone treatment (Tg: $0.57 \pm 0.06$ vs. WT: 0.30 \pm 0.07 ). The level of IL-6 (Figure 14e) was down-regulated in wild type mice and not regulated in GFAP Tg73.7 mice after 3 weeks (Tg: $0.82 \pm 0.23$ vs. WT: $0.33 \pm 0.06$ ) and after 6 weeks of cuprizone treatment (Tg: $0.63 \pm 0.16$ vs. WT: $0.33 \pm 0.06$ ). Whereas TNFa mRNA expression (Figure 14f) was up-regulated in GFAP Tg73.7 mice and wild type littermates after 3 weeks ( $T g$ : $3.75 \pm 1.01$ vs. WT: $6.52 \pm 0.88$ ) and after 6 weeks of cuprizone treatment (Tg: $3.42 \pm 0.73$ vs. WT: $4.93 \pm 0.68$ ). 


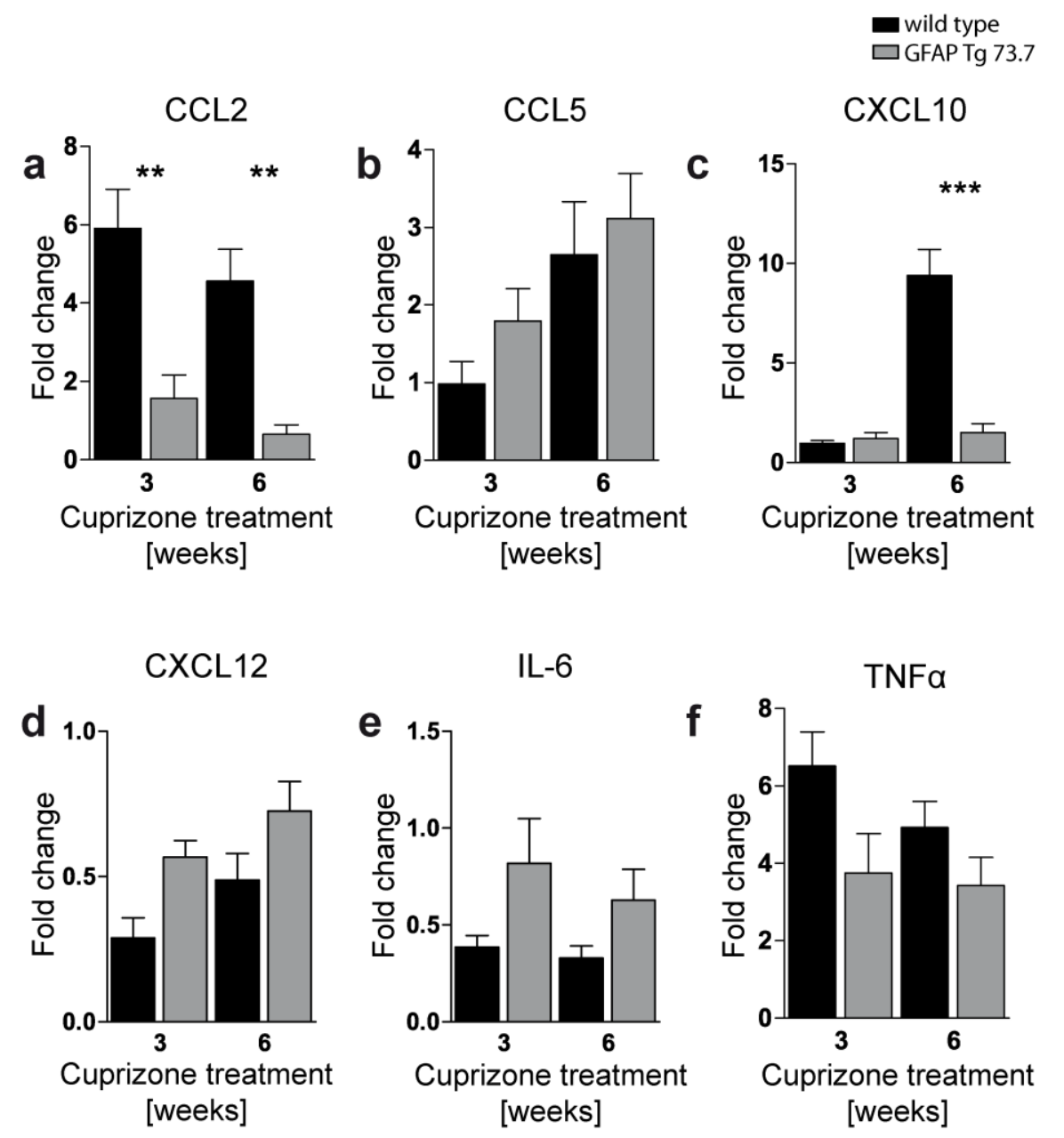

Figure 14: Cytokine and chemokine mRNA expression in vivo after 3 and 6 weeks of cuprizone-induced demyelination.

The cytokine and chemokine mRNA expression in the corpus callosum of GFAP Tg73.7 mice and wild type littermates after 3 and 6 weeks of cuprizone treatment was analysed with qPCR. The fold changes were normalized to naïve controls. CCL2 (a) expression is significantly less up-regulated in GFAP Tg73.7 mice compared to wild type littermates after 3 and 6 weeks of cuprizone treatment. The CXCL10 (c) expression level is significantly less up-regulated in GFAP Tg73.7 mice after 6 weeks of cuprizone treatment whereas it is substantially increased in wild type mice. The expression levels of CCL5 (b), CXCL12 (d), IL-6 (e) and TNFa (f) are not significantly different in GFAP Tg73.7 mice compared to wild type littermates after 3 or 6 weeks of cuprizone treatment. $\left({ }^{* \star} p<0.01\right.$, ${ }^{* * *} \mathrm{p}<0.001$ ). Fold changes are presented as mean \pm SEM.

\subsubsection{CXCL10 is expressed in astrocytes after 6 weeks of cuprizone-induced demyelination}

CXCL10 expression levels were only found to be highly up-regulated in wild type mice but not in GFAP Tg73.7 mice (Figure 14c). To assess the cellular source of CXCL10, double immunofluorescence staining with antibodies against the chemokine CXCL10 and astrocytes with GFAP were performed after 6 weeks of 
cuprizone treatment (Figure 15). Additionally, double staining against CXCL10 and lba1 (microglia) or CXCL10 and p25 (oligodendrocytes) were performed (Figure 16). Analysis of double staining showed that GFAP-positive astrocytes express the chemokine CXCL10 in GFAP Tg73.7 mice (Figure 15b) and wild type littermates (Figure 15a) after 6 weeks of cuprizone induced demyelination.
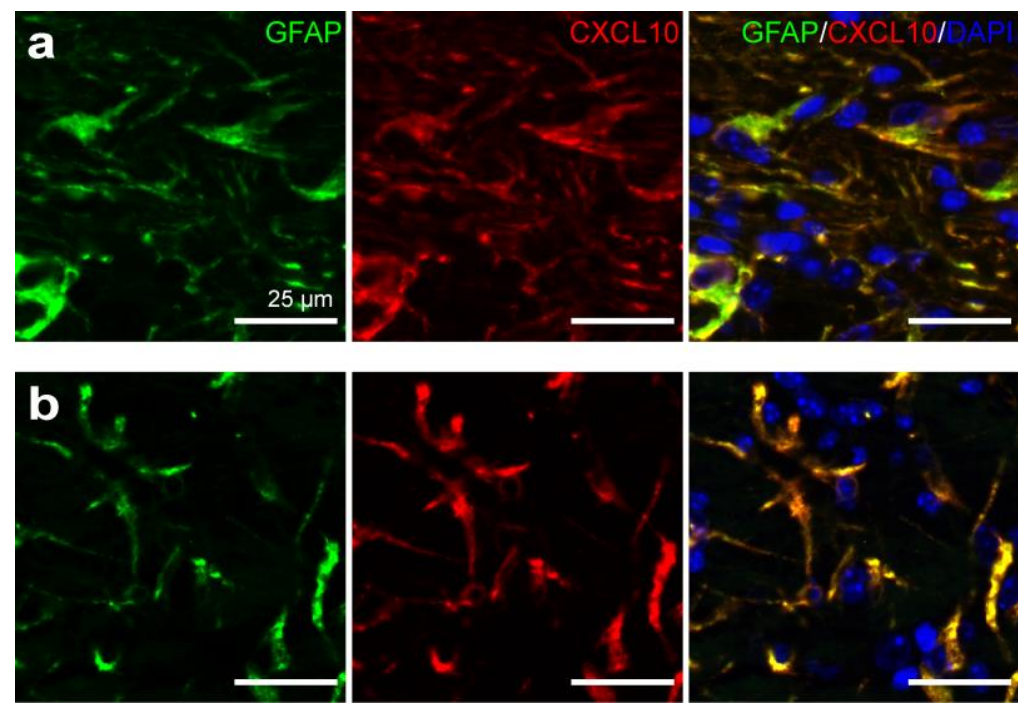

Figure 15: Astrocytes express CXCL10 after six weeks of cuprizone-induced demyelination.

Double staining with antibodies against CXCL10 (red) and GFAP (green) demonstrate that GFAPpositive astrocytes are a source of CXCL10 in wild type mice (a) and GFAP Tg73.7 mice (b) after 6 weeks of cuprizone treatment. Nuclei were counterstained with DAPI (blue). Representative pictures of the corpus callosum were taken at $400 x$ original magnification (scale bars: $25 \mu \mathrm{m}$ ).

Double staining with CXCL10 and the microglia marker lba1 showed no colocalization of CXCL10 in these cells in GFAP Tg73.7 mice (Figure 16b) and wild type littermates (Figure 16a). Additionally, double staining with CXCL10 and the oligodendrocyte marker p25 showed no co-localization of CXCL10 in the cytoplasm of oligodendrocytes in GFAP Tg73.7 mice (Figure 16d) and wild type littermates (Figure 16c). 

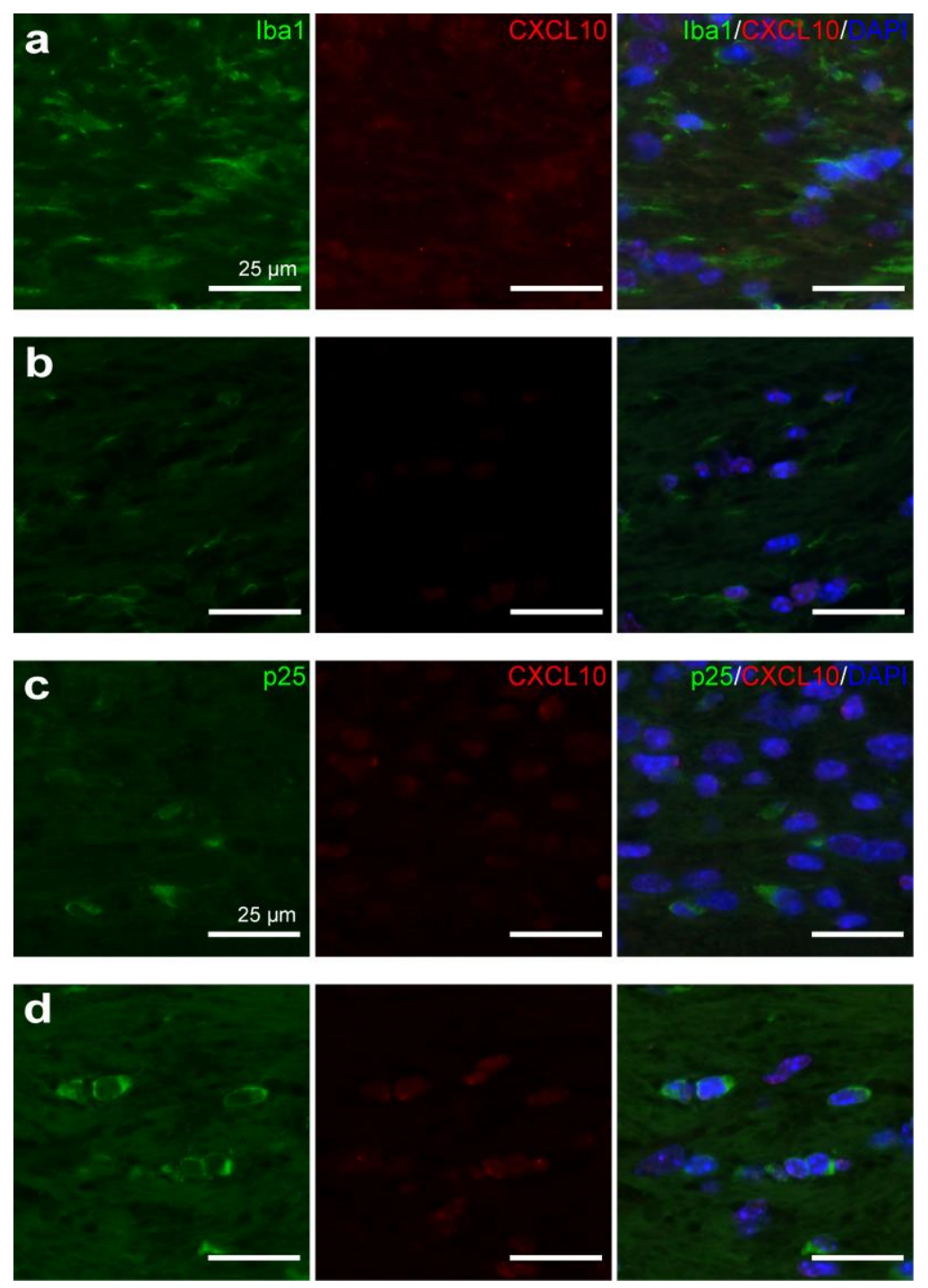

Figure 16: Microglia and oligodendrocytes do not express CXCL10 during cuprizone-induced demyelination.

Double staining with CXCL10 (red) and the microglia marker lba1 (a, b; green) or the oligodendrocyte marker p25 (c, d; green) show that neither microglia nor oligodendrocytes express CXCL10 after 6 weeks of cuprizone treatment. Microglia in wild type mice (a) and GFAP Tg73.7 mice (b) were not CXCL10 positive. In addition, oligodendrocytes in wild type (c) and GFAP Tg73.7 mice (d) were not CXCL10 positive in the cytoplasm. Nuclei were counterstained with DAPI (blue). Representative pictures of the corpus callosum were taken at $400 x$ original magnification (scale bars: $25 \mu \mathrm{m}$ ).

\subsubsection{Unaltered CCL2 and CXCL10 mRNA expression in GFAP Tg73.7} astrocytes after cytokine stimulation in vitro

To further confirm the expression of CXCL10 as well as CCL2 in astrocytes, primary astrocytes of GFAP Tg73.7 mice and wild type littermates were isolated and stimulated with TNFa or with a combination of IL-1 $\beta$ and INFy or for $3 \mathrm{~h}$. Expression of CCL2 and CXCL10 was analysed with QPCR. The fold change was normalized 
to unstimulated astrocytes. The expression of CXCL10 mRNA was not significantly altered, however, it showed a trend towards lower expression in GFAP Tg73.7 astrocytes compared to wild type astrocytes after TNFa stimulation $(p=0.06$, Tg: $17.99 \pm 1.11$ vs. WT: $33.10 \pm 5.66$; Figure 17b). CXCL10 mRNA expression after IL$1 \beta$ and INFY stimulation was not altered in GFAP Tg73.7 astrocytes (Tg: 197.90 \pm 7.13 vs. WT: $299.10 \pm 89.19$; Figure 17b). Furthermore, CCL2 mRNA expression was not altered in GFAP Tg73.7 astrocytes compared to wild type astrocytes after TNFa stimulation (Tg: $76.98 \pm 10.25$ vs. WT:55.94 \pm 8.98 ) and stimulation with IL-1 $\beta$ and INFY (Tg: $48.61 \pm 0.89$ vs WT:54.61 \pm 9.15 ; Figure 17a).

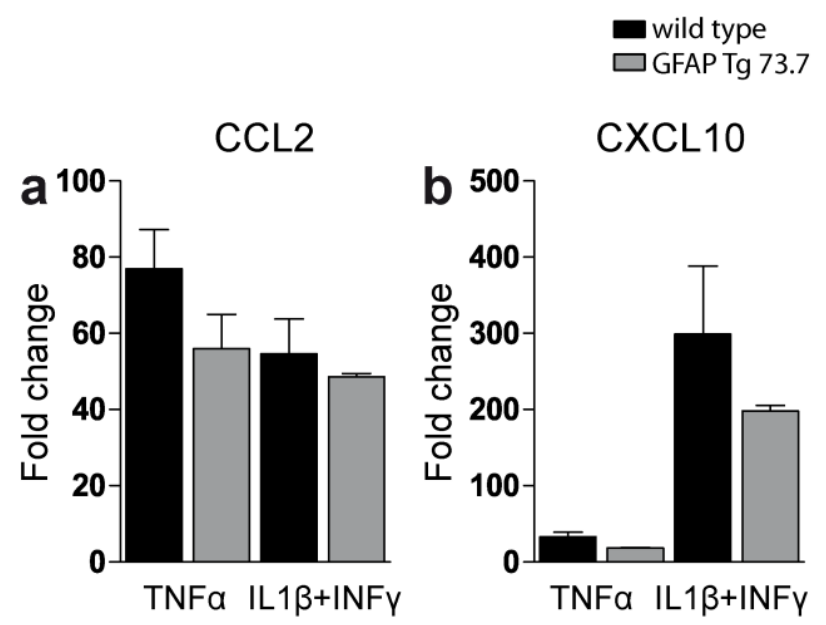

Figure 17: Similar expression levels of CCL2 and CXCL10 mRNA in GFAP Tg73.7 and wild type astrocytes in vitro.

Primary astrocytes of GFAP Tg73.7 mice and wild type littermates were stimulated with TNFa or IL-1 $\beta$ and INFY for 3h. Fold changes were normalised to unstimulated controls. CCL2 (a) and CXCL10 (b) expression was not significantly altered in GFAP Tg73.7 astrocytes compared to wild type astrocytes. GFAP Tg73.7 and wild type astrocytes show both an up-regulation of CCL2 (a) and CXCL10 (b). Fold changes are presented as mean \pm SEM.

\subsubsection{Lower NF-KB activity in GFAP Tg73.7 astrocytes after cytokine stimulation in vitro}

The NF-KB signalling pathway regulates astrocytic cytokine expression. Therefore, astrocytic NF-KB activity was analysed after cytokine stimulation in vitro. Primary astrocytes of GFAP Tg73.7 mice and wild type littermates were stimulated for $1 \mathrm{~h}$ either with TNF $\alpha$ or with IL-1 $\beta$ and INFy. Unstimulated astrocytes served as controls. NF-KB activity was measured luminometrically with the Cignal Lenti NF-KB luciferase reporter Assay. Stimulation with both cytokines increased NF-KB activity 
compared to unstimulated controls (Figure 18). NF-KB activity in GFAP Tg73.7 astrocytes was significantly lower compared to wild type astrocytes after stimulation with TNFa ( $p<0.001$; Tg: 5.67 RLU \pm 0.40 vs. WT: 13.06 RLU \pm 0.31 ; Figure 18$)$ and after stimulation with IL-1 $\beta$ and INFY ( $p<0.001 ;$ Tg: 6.72 RLU \pm 1.09 vs. WT: 15.30 RLU \pm 0.86 ; Figure 18 ).

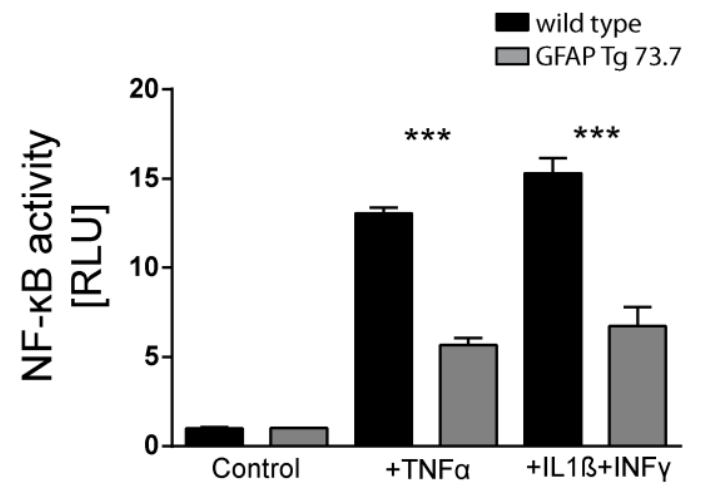

Figure 18: Diminished increase in NF-kB activity in stimulated primary astrocytes of GFAP Tg73.7 mice.

NF-KB activity was measured luminometrically (RLU) in primary astrocytes of GFAP Tg73.7 mice and wild types. NF-KB activity was stimulated with TNF $\alpha$ or IL-1 $\beta$ with INFY. Unstimulated astrocytes served as controls. Cytokine stimulation increases NF-kB activity in GFAP Tg73.7 and wild type astrocytes. Compared to NF-kB activity in wild type astrocytes, NF-kB activation is significantly less increased in GFAP Tg73.7 astrocytes after stimulation with TNF $\alpha$ or IL-1 $\beta$ with INFY $\left({ }^{* * *} p<0.001\right)$. Data are presented as mean \pm SEM.

\subsection{Reduced phagocytosis activity of microglia in co-cultures with astrocytes in vitro}

Microglia infiltration was less in GFAP Tg73.7 mice after 4, 5 and 6 weeks of cuprizone treatment (see Figure 9). As phagocytosis is one of the main functions of microglia, the effect of enhanced astrocytic hGFAP expression on microglial phagocytosis activity was analysed. This was measured by quantifying the uptake of fluorescently labelled myelin by CD11b-positive microglia measured via flow cytometry. To analyse whether astrocytes of GFAP Tg73.7 mice have an effect on myelin phagocytosis of microglia, isolated astrocytes of GFAP Tg73.7 mice or wild type littermates were co-cultured for 24h with microglia of C57BL/ 6 mice. Microglia single-cultures served as controls. Cells were incubated with myelin for $2 \mathrm{~h}$ followed by analysis with flow cytometry to measure the phagocytosis rate. The analysis by flow cytometry revealed increased phagocytosis activity in microglia single-cultures 
compared to astrocyte co-cultures with either GFAP Tg73.7 astrocytes ( $p<0.05$; Tg: $50.97 \% \pm 2.66$ vs ctrl: $63.41 \% \pm 3.47$; Figure $19 \mathrm{~g}$ ) or wild type astrocytes ( $<<0.05$; WT: $49.25 \% \pm 2.11$ vs. ctrl: $63.41 \% \pm 3.47$; Figure 19d). To investigate whether soluble factors released by astrocytes influence microglial phagocytosis, microglia were incubated for 24h with supernatant of GFAP Tg73.7 astrocyte cultures or wild type astrocyte cultures. Analysis with flow cytometry revealed supernatant of GFAP Tg73.7 astrocytes did not differentially affect phagocytosis activity compared to supernatant of wild type astrocytes (Tg: $55.07 \% \pm 6.75$ vs. WT: $55.47 \% \pm 5.82$; Figure 19d, g).

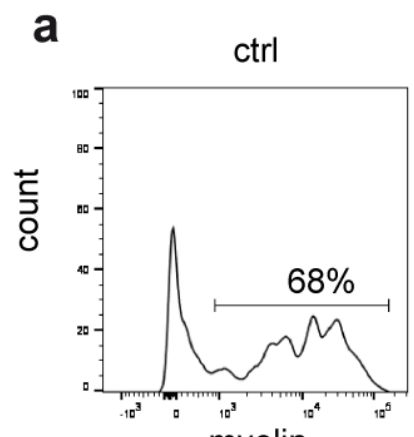

myelin

b

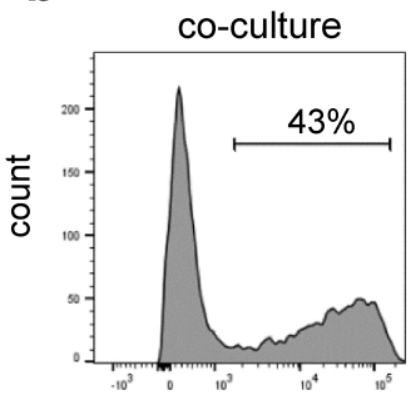

myelin

e

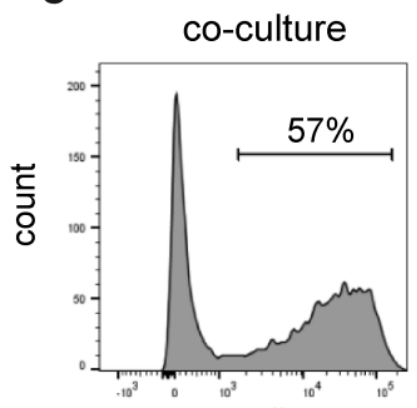

myelin
C

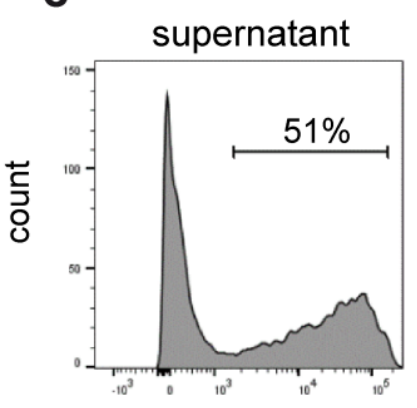

myelin

$\mathbf{f}$

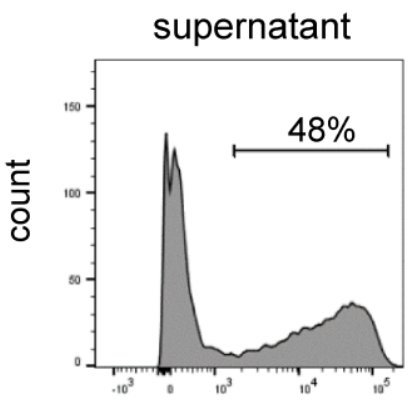

myelin

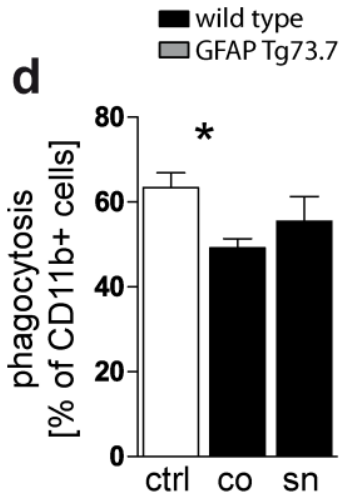

g

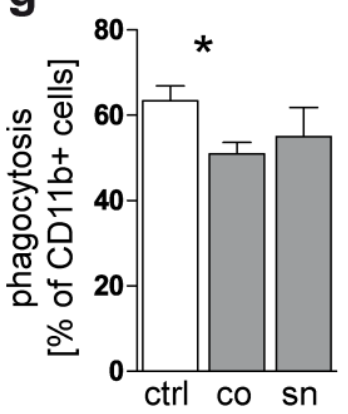

Figure 19: Astrocytes inhibit myelin phagocytosis activity of microglia in vitro.

The effect of astrocytes on microglia myelin phagocytosis was investigated in vitro in $24 \mathrm{~h}$ co-cultures (co) of microglia either with GFAP Tg73.7 astrocytes (e) or wild type astrocytes (b). Microglia singlecultures served as controls (ctrl, a). Flow cytometry histograms show representative results from 
myelin phagocytosis assays. The numbers in the histograms indicate the percentage of phagocytically active microglia cells. Phagocytosis activity is significant less in microglia-astrocyte co-cultures ( $d, g)$ compared to the control (a). Astrocyte conditioned supernatant (sn) of GFAP Tg73.7 astrocytes (f) or wild type astrocytes (c) has no effect on microglia phagocytosis activity (d, g) compared to the control (a). Data are presented as mean \pm SEM. 


\section{4 | Discussion}

\subsection{Summary of the results}

To investigate whether increased GFAP expression in astrocytes has an impact on toxin-induced demyelination, transgenic GFAP Tg73.7 mice which overexpresses human (h)GFAP (Messing 1998) were used. Overexpression of hGFAP leads to reactive astrocytes in the corpus callosum of GFAP Tg73.7 mice compared to wild type mice as identified by their morphology. Naïve GFAP Tg73.7 mice show similar myelination, oligodendrocyte and microglia numbers compared to wild type mice.

GFAP Tg73.7 mice and wild type mice were treated with cuprizone for 1, 2, 3, 4, 5, 6 and 12 weeks. Demyelination was assessed immunohistochemically as well as on the ultrastructural level using electron microscopy (EM) of the corpus callosum. This study demonstrated that cuprizone-induced demyelination was substantially less pronounced in GFAP Tg73.7 mice compared to wild type mice after 4, 5, 6 and 12 weeks of cuprizone treatment (Figure 20). This was confirmed by EM after six weeks. Furthermore, it was shown that mature oligodendrocyte numbers remained stable in GFAP Tg73.7 mice, while pronounced oligodendrocyte loss was observed in wild type mice after 4, 5 and 6 weeks of cuprizone treatment (Figure 20). GFAP Tg73.7 mice showed higher numbers of OPCs with oligodendrocytes compared to wild type mice after one week of cuprizone, however, OPC numbers were not altered from week two on. Additionally, it was demonstrated that oligodendrocyte loss and ensuing demyelination in wild type mice leads to pronounced acute axonal damage after four weeks of cuprizone treatment, while axonal damage was nearly absent in GFAP Tg73.7 mice. Reduced oligodendrocyte numbers leads to reduced mRNA expression of myelin genes (Morell et al 1998). The increased mRNA expression of myelin associated glycoprotein (MAG), proteolipid protein 1 (PLP1) and myelin basic protein (MBP) in GFAP Tg73.7 mice compared to wild type mice after three weeks of cuprizone treatment reflects stable oligodendrocytes numbers and function. Long-term cuprizone treatment after 12 weeks still demonstrated higher oligodendrocyte numbers and reduced demyelination in GFAP Tg73.7 mice compared to wild type mice. 


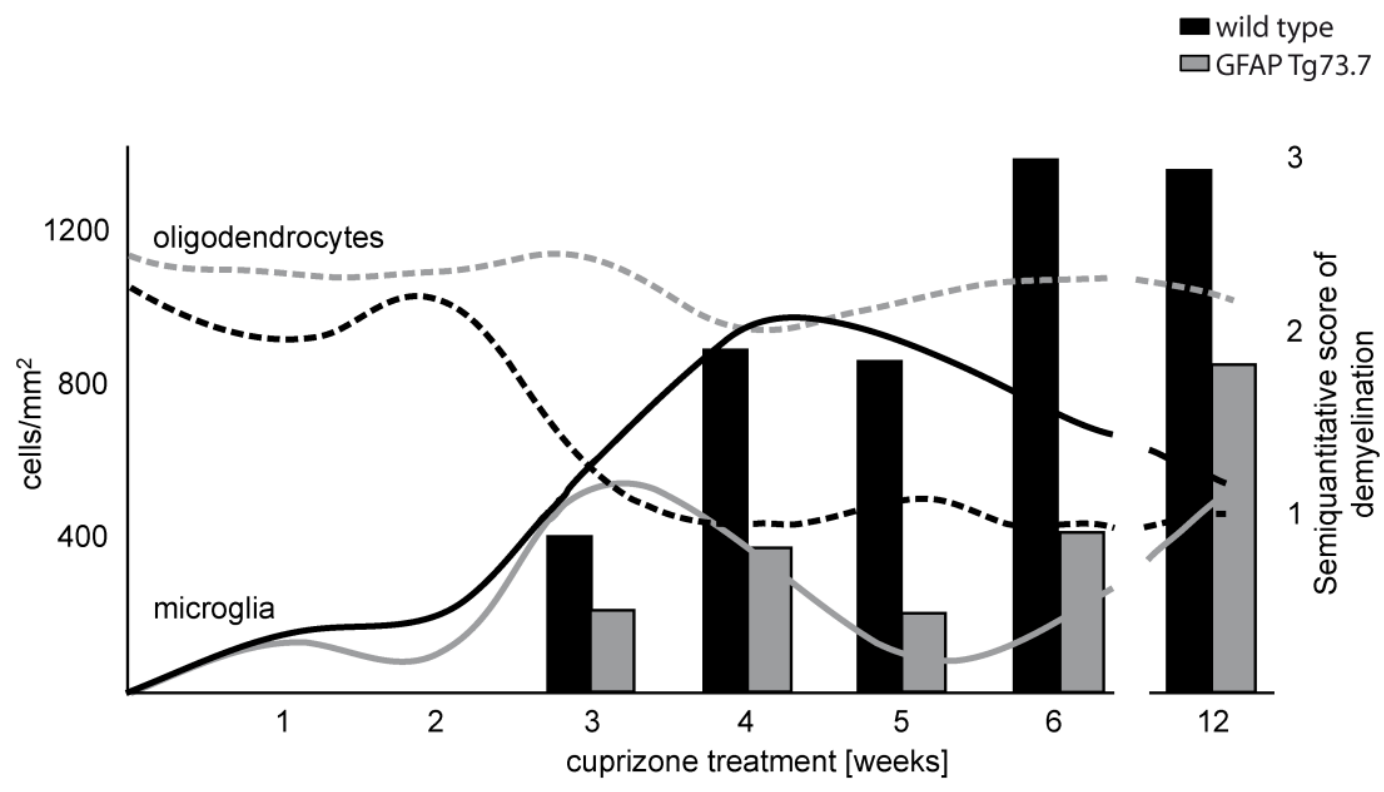

Figure 20: Summary of the effects of enhanced hGFAP expression in astrocytes on demyelination, mature oligodendrocyte numbers and microglia infiltration during cuprizoneinduced demyelination.

In wild type mice (black) decreasing mature oligodendrocyte numbers (dashed line) were associated with increasing demyelination (bars) and is paralleled by increasing microglia numbers (continuous line). Whereas in GFAP Tg73.7 mice (grey), increased astrocyte activation might lead to stable oligodendrocyte numbers and short-time microglia infiltration, with a peak at week three. Both effects are associated with attenuated cuprizone-induced demyelination (bars).

Furthermore, this study demonstrated that microglia infiltration was increased to the same extent in wild type and GFAP Tg73.7 mice after three weeks of cuprizone. Interestingly, GFAP Tg73.7 mice showed substantially less microglia infiltration from week four on compared to wild type mice. In wild type mice microglia infiltration was increasing over treatment duration with a peak after four weeks (Figure 20). To analyse the effect of enhanced astrocytic hGFAP expression on microglial myelin phagocytosis, phagocytosis activity of microglia was analysed via flow cytometry in vitro. For that purpose, microglia were co-culture for 24 hours with either astrocytes with enhanced hGFAP expression or wild type astrocytes and incubated with isolated myelin. This study shows that astrocytes reduced microglia phagocytosis activity independent of enhanced hGFAP expression.

Additionally, focal lesion induction via lysolecithin injection was performed in the corpus callosum of GFAP Tg73.7 mice and wild type mice. Seven days post lesion induction demyelinated lesion size was smaller in GFAP Tg73.7 mice compared to 
wild type mice. Oligodendrocyte numbers in the lesion area were decreased and microglia infiltration increased in both transgenic and wild type mice.

To investigate underlying mechanisms of the attenuated cuprizone course in GFAP Tg73.7 mice, cytokine mRNA expression was analysed with quantitative real-time PCR (qPCR) after three and six weeks of cuprizone. This study demonstrated that the expression of $\mathrm{C}-\mathrm{C}$ motif ligand 2 (CCL2) was less up-regulated in GFAP Tg73.7 mice compared to wild type mice after three and six weeks of cuprizone treatment. The expression level of C-X-C motif ligand 10 (CXCL10) was also less up-regulated after six weeks of cuprizone treatment in GFAP Tg73.7 mice but highly up-regulated in wild type mice. Both chemokines are regulated by the nuclear factor (NF)-KB pathway (Ohmori \& Hamilton 1993, Ueda et al 1994).

To investigate whether NF-KB activation is regulated in astrocytes with enhanced hGFAP expression, NF-KB activity was assessed in vitro and in vivo. In vitro results show that in astrocytes of GFAP Tg73.7 mice NF-kB activity was substantially less compared to wild type astrocytes upon cytokine stimulation. Furthermore, NF-KB activity was assessed in vivo in astrocytes in mice with focal lesions. In line with the in vitro results astrocytes of GFAP Tg73.7 mice showed less NF-kB activity compared to activity in wild type mice within the lesion area.

\subsection{Reactive astrocytes have diverse function}

In the present study a transgenic model with reactive astrocytes was used. The present study confirms that in naïve GFAP Tg73.7 mice enhanced expression of hGFAP in astrocytes leads to a phenotype of reactive astrocytes without external stimuli, as shown before (Brenner et al 2001, Hagemann et al 2005, Messing 1998). In this study, GFAP-positive astrocytes showed a reactive morphology with easily visible, enlarged cell bodies and thickened processes (Figure 2). This is in line with the described up-regulation of GFAP in reactive astrocytes (Eng \& Ghirnikar 1994), which is accompanied by modifications in the cell morphology shown by increased thickness of astrocytic processes (Wilhelmsson et al 2006).

During demyelination reactive astrocytes are discussed to have detrimental as well as beneficial effects. On the one hand, reactive astrocytes around the demyelinated lesion create a functional barrier (glial scar) between lesion and surrounding tissue 
(Sofroniew 2009, Sofroniew 2015). This barrier decreases the spreading of inflammatory cells into the lesion and therefore regulates inflammation (Brambilla et al 2014, Voskuhl et al 2009). In the present study, reactive astrocytes might barrier the diffusion of injected lysolecithin and reduced the demyelinated lesion area (for detailed discussion see section 4.3.1). Furthermore, reactive astrocytes secrete, among others, the growth factors brain-derived neurotrophic factor (BDNF) and platelet derived growth factor (PDGF) to promote oligodendrocyte differentiation and improve myelination after demyelination (Fulmer et al 2014, Moore et al 2011). Recently it was demonstrated that also human astrocytes grown under serum-free conditions promote neuronal survival by secreting soluble factors in vitro (Zhang et al 2016). In regard to the present results, the secretion of growth factors might promote oligodendrocyte survival in GFAP Tg73.7 mice during cuprizone-induced demyelination (see section 4.3.2). With their reactive oxygen species (ROS) eliminating ability astrocytes protect neurons from oxidative stress (Desagher et al 1996). High levels of reactive oxygen species (ROS) are toxic to oligodendrocytes and neurons and contribute to demyelination and axonal damage during MS (Gilgun-Sherki et al 2004, Lassmann et al 2001). During demyelination ROS is produced by microglia through the activation of the nicotinamide adenine dinucleotide phosphate (NAPDH) oxidase (Block et al 2007, Qian et al 2007). On the other hand, also reactive astrocytes contribute to increased demyelination through the production of ROS, as demonstrated in human astrocytes in vitro (Sheng et al 2013). Additionally, the glial scar formed by reactive astrocytes inhibits the regeneration ability in the central nervous system (CNS) by providing inhibitory factors that stop axonal growths (Davies et al 1999, Davies et al 1997). The diverse functions of astrocyte are complex and can prevent or increase demyelination. Alerted astrocyte function may lead to the observed attenuated toxin-induced demyelination may in this study.

Reactive astrocytes modulate their environment by secreting cytokines. Therefore, reactive astrocytes express a specific subset of cytokines and chemokines (Choi et al 2014, Eddleston \& Mucke 1993, Meeuwsen et al 2003, Zamanian et al 2012). Indeed, CXCL10 and CCL2 play an important role in the recruitment of microglia (Ransohoff et al 1993). By binding to the complementary receptor these chemokines induce chemotaxis and activation in microglia; the receptors expressed by microglia include CXCR3 (ligand CXCL10) and CCR2 (ligand CCL2) (Hanisch 2002, Simpson 
et al 2000a). In the present study less up-regulated chemokine expression may regulate microglia recruitment during cuprizone treatment (for detailed discussion see section 4.4.2). Furthermore, CXC chemokines secreted by astrocytes can interact with oligodendrocytes as oligodendrocytes express the chemokine receptor CCR1, CCR2 and CXCR3 (Omari et al 2005). The less up-regulation of chemokine expression observed in the present study may affect oligodendrocytes (see section 4.3.3). Altered chemokine expression by reactive astrocytes may have various consequences on the other glial cells.

\subsection{Astrocytes with enhanced hGFAP expression protect from oligodendrocyte loss during cuprizone-induced demyelination}

\subsubsection{Beneficial effects of reactive astrocytes due to enhanced hGFAP expression during toxic demyelination}

The present results point out that enhanced astrocytic hGFAP expression leads to reduced cuprizone- (Figure 5) and lysolecithin-induced demyelination (Figure 11) in GFAP Tg73.7 mice. In contrast, pronounced demyelination is observed in wild type mice. The course of demyelination observed in wild type mice is in line with previous studies where cuprizone induced demyelination starts around week three and results in severe demyelination after six weeks (Buschmann et al 2012, Gudi et al 2009, Hiremath et al 1998), whereas lysolecithin induces demyelinated lesions within days (Hall 1972, Hall \& Gregson 1971).

Reactive astrocytes with increased thickness of their processes are able to build the glial scar over time and restrict the spread of inflammatory cells as well as infectious agents (Sofroniew 2009). In the present study, the enhanced hGFAP expression in astrocytes resulted in phenotypically reactive astrocytes already in naïve mice. Therefore, it could be concluded that reactive astrocytes were already present at the time point when lysolecithin was injected. The reactive phenotype might have restricted the dispersion of lysolecithin to a smaller area than in wild types leading to reduced demyelination. The beneficial effect of reactive astrocytes was demonstrated before as their ablation increases the outcome of CNS injuries indicating a protective role of the glial scar formation. Here, proliferating reactive astrocytes were conditionally ablated in transgenic mice expressing the herpes 
simplex virus thymidine kinase (HSV-TK) under the GFAP promotor, by administering the antiviral agent ganciclovir. These mice were generated using a fusion gene construct of HSV-TK sequence inserted into the exon of a $15 \mathrm{~kb}$ GFAP promoter cassette (Bush et al 1998). The ablation of reactive astrocytes resulted in increased damage of moderate cortical contusion injury with a $60 \%$ greater loss of cortical tissue and increased neuronal degeneration. Additionally, forebrain and spinal cord stab injuries in mice with astrocyte ablation caused increased disruption of the BBB. This disruption of the BBB increased immune cell infiltration and results in increased neuronal degeneration (Bush et al 1999, Faulkner et al 2004). Moreover, in the experimental autoimmune encephalomyelitis (EAE) model the ablation of astrocytes leads to increased disease severity with increased macrophage infiltration (Toft-Hansen et al 2011).

The beneficial effect of astrocytic GFAP expression during CNS injury was previously demonstrated in studies using mice with a GFAP knockout. GFAP knockout mice were generated by disrupting the first exon of the GFAP gene in embryonic stem cells. These mice do not develop anatomical abnormalities and astrocytes are present. In mice generated by Gomi et al (1995) and McCall et al (1996) other intermediate filaments like vimentin, nestin or neurofilaments were present, whereas in the mice generated by Pekny et al (1995) intermediate filaments are completely absent. The GFAP knockout mice generated by McCall et al (1996) were demonstrated to be more vulnerable to percussive cervical spinal cord injury. Most knockout mice died within a few minutes after injury whereas wild type mice survived several days (Nawashiro et al 1998). Another mouse strain lacking GFAP (generated by Gomi et al 1995) show increased neuronal damage in the hippocampus after traumatic brain injury or the neuroexcitotoxic agent kainic acidinduced neurotoxicity (Otani et al 2006). Further contrasting evidence was provided by other studies. Here, mice lacking GFAP show no alterations in the severity of fine needle injury of the brain (Pekny et al 1995). However, the present study provides evidence that enhanced hGFAP expression in astrocytes leads to increased resistance to toxic demyelination. In line with the above mentioned studies, this demonstrates that enhanced hGFAP expression alters astrocyte function towards being beneficial during demyelination. Previously, an altered astrocytes function was shown to attenuates cuprizone-induced demyelination (Raasch et al 2011). 
Mice with double knockout of GFAP and vimentin in astrocytes do not form intermediate filaments or develop reactive astrocytes after spinal cord injury and show increased spinal cord lesions (Pekny et al 1999). This suggests that the lack of GFAP alone in some cases can be compensated by other filament proteins such as vimentin during fine needle injuries.

\subsubsection{Astrocytes with enhanced hGFAP expression lead to oligodendrocyte preservation during cuprizone-induced demyelination but not in focal lesions}

Oligodendrocyte apoptosis is the first pathological observation during cuprizoneinduced demyelination (Hesse et al 2010, Komoly et al 1987, Mason et al 2004). The present results point out that enhanced hGFAP expression in astrocytes leads to preserved oligodendrocyte numbers during cuprizone treatment (Figure 7). The observed oligodendrocyte loss in wild type mice is in line with earlier studies (Blakemore 1972, Mason et al 2004). Oligodendrocyte apoptosis is accompanied by down-regulation of myelin protein mRNA expression after two and three weeks of cuprizone treatment (Jurevics et al 2002, Morell et al 1998). Additionally, acute axonal damage occurs due to cuprizone-induced demyelination (Lindner et al 2009).

Furthermore, this study demonstrated that enhanced hGFAP expression in reactive astrocytes decreased oligodendrocyte apoptosis by $80 \%$ indicated by activated caspase-3 immunostaining (Figure 4) after one week of cuprizone treatment. It was previously shown that oligodendrocytes undergoing apoptosis express caspase-3 during the first week of cuprizone treatment (Goldberg et al 2013, Hesse et al 2010). The decrease in oligodendrocyte apoptosis is consistent with the stable oligodendrocyte numbers observed in the present study (Figure 20) and suggests that reactive astrocytes with enhanced hGFAP expression provide protection or support for oligodendrocytes. In line with the present results another study showed that the ablation of reactive astrocytes increases oligodendrocyte damage after five weeks of cuprizone treatment by using GFAP HSV-TK transgenic mice (Skripuletz et al 2012). Additionally in line, the ablation of reactive astrocytes caused a significant increase of more than $90 \%$ oligodendrocyte loss and more severe demyelination of the white matter after longitudinal stab spinal cord injury (Faulkner et al 2004). 
Previous studies show that reactive astrocytes contribute to oligodendrocyte survival by providing growth factors. In vitro, astrocytes were shown to express increased mRNA levels of growth factors like PDGF, BDNF or bone morphogenetic protein-2A/3 (Meeuwsen et al 2003). In vivo it was shown that the overexpression of PDGF in astrocytes increased OPCs survival in lysolecithin-induced demyelinated lesions (Woodruff et al 2004). Therefore, reactive astrocytes may support oligodendrocyte survival during demyelination. Furthermore, the function of astrocytes to eliminate ROS for instance via the enzyme catalase (Desagher et al 1996) could also preserve oligodendrocytes. That ROS is selectively toxic to oligodendrocytes was demonstrated in vitro (Griot et al 1990) and cuprizone is known to induce increased oxidative stress on oligodendrocytes (Cammer 1999, Goldberg et al 2013, Hiremath et al 1998, Pasquini et al 2007). Enhanced GFAP expression might influence the ROS elimination function as it was shown that the double-knockout of GFAP and vimentin impaired the astrocyte ROS elimination function and causes increased cell death in vitro (de Pablo et al 2013).

In the present study acute axonal damage was nearly absent in GFAP Tg73.7 mice resulting in a difference of 95\% amyloid precursor protein (APP) accumulation between wild type and transgenic mice after six weeks of cuprizone treatment (Figure 8). The accumulation of APP marks disturbed anterograde axonal transport of an injured axon and, by inference, acute axonal damage (Bjartmar et al 2003, Kuhlmann et al 2002). The results of the present study demonstrated that the preserved myelination in GFAP Tg73.7 mice leads to reduced axonal damage observed in these mice (Figure 8). This is consistent with myelin sheaths being essential for maintaining axonal functions, including axonal transport (Brady et al 1999). The increased preservation of myelin in GFAP Tg73.7 mice were further confirmed on the ultrastructural level using EM. Supporting the present results a previous publication demonstrated in mice with ablated astrocytes that viable oligodendrocytes and myelinated axons correlate with the presence of reactive astrocytes whereas areas devoid of reactive astrocytes exhibit degeneration of myelin after crush spinal cord injury (Faulkner et al 2004).

Axonal integrity can also be preserved by remyelination. Here, damaged oligodendrocytes are replaced by newly generated oligodendrocytes from OPC (Blakemore 1973, Franklin 1993). In contrast, the present results indicate that 
enhanced astrocytic hGFAP expression did not affect OPCs and oligodendrocyte numbers during cuprizone treatment, except during the first week of treatment (Figure 7). Moreover, myelin sheaths in EM do not appear thinner which would indicate remyelinated axons (Dubois-Dalcq et al 2005). Together with the relatively stable oligodendrocyte numbers in GFAP Tg73.7 mice, these findings argue against a replacement of oligodendrocytes and are consistent with the theory that oligodendrocyte loss is prevented and myelin remained present. After 12 weeks of cuprizone treatment OPC and oligodendrocyte numbers were more in GFAP TG73.7 mice compared to wild type mice. This leads to the question whether increased hGFAP expression might affect remyelination which was not investigated in the present study but would be interesting for future research.

The expression of myelin proteins is required for the formation of intact myelin (Brady et al 1999, Fitzner et al 2006, Griffiths et al 1998) and, for instance, mice lacking MBP are unable to form compact myelin sheaths (Brady et al 1999). Consequently, the results of the present study show an up-regulation of MBP, PLP1 and MAG mRNA expression in GFAP TG73.7 mice after three weeks of cuprizone treatment normalised to wild type mice (Figure 13). Since a pronounced oligodendrocyte loss was observed in wild type mice from week four of cuprizone treatment leading to reduced mRNA expression of myelin genes, the measured myelin gene expression in transgenic mice represents the higher number of preserved oligodendrocytes during cuprizone treatment. Furthermore, the high levels of myelin mRNA in transgenic mice might further indicate that preserved oligodendrocytes were intact. The study by Griffiths (1998) point out that histologically visible myelin might be non-functional. PLP-deficient mice show myelin but disturbed oligodendrocyte support as the mice develop axonal swellings and degeneration (Griffiths 1998). Furthermore, in this study myelin protein expression was regulated in wild type mice before pronounced myelin loss was observed on the histological level which emphasizes that oligodendrocytes die before myelin is lost. In line, previous studies demonstrated that regulation of MBP, MAG and PLP mRNA expression starts during the first week of cuprizone treatment (Buschmann et al 2012, Hesse et al 2010). MBP and MAG had the lowest expression levels after three weeks of cuprizone treatment and then expression increased again until week six (Morell et al 1998) whereas PLP decreases over treatment duration (Groebe et al 2009). In line, in the present study MBP, MAG but 
also PLP mRNA expression is less up-regulated after six weeks compared to after three weeks of cuprizone treatment.

In contrast to preserved oligodendrocyte numbers in the cuprizone mode, in lysolecithin-induced focal lesions oligodendrocyte numbers were similarly decreased in the demyelinated lesion area of transgenic mice compared to wild type mice (Figure 11). Lysolecithin is a potent detergent lysing cell membranes including myelin (Gregson 1989, Hall 1972, Hall \& Gregson 1971). It acts rapidly within 30 minutes, after two days swollen tongues of oligodendrocytes were observed and after three days also oligodendrocyte damage (Hall 1972). The present results demonstrated that the number of oligodendrocytes in the lesion areas were not different between GFAP Tg73.7 mice and wild type mice. However, compared to the corpus callosum of naïve mice oligodendrocyte numbers were strongly decreased per square millimetre in the lesion area in GFAP Tg73.7 mice by $90 \%$ and in wild type mice by $93 \%$ indicating an extensive oligodendrocyte loss seven days after lesion induction. This suggests that most oligodendrocytes in both lesions died due to the detergent function of lysolecithin. The enhanced hGFAP expression in astrocytes seems to be prevent oligodendrocyte death in the cuprizone model but not in the lysolecithin model. However, demyelination was reduced in both models indicating different beneficial effects of reactive astrocytes during cuprizone- and lysolecithin-induced demyelination.

\subsubsection{Altered chemokine expression of astrocytes may be beneficial for oligodendrocytes during cuprizone-induced demyelination}

Oligodendrocytes express different chemokine receptors and are therefore a possible target of chemokines secreted by astrocytes. The effect of chemokines on oligodendrocytes has not yet been investigated in detail (Zeis et al 2015). However, it has been shown that oligodendrocytes express chemokine receptors such as CXCR1, CXCR2 (ligand CCL2) and CXCR3 (ligand CXCL10) which are also expressed at increased levels on oligodendrocytes in MS. The complementary ligand CXCL10 was up-regulated in activated astrocytes at the edge of active MS lesions suggesting a potential cross-talk with oligodendrocytes (Omari et al 2005). Furthermore, the effect of chemokines on oligodendrocytes was previously analysed in vitro. It was shown that quiescent astrocytes inhibited myelination by 
secreting CXCL10 whereas activated astrocytes supported myelination in rat spinal cord co-cultures. Additionally, CXCL10 protein inhibits myelination in culture (Nash et al 2011). Moreover, the treatment of OPCs with CXCL10 resulted in cell death in a concentration-dependent manner in vitro (Tirotta et al 2011). These studies suggest that CXCL10 expression during demyelination may contribute to damage of oligodendrocytes by signalling through CXCR3. In this study, CXCL10 expression was less up-regulated in GFAP Tg73.7 mice but highly up-regulated in wild type mice after six weeks of cuprizone treatment (Figure 14). This indicates that the altered CXCL10 expression in GFAP Tg73.7 mice may directly contributed to the prevented oligodendrocyte loss during cuprizone-induced demyelination.

Additionally, OPCs were shown to express the receptor for CXCL12 CXCR4. Activation via CXCR4 promotes OPC differentiation and remyelination. Furthermore, increased CXCL12 activation was observed in reactive astrocytes during cuprizone treatment (Patel et al 2010). In contrast, it was also shown that astrocytes inhibit OPC recruitment and differentiation by secretion of CXCL12 (Maysami et al 2006, Williams et al 2007). The present results demonstrated that enhanced astrocytic hGFAP expression did not affect CXCL12 mRNA expression. Expression levels were similarly not regulated in GFAP Tg73.7 mice and wild type mice after six weeks of cuprizone treatment (Figure 14). In line with this, the present study demonstrated that enhanced astrocytic hGFAP expression only leads to increased OPC numbers after one and 12 weeks of cuprizone treatment. OPC proliferation was not investigated but it might be interesting to investigate the effect of enhanced hGFAP expression on OPC proliferation and remyelination. This could be achieved, for instance, in lysolecithin-induced focal lesions.

\subsection{Astrocytes with enhanced hGFAP expression regulate microglia recruitment during cuprizone treatment}

\subsubsection{Reduced cuprizone-induced oligodendrocyte death and less myelin degeneration is associated with less microglia infiltration but not in focal lesions}

Microglia activation is crucial for demyelination. The present results confirmed this and emphasize additionally that enhanced hGFAP expression in astrocytes leads 
to a decline of infiltrated microglia after three weeks of cuprizone treatment paralleled by reduced demyelination, whereas in wild type mice microglia infiltration is increased until week six with a maximum after four weeks of cuprizone treatment (Figure 9; Figure 20). This is consistent with previous studies where microglia infiltration increased over the duration of cuprizone treatment (Blakemore 1972, Blakemore 1973, Hiremath et al 1998) with a peak after four and a half weeks (Voß et al 2012). Microglia infiltration starts during the first two weeks of cuprizone treatment, prior to demyelination and is subsequently increased until complete myelin loss (Hiremath et al 1998). Additionally, microglia infiltration correlates with acute axonal damage in the cuprizone model (Lindner et al 2009) as well as lesional macrophages in paediatric MS patients (Pfeifenbring et al 2015). This indicates an active participation of microglia in the exacerbation of the demyelination process. The contribution of microglia to demyelination is diverse as activated microglia produce inflammatory cytokines, reactive oxygen and nitrogen, which are potentially toxic for oligodendrocytes and they phagocytose myelin debris. In the cuprizone model it was previously demonstrated that phagocytosis activity of microglia is highly up-regulated during demyelination (Voß et al 2012).

Oligodendrocytes are vulnerable to inflammatory products released by microglia. In vitro it was previously shown that isolated rat microglia release nitric oxide which induces oligodendrocyte damage (Merrill et al 1993). Moreover, in vitro experiments demonstrated that oligodendrocytes are extremely sensitive to damage mediated by free radicals (Griot et al 1990). Activated microglia express increased levels of TNFa during five weeks of cuprizone treatment (Voß et al 2012) which causes oligodendrocyte and myelin damage in vitro (Selmaj \& Raine 1988). Furthermore, an in vitro study demonstrated that TNFa or IFNy is required for the neurotoxic effect of cuprizone (Pasquini et al 2007). Thus, the reduced microglia infiltration observed in GFAP Tg73.7 mice might lead to a reduced inflammatory and cytotoxic environment for oligodendrocytes in this model.

Additionally, the prevented oligodendrocyte loss in transgenic mice during cuprizone treatment resulted in less myelin degradation and might further contributed to the reduced microglia infiltration. Furthermore, the present results demonstrated that in lysolecithin-induced lesions the density of microglia infiltration was comparable increased in the lesion area of transgenic mice compared to wild type mice (Figure 
11). The high amount of death cell and myelin debris inside the focal lesions rapidly recruits microglia to remove debris which accounts for the similarly high numbers of microglia in GFAP Tg73.7 mice and wild type mice observed in this study. This assumption is further supported by previous studies which show that lysolecithin induces an influx of T-cells and rapid recruitment of monocytes, followed by resident microglia in the mouse spinal cord (Ousman \& David 2000). Furthermore, myelin phagocytosis by perivascular macrophages was observed in demyelinated lesions (Hall 1972) as well as debris-filled macrophages in rat spinal cord lesions 10 days after lesion induction (Hinks \& Franklin 1999). This further supports the assumption that high numbers of microglia infiltrated the lesion in transgenic and wild type mice to phagocytose cell and myelin debris in this study.

Whether astrocytes with enhanced hGFAP expression inhibit myelin phagocytosis was analysed in vitro in the present study in astrocyte-microglia co-cultures incubated with fluorescently labelled myelin. The presence of astrocytes reduced myelin phagocytosis activity of microglia. This is in line with a previous publication that has shown that astrocytes inhibit the phagocytosis activity of microglia in vitro by direct contact and also by the secretion of inhibitory factors (DeWitt et al 1998). However, in the present study astrocyte conditioned media had no inhibitory effect on phagocytosis activity. Thus, here direct cell-cell contact seems required. Furthermore, the present results also demonstrated that there was no difference in microglial phagocytosis between co-cultures with transgenic astrocytes or wild type astrocytes. Therefore, microglial phagocytosis activity might not be affected by astrocytes with enhanced hGFAP expression in vitro. However, enhanced astrocytic hGFAP expression may lead to reduced microglia infiltration during cuprizoneinduced demyelination in this study.

\subsubsection{Reduced CCL2 and CXCL10 mRNA expression decreases microglia recruitment during cuprizone-induced demyelination}

This study points out that elevated hGFAP expression affects microglia recruitment leading to a decline of microglia infiltration, which could be regulated by chemokines. The results of the present study demonstrated also that levels of CCL2 mRNA were less up-regulated in GFAP Tg73.7 mice while they were increased up-regulated in wild type mice after three and six weeks of cuprizone treatment. Additionally, levels 
of CXCL10 were not up-regulated in GFAP Tg73.7 mice but highly up-regulated in wild type mice after six weeks of cuprizone treatment (Figure 14). Both complementary receptors were expressed by microglia, for CCL2 (CCR2) and for CXCL10 (CXCR3) (Flynn et al 2003, Zhang et al 2007). And CCL2 and CXCL10 were demonstrated to induce migration in human and rat microglia in vitro via the induction of redistribution and polymerization of $\mathrm{f}$-actin in the microglia cytoskeleton (Cross \& Woodroofe 1999). The molecular mechanisms underlying the CCL2induced migratory activity of microglia cells involve the signalling of the ERK/MAPK pathway. It was in vitro shown that CCL2 induces the phosphorylation of Akt, Mek1/2, ERK1/2 and p90RSK whose are the downstream effectors of the phosphoinositide 3-kinase (Bose et al 2016). Thus, CCL2 is one important chemoattractant for microglia migration.

Further in vivo studies underline the relevance of CCL2 for microglia recruitment (Biancotti et al 2008, Buschmann et al 2012, Kim et al 2014). CCL2 was suggested to be involved in early microglia activation during cuprizone treatment. As it has been shown that CCL2 mRNA expression reached the maximum after one week of cuprizone treatment when microglia activation and recruitment occurs (Biancotti et al 2008). Consistent with this in dissected corpora callosa CCL2 mRNA expression peaked after one week but then decreased again (Buschmann et al 2012). Furthermore, the therapeutic effect of the drug fingolimod, which decreased the rate of relapses in relapsing-remitting MS, is associated with a reduction of CCL2 mRNA expression and a reduction of microglia recruitment after six weeks of cuprizone treatment (Kim et al 2011). This further demonstrates that CCL2 mRNA expression is associated with microglia recruitment. That astrocytes can contribute to CCL2 mRNA expression was previously shown in microdissected astrocytes via laser capture microscopy. Here, the expression of CCL2 mRNA was increased in astrocytes after five weeks of cuprizone treatment (Raasch et al 2011). Additionally, the astrocytic specific knockout of CCL2 was shown to decrease microglia recruitment in $E A E$ which was associated with a less severe EAE disease course and reduced axonal loss and demyelination (Kim et al 2014). In contrast, another studies demonstrated that microglia did not show increased CCL2 expression during five weeks of cuprizone treatment as analysed via flow cytometry (Voß et al 2012). The mentioned studies support the assumption, that astrocytes but not microglia might be the source of the measured CCL2 alterations in the present study. A further 
study demonstrated that astrocytes secrete CCL2 which induces microglia migration in vitro (El-Hage et al 2006). Together with previously published in vivo and in vitro data it can be concluded that astrocytes with enhanced hGFAP expression may regulate microglia recruitment via CCL2 in the present study.

Contrasting studies using the cuprizone model demonstrated that the mice lacking CCL2 did not show altered microglia activation after one (Clarner et al 2015), three and five weeks of treatment (Janssen et al 2016, Remington et al 2007). Only macrophage numbers were reduced in mice lacking CCL2. However, only very few macrophages, $0.5 \%$ of CD11b-positve cells, were observed in the corpus callosum during cuprizone treatment and microglia are the main immune cell population (Remington et al 2007). Furthermore, the ablation of astrocytes in the EAE model leads to an increase of CCL2 mRNA expression and no alterations of microglia infiltration in spinal cords (Toft-Hansen et al 2011). But, it is unclear whether the small number of animals, infiltrated microglia or remaining astrocytes contribute to the CCL2 increase. However, in line with the present results, the general knockout of the CCL2 receptor was shown to reduce microglia activation and disease course in EAE (Fife et al 2000).

Besides CCL2 also CXCL10 mRNA up-regulation was less in GFAP Tg73.7 mice after six weeks of cuprizone treatment in the present study. In line with this, another study showed an up-regulation of CXCL10 after five weeks of cuprizone treatment (Raasch et al 2011). Whereas others demonstrated that CXCL10 was up-regulated after one week of cuprizone treatment in wild type mice and then decreases (Biancotti et al 2008). The relevance of CXCL10 for the recruitment of microglia during cuprizone-induced demyelination was previously demonstrated in GFAP HSV-TK transgenic mice. The ablation of astrocytes reduces CXCL10 mRNA expression after three weeks of cuprizone treatment leading to a delayed microglia recruitment (Skripuletz et al 2012). Consistent with this the knockout of CXCL10 was previously shown to reduce microglia activation after one and three weeks of cuprizone treatment (Clarner et al 2015). And the knockout of its receptor CXCR3 reduces CD45- and CD11b-positive microglia after three weeks of cuprizone treatment without affecting demyelination (Krauthausen et al 2014). Also in the EAE model CXCL10 was shown to enhance microglia migration into the sub-ventricular zone (Muzio et al 2010). Additionally, it was shown that CXCL10 regulates early 
microglia recruitment during the first (Biancotti et al 2008, Clarner et al 2015) and the first three weeks (Skripuletz et al 2012) of cuprizone-induced demyelination. However, the present study demonstrated that reduced CXCL10 mRNA expression might be involved in later microglia recruitment as CXCL10 mRNA expression is upregulated in wild type mice after six weeks of cuprizone treatment. This is in line with another study demonstrating an up-regulated CXCL10 level in astrocytes after five weeks of cuprizone treatment (Raasch et al 2011). Furthermore, the present results suggest that early microglia recruitment is regulated by CCL2, which is reduced after three weeks, and later microglia recruitment might be regulated by CCL2 and CXCL10 synergistically.

The present study demonstrated by double-immunofluorescent staining that astrocytes, not microglia or oligodendrocytes express CXCL10 after six weeks of cuprizone treatment. Other studies further support astrocytes as source of CXCL10 (Clarner et al 2015, Skripuletz et al 2012). The ablation of proliferating astrocytes in GFAP HSV-TK mice leads to decreased CXCL10 mRNA expression in the EAE model (Toft-Hansen et al 2011). Here, the decrease of CXCL10 due to ablated astrocyte was not associated with a decrease of microglia infiltration, whereas the astrocyte ablation caused an increase in T-cell infiltration as well as disease severity (Toft-Hansen et al 2011). This contradictory response of T-cells and microglia to altered CXCL10 expression emphasizes the complexity of chemokine-immune-cell interactions. Also, an astrocytic knockout of CXCL10 did not alter microglia recruitment in EAE. However, clinical onset of EAE, acute demyelination and accumulation of lymphocytes was delayed due to the absence of CXCL10 (Mills Ko et al 2014) further suggesting that CXCL10 might be involved in activation and recruitment of other immune cells.

In the present work, the reduction of CXCL10 mRNA measured in vivo was additionally investigated in vitro. The results show that CXCL10 mRNA expression in astrocytes with enhanced hGFAP showed a trend towards less CXCL10 mRNA expression upon TNFa stimulation in vitro, which was, however, not significant. A possible explanation might be that the stimulation time of three hours was too short as in other studies astrocytes were stimulated for 24 hours (Choi et al 2014) or up to 48 hours (Meeuwsen et al 2003). Therefore, further experiments are needed to 
investigate in more detail whether enhanced hGFAP expression alters chemokine expression in astrocytes in vitro.

The relevance of chemokine expression for demyelinating diseases is emphasized by the finding of CXCL10 and CCL2 in MS lesions. In the brain of MS patients CXCL10 and CCL2 were localized in astrocytes of active lesions assessed in post mortem brain sections via immunohistochemical analysis (Balashov et al 1999). Further studies demonstrated via immunohistochemical analysis that CCL2 is localized in astrocytes within the lesion and in the surrounding tissue (McManus et al 1998, Simpson et al 2000b). Also in patients with secondary progressive MS CCL2 and CXCL10 are expressed by reactive astrocytes at the rim of lesions (Tanuma et al 2006). Furthermore, CXCL10 is upregulated in the cerebrospinal fluid of MS patients (Balashov et al 1999, Sorensen et al 1999).

\subsection{Reduced NF-KB activity in reactive astrocytes protects from exacerbated toxic demyelination}

It has recently been shown that reduced astrocytic NF-KB activity is associated with reduced cuprizone-induced demyelination. Brück et al (2012) demonstrated that the immunomodulatory drug laquinimod protects from cuprizone-induced demyelination via down-modulation of astrocytic NF-KB activity. The astrocyte-specific inhibition of NF-kB in knockout mice leads to reduced cuprizone-induced demyelination (Raasch et al 2011). These knockout mice were generated by overexpressing the inhibitor of KBa (human IKBa gene) under the hGFAP promoter (Brambilla et al 2005). Moreover, it was previously shown that in GFAP Tg73.7 mice astrocytic NF-kB activity was reduced after six weeks of cuprizone treatment (Pförtner 2013) which corresponds to the attenuated demyelination course observed in the present study. In addition, the present study demonstrated that enhanced hGFAP expression might lead to reduced NF-KB activity in astrocytes in lysolecithin-induced demyelinated lesions in vivo since lesions were smaller in GFAP Tg73.7 mice (Figure 12). In line with the in vivo data, this study further demonstrated that NF-KB activity was reduced in vitro in isolated astrocytes with enhanced hGFAP expression upon cytokine stimulation compared to wild type astrocytes (Figure 18). The in vitro results suggest that the decrease of NF-KB activity in transgenic astrocytes is an intrinsic process and not mediated by external factors like lysolecithin. 
A CNS wide NF-KB inhibition was previously shown to lead to reduced demyelination after five and ten weeks of cuprizone treatment whereas an oligodendrocyte specific NF-KB inhibition had no effect on cuprizone-induced demyelination (Raasch et al 2011). This suggests that oligodendroglial NF-KB is not actively involved in the demyelination process. Furthermore, the CNS wide NF-kB inhibition was shown to not alter lysolecithin-induced spinal cord demyelinated lesions 14 days post lesion (Raasch et al 2011). These findings are in contrast to the present study, because here, reduced astrocytic NF-kB activity was accompanied by reduced Iysolecithin-induced demyelination. A possible explanation for the differences might be that lesions were evaluated earlier after lesion induction in the present study, and 14 days after lesion induction early remyelination might abolish possible differences.

Furthermore, astrocytic NF-KB is also important in the EAE model. Thus, astrocytic NF-KB inhibition was shown to lead to a less severe disease course (Brambilla et al 2009) and to protect from myelin loss in the optic nerve in EAE (Brambilla et al 2012). Inhibition of astrocytic NF-KB additionally suppressed the expression of oxidative stress-related genes in the optic nerve including the inducible nitric oxide synthase and nicotinamide adenine dinucleotide phosphate (NADPH) oxidase in EAE (Brambilla et al 2012). A reduced ROS production is one mechanism how reactive astrocytes with reduced NF-KB activity may contribute to increased oligodendrocyte survival during cuprizone treatment.

If the results obtained here and the already published work in the literature is put into context, reactive astrocytes with altered NF-KB activity were shown to attenuate demyelination. The up-regulation of NF-KB dependent chemokines seem to play a major role in demyelination. The present study demonstrated less CCL2 and CXCL10 mRNA expression during reduced cuprizone-induced demyelination in GFAP Tg73.7 mice. Both chemokines are direct targets of the NF-kB signalling pathway (Ohmori \& Hamilton 1993, Ueda et al 1994). In line with the present results it was demonstrated that astrocytes from mice with a CNS-wide NF-KB inhibition show reduced expression of CXCL10 and CCL2 mRNA after five weeks of cuprizone treatment, in the EAE model and after contusive spinal cord injury (Brambilla et al 2005, Brambilla et al 2009, Raasch et al 2011). Together these results point out that a down-modulation of astrocytic NF-KB activity is beneficial 
during demyelination and could be responsible for the reduced CXCL10 and CCL2 mRNA expression. Furthermore, the findings suggest that modelling astrocytic NF$\mathrm{KB}$ activity could be a future target treating demyelinating diseases. As NF-KB regulates many cellular processes a broad systemic inhibition of NF-KB could have sever and incalculable consequences. Although, there is interest in developing efficient NF-KB inhibitor for neurodegenerative diseases (Srinivasan \& Lahiri 2015, Yamamoto \& Gaynor 2001, Yan \& Greer 2008).

\subsection{Summary and conclusions}

During the last decades it was shown that astrocytes have detrimental as well as beneficial effects during demyelination. This thesis confirms that reactive astrocytes have protective effects in models of toxic demyelination in vivo. The present results emphasize that enhanced hGFAP expression in astrocytes changed the interaction with other glia cells during cuprizone-induced demyelination. The observed altered astrocyte function leads to a protective effect on oligodendrocytes which was indicated by stable oligodendrocyte numbers, less oligodendrocyte apoptosis, increased myelin mRNA expression and less acute axonal damage during cuprizone-induced demyelination. Furthermore, it was shown that enhanced hGFAP expression in astrocytes mediated microglia recruitment indicated by lower microglia numbers. Whereas both effects were not observed in lysolecithin-induced lesions. Here oligodendrocyte loss and microglia infiltration was similar in transgenic and wild type mice. However, demyelination was also reduced in this model indicating different beneficial effects of astrocytes with enhanced hGFAP expression. Moreover, the enhanced hGFAP expression changed astrocytic chemokine expression and NF-KB signalling.

To conclude, the enhanced hGFAP expression in astrocytes causes an altered astrocyte function which leads to reduced toxin-induced demyelination. Furthermore, the present results confirm astrocytic NF-KB as one major mediating signalling pathway in this process. The measured decreased astrocytic NF-KB activity in this work might regulate the decreased CCL2 and CXCL10 mRNA expression. Thus, the reduced chemokine expression results in decreased microglia infiltration during cuprizone-induced demyelination which prevents oligodendrocyte apoptosis and 
demyelination. Therefore, the present results show that astrocytes with enhanced hGFAP expression have beneficial functions during demyelination.

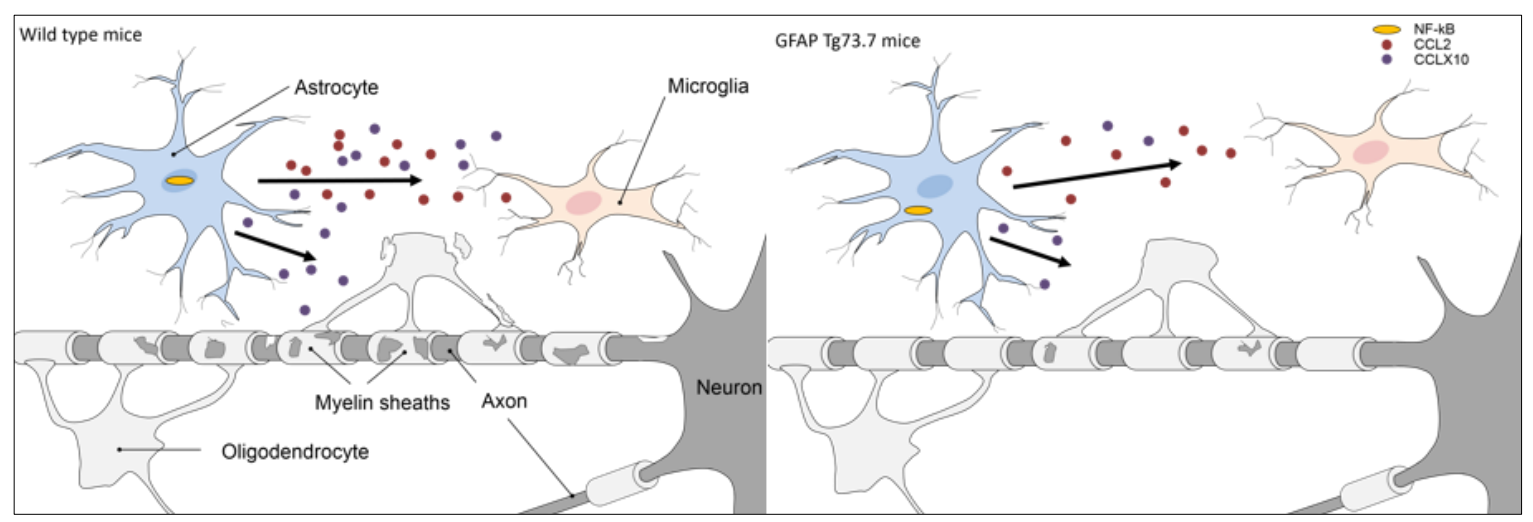

Figure 21: Schematic overview of the effects of enhanced hGFAP expression in astrocytes during cuprizone-induced demyelination resulting in preserved oligodendrocytes, myelin and reduced microglia recruitment in GFAP Tg73.7 mice.

In wild type mice (left) cuprizone induces oligodendrocyte damage and myelin degradation. The CXCL10 and CCL2 expression in astrocytes is up-regulated by nuclear translocation of NF-KB which might induce migration of microglia. Additionally, CXCL10 might directly affect oligodendrocytes. In GFAP Tg73.7 mice (right) elevated hGFAP expression in astrocytes leads to reduced oligodendrocyte apoptosis and reduced myelin degradation. The reduced NF-KB activity leads to reduced up-regulation of CXCL10 and CCL2 and decreases microglia recruitment. Lower microglia numbers might lead to the reduced oligodendrocyte loss. Thus, the present results show that astrocytes with enhanced hGFAP expression have beneficial functions during demyelination. 


\section{5 | Outlook}

The present study demonstrates that enhanced astrocytic hGFAP expression alters astrocyte functions. It would be suggested to analyse the expression of GFAP in reactive astrocytes in detail to clarify the phenotype of reactive astrocytes better. $\mathrm{A}$ newly published purification method to grow human astrocytes in serum-free conditions avoids a reactive state induced by serum contact (Zhang et al 2016). This method may be suitable to investigate the function of astrocytes with enhanced hGFAP expression in vitro. Moreover, this study shows that enhanced astrocytic hGFAP alters chemokine mRNA expression in GFAP Tg73.7 mice. Therefore, it would be interesting to investigate glial chemokine and chemokine receptor expression for each glia cell separately to draw a more detailed conclusions about the network of glia cell interaction. To understand the course of glial cell-cell interaction is relevant to better understand the role of astrocytes during the demyelination process. Additionally, earlier time points during the first days of cuprizone treatment are suggested to detect early alterations of gene expression.

Remyelination is an intrinsic repair mechanism of the CNS. To promote efficient remyelination could be a tool to improve the chronic progressive of the disease course in MS (Olsen \& Akirav 2015). The results of this study show that OPC and oligodendrocyte numbers remained high in GFAP Tg73.7 mice after six as well as after the long-term treatment of 12 weeks. OPCs differentiate to mature oligodendrocytes during remyelination and can replace damaged oligodendrocytes. Therefore, it would be of interest to investigate in vivo whether enhanced astrocytic hGFAP expression has an effect on OPC differentiation and remyelination. Additionally, in vitro experiments investigating the effect of isolated primary astrocytes with enhanced hGFAP expression on OPC proliferation in OPC enriched cell culture might provide further information about the OPC-astrocyte interaction. To understand how reactive astrocytes with enhanced hGFAP expression influence the remyelination process, might help to understand how remyelination could be promoted and whether reactive astrocytes are a target to improve recovery after demyelination. 
$6 \mid$ References

\section{6 | References}

Abbott NJ, Ronnback L, Hansson E. (2006). Astrocyte-endothelial interactions at the blood-brain barrier. Nat Rev Neurosci 7: 41-53

Alexander WS. (1949). Progressive fibrinoid degeneration of fibrillary astrpcytes associated with mental retardation in a hydrocephalic infant. Brain 72: 373381

Allen NJ, Bennett ML, Foo LC, Wang GX, Chakraborty C, et al. (2012). Astrocyte glypicans 4 and 6 promote formation of excitatory synapses via GluA1 AMPA receptors. Nature 486: 410-414

Baeuerle PA, Baltimore D. (1988). I kappa B: a specific inhibitor of the NF-kappa B transcription factor. Science 242: 540-546

Bakker DA, Ludwin SK. (1987). Blood-brain barrier permeability during Cuprizoneinduced demyelination: Implications for the pathogenesis of immunemediated demyelinating diseases. Journal of the Neurological Sciences 78: 125-137

Balabanov R, Strand K, Goswami R, McMahon E, Begolka W, et al. (2007). Interferon- $y$-oligodendrocyte interactions in the regulation of experimental autoimmune encephalomyelitis. The Journal of Neuroscience 27: 2013-2024

Balashov KE, Rottman JB, Weiner HL, Hancock WW. (1999). CCR5(+) and CXCR3(+) T cells are increased in multiple sclerosis and their ligands MIP1alpha and IP-10 are expressed in demyelinating brain lesions. Proc Natl Acad Sci U S A 96: 6873-6878

Bénardais K, Kotsiari A, Škuljec J, Koutsoudaki P, Gudi V, et al. (2013). Cuprizone [Bis(Cyclohexylidenehydrazide)] is Selectively Toxic for Mature Oligodendrocytes. Neurotoxicity Research: 1-7

Bergles DE, Jahr CE. (1997). Synaptic activation of glutamate transporters in hippocampal astrocytes. Neuron 19: 1297-1308

Besnard F, Brenner M, Nakatani Y, Chao R, Purohit HJ, Freese E. (1991). Multiple interacting sites regulate astrocyte-specific transcription of the human gene for glial fibrillary acidic protein. J Biol Chem 266: 18877-18883

Biancotti JC, Kumar S, de Vellis J. (2008). Activation of inflammatory response by a combination of growth factors in cuprizone-induced demyelinated brain leads to myelin repair. Neurochemical Research 33: 2615-2628

Bignami A, Eng LF, Dahl D, Uyeda CT. (1972). Localization of the glial fibrillary acidic protein in astrocytes by immunofluorescence. Brain Research 43: 429435

Bjartmar C, Wujek JR, Trapp BD. (2003). Axonal loss in the pathology of MS: consequences for understanding the progressive phase of the disease. Journal of the Neurological Sciences 206: 165-171

Blakemore WF. (1972). Observations on oligodendrocyte degeneration, the resolution of status spongiosus and remyelination in cuprizone intoxication in mice. Journal of Neurocytology 1: 413-426

Blakemore WF. (1973). Remyelination of the superior cerebellar peduncle in the mouse following demyelination induced by feeding cuprizone. Journal of the Neurological Sciences 20: 73-83

Block ML, Zecca L, Hong J-S. (2007). Microglia-mediated neurotoxicity: uncovering the molecular mechanisms. Nat Rev Neurosci 8: 57-69

Bose S, Kim S, Oh Y, Moniruzzaman M, Lee G, Cho J. (2016). Effect of CCL2 on BV2 microglial cell migration: Involvement of probable signaling pathways. Cytokine 81: 39-49 
Brady ST, Witt AS, Kirkpatrick LL, de Waegh SM, Readhead C, et al. (1999). Formation of compact myelin is required for maturation of the axonal cytoskeleton. J Neurosci 19: 7278-7288

Brambilla R, Bracchi-Ricard V, Hu W-H, Frydel B, Bramwell A, et al. (2005). Inhibition of astroglial nuclear factor $\mathrm{kB}$ reduces inflammation and improves functional recovery after spinal cord injury. The Journal of Experimental Medicine 202: 145-156

Brambilla R, Dvoriantchikova G, Barakat D, Ivanov D, Bethea JR, Shestopalov VI. (2012). Transgenic inhibition of astroglial NF-kappaB protects from optic nerve damage and retinal ganglion cell loss in experimental optic neuritis. $J$ Neuroinflammation 9: 213

Brambilla R, Morton PD, Ashbaugh JJ, Karmally S, Lambertsen KL, Bethea JR. (2014). Astrocytes play a key role in EAE pathophysiology by orchestrating in the CNS the inflammatory response of resident and peripheral immune cells and by suppressing remyelination. Glia 62: 452-467

Brambilla R, Persaud T, Hu X, Karmally S, Shestopalov VI, et al. (2009). Transgenic Inhibition of Astroglial NF-kB Improves Functional Outcome in Experimental Autoimmune Encephalomyelitis by Suppressing Chronic Central Nervous System Inflammation. The Journal of Immunology 182: 2628-2640

Brenner M, Johnson AB, Boespflug-Tanguy O, Rodriguez D, Goldman JE, Messing A. (2001). Mutations in GFAP, encoding glial fibrillary acidic protein, are associated with Alexander disease. Nature genetics 27: 117-120

Brenner M, Kisseberth W, Su Y, Besnard F, Messing A. (1994). GFAP promoter directs astrocyte-specific expression in transgenic mice. The Journal of Neuroscience 14: 1030-1037

Brenner M, Lampel K, Nakatani Y, Mill J, Banner C, et al. (1990). Characterization of human cDNA and genomic clones for glial fibrillary acidic protein. Brain Res Mol Brain Res 7: 277-286

Brück W, Pförtner R, Pham T, Zhang J, Hayardeny L, et al. (2012). Reduced astrocytic NF-KB activation by laquinimod protects from cuprizone-induced demyelination. Acta Neuropathologica 124: 411-424

Brück W, Porada P, Poser S, Rieckmann P, Hanefeld F, et al. (1995). Monocyte/macrophage differentiation in early multiple sclerosis lesions. Annals of Neurology 38: 788-796

Brück W, Schmied M, Suchanek G, Brück Y, Breitschopf H, et al. (1994). Oligodendrocytes in the early course of multiple sclerosis. Annals of Neurology 35: 65-73

Brück W, Stadelmann C. (2005). The spectrum of multiple sclerosis: new lessons from pathology. Current Opinion in Neurology 18: 221-224

Buschmann JP, Berger K, Awad H, Clarner T, Beyer C, Kipp M. (2012). Inflammatory response and chemokine expression in the white matter corpus callosum and gray matter cortex region during cuprizone-induced demyelination. Journal of Molecular Neuroscience 48: 66-76

Bush TG, Puvanachandra N, Horner CH, Polito A, Ostenfeld T, et al. (1999). Leukocyte Infiltration, Neuronal Degeneration, and Neurite Outgrowth after Ablation of Scar-Forming, Reactive Astrocytes in Adult Transgenic Mice. Neuron 23: 297-308

Bush TG, Savidge TC, Freeman TC, Cox HJ, Campbell EA, et al. (1998). Fulminant Jejuno-lleitis following Ablation of Enteric Glia in Adult Transgenic Mice. Cell 93: 189-201 
Cammer W. (1999). The neurotoxicant, cuprizone, retards the differentiation of oligodendrocytes in vitro. J Neurol Sci 168: 116-120

Carlton WW. (1966). Response of mice to the chelating agents sodium diethyldithiocarbamate, a-benzoinoxime, and biscyclohexanone oxaldihydrazone. Toxicology and Applied Pharmacology 8: 512-521

Choi SS, Lee HJ, Lim I, Satoh J-i, Kim SU. (2014). Human Astrocytes: Secretome Profiles of Cytokines and Chemokines. PLoS One 9: e92325

Clarner T, Janssen K, Nellessen L, Stangel M, Skripuletz T, et al. (2015). CXCL10 Triggers Early Microglial Activation in the Cuprizone Model. The Journal of Immunology 194: 3400-3413

Cross AK, Woodroofe MN. (1999). Chemokines induce migration and changes in actin polymerization in adult rat brain microglia and a human fetal microglial cell line in vitro. J Neurosci Res 55: 17-23

Dahl D, Bignami A. (1974). Heterogeneity of the glial fibrillary acidic protein in gliosed human brains. J Neurol Sci 23: 551-563

Danbolt NC. (2001). Glutamate uptake. Prog Neurobiol 65: 1-105

Davies SJ, Goucher DR, Doller C, Silver J. (1999). Robust regeneration of adult sensory axons in degenerating white matter of the adult rat spinal cord. $J$ Neurosci 19: 5810-5822

Davies SJA, Fitch MT, Memberg SP, Hall AK, Raisman G, Silver J. (1997). Regeneration of adult axons in white matter tracts of the central nervous system. Nature 390: 680-683

de Pablo Y, Nilsson M, Pekna M, Pekny M. (2013). Intermediate filaments are important for astrocyte response to oxidative stress induced by oxygenglucose deprivation and reperfusion. Histochem Cell Biol 140: 81-91

Desagher S, Glowinski J, Premont J. (1996). Astrocytes protect neurons from hydrogen peroxide toxicity. The Journal of Neuroscience 16: 2553-2562

DeWitt DA, Perry G, Cohen M, Doller C, Silver J. (1998). Astrocytes Regulate Microglial Phagocytosis of Senile Plaque Cores of Alzheimer's Disease. Experimental Neurology 149: 329-340

Dong Y, Benveniste EN. (2001). Immune function of astrocytes. Glia 36: 180-190

Dubois-Dalcq M, ffrench-Constant C, Franklin RJM. (2005). Enhancing Central Nervous System Remyelination in Multiple Sclerosis. Neuron 48: 9-12

Eddleston M, Mucke L. (1993). Molecular profile of reactive astrocytesImplications for their role in neurologic disease. Neuroscience 54: 15-36

El-Hage N, Wu G, Wang J, Ambati J, Knapp PE, et al. (2006). HIV-1 Tat and opiateinduced changes in astrocytes promote chemotaxis of microglia through the expression of MCP-1 and alternative chemokines. Glia 53: 132-146

Eliasson C, Sahlgren C, Berthold C-H, Stakeberg J, Celis JE, et al. (1999). Intermediate Filament Protein Partnership in Astrocytes. Journal of Biological Chemistry 274: 23996-24006

Eng LF. (1985). Glial fibrillary acidic protein (GFAP): the major protein of glial intermediate filaments in differentiated astrocytes. Journal of Neuroimmunology 8: 203-214

Eng LF, Ghirnikar RS. (1994). GFAP and astrogliosis. Brain Pathol 4: 229-237

Eng LF, Vanderhaeghen JJ, Bignami A, Gerstl B. (1971). An acidic protein isolated from fibrous astrocytes. Brain Research 28: 351-354

Faulkner JR, Herrmann JE, Woo MJ, Tansey KE, Doan NB, Sofroniew MV. (2004). Reactive Astrocytes Protect Tissue and Preserve Function after Spinal Cord Injury. The Journal of Neuroscience 24: 2143-2155 
Fife BT, Huffnagle GB, Kuziel WA, Karpus WJ. (2000). Cc Chemokine Receptor 2 Is Critical for Induction of Experimental Autoimmune Encephalomyelitis. The Journal of Experimental Medicine 192: 899-906

Fitzner D, Schneider A, Kippert A, Mobius W, Willig KI, et al. (2006). Myelin basic protein-dependent plasma membrane reorganization in the formation of myelin. Embo j 25: 5037-5048

Flach AC, Litke T, Strauss J, Haberl M, Gomez CC, et al. (2016). Autoantibodyboosted T-cell reactivation in the target organ triggers manifestation of autoimmune CNS disease. Proc Natl Acad Sci U S A 113: 3323-3328

Flynn G, Maru S, Loughlin J, Romero IA, Male D. (2003). Regulation of chemokine receptor expression in human microglia and astrocytes. Journal of Neuroimmunology 136: 84-93

Franklin RJM. (1993). Reconstructing myelin-deficient environments in the CNS by glial cell transplantation. Seminars in Neuroscience 5: 443-451

Fulmer CG, VonDran MW, Stillman AA, Huang Y, Hempstead BL, Dreyfus CF. (2014). Astrocyte-Derived BDNF Supports Myelin Protein Synthesis after Cuprizone-Induced Demyelination. The Journal of Neuroscience 34: 81868196

Funfschilling U, Supplie LM, Mahad D, Boretius S, Saab AS, et al. (2012). Glycolytic oligodendrocytes maintain myelin and long-term axonal integrity. Nature 485: $517-521$

Ghosh S, Baltimore D. (1990). Activation in vitro of NF-kappa B by phosphorylation of its inhibitor I kappa B. Nature 344: 678-682

Gilgun-Sherki Y, Melamed E, Offen D. (2004). The role of oxidative stress in the pathogenesis of multiple sclerosis: the need for effective antioxidant therapy. $J$ Neurol 251: 261-268

Goldberg J, Daniel M, van Heuvel Y, Victor M, Beyer C, et al. (2013). Short-term cuprizone feeding induces selective amino acid deprivation with concomitant activation of an integrated stress response in oligodendrocytes. Cell Mol Neurobiol 33: 1087-1098

Gomez-Nicola D, Perry VH. (2015). Microglial Dynamics and Role in the Healthy and Diseased Brain: A Paradigm of Functional Plasticity. The Neuroscientist 21: $169-184$

Gomi H, Yokoyama T, Fujimoto K, Ikeda T, Katoh A, et al. (1995). Mice devoid of the glial fibrillary acidic protein develop normally and are susceptible to scrapie prions. Neuron 14: 29-41

Gregson NA. (1989). Lysolipids and membrane damage: lysolecithin and its interaction with myelin. Biochemical Society Transactions 17: 280-283

Griffiths I, Klugmann M, Anderson T, Yool D, Thomson C, et al. (1998). Axonal Swellings and Degeneration in Mice Lacking the Major Proteolipid of Myelin. Science 280: 1610-1613

Griot C, Vandevelde M, Richard A, Peterhans E, Stocker R. (1990). Selective degeneration of oligodendrocytes mediated by reactive oxygen species. Free Radic Res Commun 11: 181-193

Groebe A, Clarner T, Baumgartner W, Dang J, Beyer C, Kipp M. (2009). Cuprizone treatment induces distinct demyelination, astrocytosis, and microglia cell invasion or proliferation in the mouse cerebellum. Cerebellum 8: 163-174

Gudi V, Moharregh-Khiabani D, Skripuletz T, Koutsoudaki PN, Kotsiari A, et al. (2009). Regional differences between grey and white matter in cuprizone induced demyelination. Brain Research 1283: 127-138 
Hagemann TL, Gaeta SA, Smith MA, Johnson DA, Johnson JA, Messing A. (2005). Gene expression analysis in mice with elevated glial fibrillary acidic protein and Rosenthal fibers reveals a stress response followed by glial activation and neuronal dysfunction. Human Molecular Genetics 14: 2443-2458

Hall SM. (1972). The Effect of Injections of Lysophosphatidyl Choline into White Matter of the Adult Mouse Spinal Cord. Journal of Cell Science 10: 535-546

Hall SM, Gregson N. (1971). The in vivo and ultrastructural effects of injection of lysophosphatidyl choline into myelinated peripheral nerve fibres of the adult mouse. Journal of Cell Science 9: 769-789

Hanisch U-K. (2002). Microglia as a source and target of cytokines. Glia 40: 140155

Hanisch U-K, Kettenmann H. (2007). Microglia: active sensor and versatile effector cells in the normal and pathologic brain. Nat Neurosci 10: 1387-1394

He Y, Hakvoort TB, Vermeulen JL, Ruijter JM, Uylings HB, Lamers WH. (2007). Glutamine synthetase deficiency in murine astrocytes results in neonatal death. Effects of tissue-specific inactivation of Glutamine Synthetase in the mouse: 45

Hemmer B, Cepok S, Nessler S, Sommer N. (2002). Pathogenesis of multiple sclerosis: an update on immunology. Current Opinion in Neurology 15: 227231

Hertz L. (1965). Possible role of neuroglia: a potassium-mediated neuronal-neuroglial--neuronal impulse transmission system. Nature 206: 1091-1094

Hertz L, Gerkau NJ, Xu J, Durry S, Song D, et al. (2015). Roles of astrocytic Na+,K+ATPase and glycogenolysis for $\mathrm{K}+$ homeostasis in mammalian brain. Journal of Neuroscience Research 93: 1019-1030

Hesse A, Wagner M, Held J, Brück W, Salinas-Riester G, et al. (2010). In toxic demyelination oligodendroglial cell death occurs early and is FAS independent. Neurobiology of Disease 37: 362-369

Hibbits N, Hibbits J, Yoshino T, Le R, Armstrong. (2012). Astrogliosis during acute and chronic cuprizone demyelination and implications for remyelination. ASN neuro 4: 393-408

Hinks GL, Franklin RJ. (1999). Distinctive patterns of PDGF-A, FGF-2, IGF-I, and TGF-beta1 gene expression during remyelination of experimentally-induced spinal cord demyelination. Mol Cell Neurosci 14: 153-168

Hiremath MM, Saito Y, Knapp GW, Ting JPY, Suzuki K, Matsushima GK. (1998). Microglial/macrophage accumulation during cuprizone-induced demyelination in C57BL/6 mice. Journal of Neuroimmunology 92: 38-49

Höftberger R, Fink S, Aboul-Enein F, Botond G, Olah J, et al. (2010). Tubulin polymerization promoting protein (TPPP/p25) as a marker for oligodendroglial changes in multiple sclerosis. Glia 58: 1847-1857

Huang C, Jacobson K, Schaller MD. (2004). MAP kinases and cell migration. Journal of Cell Science 117: 4619-4628

Hubbard JA, Hsu MS, Seldin MM, Binder DK. (2015). Expression of the Astrocyte Water Channel Aquaporin-4 in the Mouse Brain. ASN neuro 7

Janssen K, Rickert M, Clarner T, Beyer C, Kipp M. (2016). Absence of CCL2 and CCL3 Ameliorates Central Nervous System Grey Matter But Not White Matter Demyelination in the Presence of an Intact Blood-Brain Barrier. Mol Neurobiol 53: 1551-1564

Jurevics H, Largent C, Hostettler J, Sammond DW, Matsushima GK, et al. (2002). Alterations in metabolism and gene expression in brain regions during 
cuprizone-induced demyelination and remyelination. J Neurochem 82: 126136

Kaltschmidt B, Kaltschmidt C. (2009). NF-kappaB in the nervous system. Cold Spring Harb Perspect Biol 1: a001271

Kang K, Lee S-W, Han JE, Choi JW, Song M-R. (2014). The complex morphology of reactive astrocytes controlled by fibroblast growth factor signaling. Glia 62: 1328-1344

Keough MB, Jensen SK, Yong VW. (2015). Experimental demyelination and remyelination of murine spinal cord by focal injection of lysolecithin. $J$ Vis Exp

Kim HJ, Miron VE, Dukala D, Proia RL, Ludwin SK, et al. (2011). Neurobiological effects of sphingosine 1-phosphate receptor modulation in the cuprizone model. The FASEB Journal 25: 1509-1518

Kim RY, Hoffman AS, Itoh N, Ao Y, Spence R, et al. (2014). Astrocyte CCL2 sustains immune cell infiltration in chronic experimental autoimmune encephalomyelitis. Journal of Neuroimmunology 274: 53-61

Kinzel S, Lehmann-Horn K, Torke S, Hausler D, Winkler A, et al. (2016). Myelinreactive antibodies initiate $\mathrm{T}$ cell-mediated $\mathrm{CNS}$ autoimmune disease by opsonization of endogenous antigen. Acta Neuropathologica

Kipp M, Clarner T, Dang J, Copray S, Beyer C. (2009). The cuprizone animal model: new insights into an old story. Acta Neuropathologica 118: 723-736

Komoly S, Jeyasingham MD, Pratt OE, Lantos PL. (1987). Decrease in oligodendrocyte carbonic anhydrase activity preceding myelin degeneration in cuprizone induced demyelination. J Neurol Sci 79: 141-148

Kondo A, Nakano T, Suzuki K. (1987). Blood-brain barrier permeability to horseradish peroxidase in twitcher and cuprizone-intoxicated mice. Brain Research 425: 186-190

Kornek B, Lassmann H. (1999). Axonal pathology in multiple sclerosis. A historical note. Brain Pathol 9: 651-656

Krauthausen M, Saxe S, Zimmermann J, Emrich M, Heneka MT, Muller M. (2014). CXCR3 modulates glial accumulation and activation in cuprizone-induced demyelination of the central nervous system. J Neuroinflammation 11: 109

Kuang Y, Wu Y, Jiang H, Wu D. (1996). Selective G Protein Coupling by C-C Chemokine Receptors. Journal of Biological Chemistry 271: 3975-3978

Kuhlmann T, Lingfeld G, Bitsch A, Schuchardt J, Brück W. (2002). Acute axonal damage in multiple sclerosis is most extensive in early disease stages and decreases over time. Brain 125: 2202-2212

Lassmann H, Brück W, Lucchinetti C. (2001). Heterogeneity of multiple sclerosis pathogenesis: implications for diagnosis and therapy. Trends in Molecular Medicine 7: 115-121

Lee SH, Kim WT, Cornell-Bell AH, Sontheimer H. (1994). Astrocytes exhibit regional specificity in gap-junction coupling. Glia 11: 315-325

Lee Y, Messing A, Su M, Brenner M. (2008). GFAP promoter elements required for region-specific and astrocyte-specific expression. Glia 56: 481-493

Lee Y, Su M, Messing A, Brenner M. (2006). Astrocyte heterogeneity revealed by expression of a GFAP-LacZ transgene. Glia 53: 677-687

Liddelow SA, Barres BA. (2016). Regeneration: Not everything is scary about a glial scar. Nature 532: 182-183

Lindner M, Fokuhl J, Linsmeier F, Trebst C, Stangel M. (2009). Chronic toxic demyelination in the central nervous system leads to axonal damage despite remyelination. Neuroscience Letters 453: 120-125 
Martinez-Hernandez A, Bell KP, Norenberg MD. (1977). Glutamine synthetase: glial localization in brain. Science 195: 1356-1358

Mason JL, Toews A, Hostettler JD, Morell P, Suzuki K, et al. (2004). Oligodendrocytes and Progenitors Become Progressively Depleted within Chronically Demyelinated Lesions. The American Journal of Pathology 164: 1673-1682

Maysami S, Nguyen D, Zobel F, Pitz C, Heine S, et al. (2006). Modulation of rat oligodendrocyte precursor cells by the chemokine CXCL12. NeuroReport 17: 1187-1190

Mc Guire C, Prinz M, Beyaert R, van Loo G. (2013). Nuclear factor kappa B (NF-kB) in multiple sclerosis pathology. Trends in Molecular Medicine 19: 604-613

McCall MA, Gregg RG, Behringer RR, Brenner M, Delaney CL, et al. (1996). Targeted deletion in astrocyte intermediate filament (Gfap) alters neuronal physiology. Proceedings of the National Academy of Sciences 93: 6361-6366

McMahon EJ, Suzuki K, Matsushima GK. (2002). Peripheral macrophage recruitment in cuprizone-induced CNS demyelination despite an intact blood-brain barrier. Journal of Neuroimmunology 130: 32-45

McManus C, Berman JW, Brett FM, Staunton H, Farrell M, Brosnan CF. (1998). MCP-1, MCP-2 and MCP-3 expression in multiple sclerosis lesions: an immunohistochemical and in situ hybridization study. Journal of Neuroimmunology 86: 20-29

Meeuwsen S, Persoon-Deen C, Bsibsi M, Ravid R, van Noort JM. (2003). Cytokine, chemokine and growth factor gene profiling of cultured human astrocytes after exposure to proinflammatory stimuli. Glia 43: 243-253

Merrill JE, Ignarro LJ, Sherman MP, Melinek J, Lane TE. (1993). Microglial cell cytotoxicity of oligodendrocytes is mediated through nitric oxide. The Journal of Immunology 151: 2132-2141

Messing A. (1998). Fatal encephalopathy with astrocyte inclusions in GFAP transgenic mice. The American Journal of Pathology 152: 391

Mills Ko E, Ma J, Guo F, Miers L, Lee E, et al. (2014). Deletion of astroglial CXCL10 delays clinical onset but does not affect progressive axon loss in a murine autoimmune multiple sclerosis model. J Neuroinflammation 11: 105

Moore CS, Abdullah SL, Brown A, Arulpragasam A, Crocker SJ. (2011). How factors secreted from astrocytes impact myelin repair. Journal of Neuroscience Research 89: 13-21

Moore JW, Joyner RW, Brill MH, Waxman SD, Najar-Joa M. (1978). Simulations of conduction in uniform myelinated fibers. Relative sensitivity to changes in nodal and internodal parameters. Biophysical Journal 21: 147-160

Morell P, Barrett CV, Mason JL, Toews AD, Hostettler JD, et al. (1998). Gene expression in brain during cuprizone-induced demyelination and remyelination. Mol Cell Neurosci 12: 220-227

Muzio L, Cavasinni F, Marinaro C, Bergamaschi A, Bergami A, et al. (2010). Cxcl10 enhances blood cells migration in the sub-ventricular zone of mice affected by experimental autoimmune encephalomyelitis. Mol Cell Neurosci 43: 268280

Nash B, Thomson CE, Linington C, Arthur AT, McClure JD, et al. (2011). Functional duality of astrocytes in myelination. The Journal of Neuroscience 31: 1302813038

Nawashiro H, Messing A, Azzam N, Brenner M. (1998). Mice lacking GFAP are hypersensitive to traumatic cerebrospinal injury. NeuroReport 9: 1691-1696 
Nielsen S, Nagelhus EA, Amiry-Moghaddam M, Bourque C, Agre P, Ottersen OP. (1997). Specialized membrane domains for water transport in glial cells: highresolution immunogold cytochemistry of aquaporin-4 in rat brain. $J$ Neurosci 17: $171-180$

Ohmori Y, Hamilton TA. (1993). Cooperative interaction between interferon (IFN) stimulus response element and kappa B sequence motifs controls IFN gamma-and lipopolysaccharide-stimulated transcription from the murine IP10 promoter. Journal of Biological Chemistry 268: 6677-6688

Olsen JA, Akirav EM. (2015). Remyelination in multiple sclerosis: cellular mechanisms and novel therapeutic approaches. J Neurosci Res 93: 687-696

Omari KM, John GR, Sealfon SC, Raine CS. (2005). CXC chemokine receptors on human oligodendrocytes: implications for multiple sclerosis. Brain 128: 10031015

Otani N, Nawashiro H, Fukui S, Ooigawa H, Ohsumi A, et al. (2006). Enhanced hippocampal neurodegeneration after traumatic or kainate excitotoxicity in GFAP-null mice. J Clin Neurosci 13: 934-938

Ousman SS, David S. (2000). Lysophosphatidylcholine induces rapid recruitment and activation of macrophages in the adult mouse spinal cord. Glia 30: 92104

Pasquini LA, Calatayud CA, Bertone Uña AL, Millet V, Pasquini JM, Soto EF. (2007). The Neurotoxic Effect of Cuprizone on Oligodendrocytes Depends on the Presence of Pro-inflammatory Cytokines Secreted by Microglia. Neurochemical Research 32: 279-292

Patel JR, McCandless EE, Dorsey D, Klein RS. (2010). CXCR4 promotes differentiation of oligodendrocyte progenitors and remyelination. Proceedings of the National Academy of Sciences of the United States of America 107: 11062-11067

Peferoen L, Kipp M, van der Valk P, van Noort JM, Amor S. (2014). Oligodendrocyte-microglia cross-talk in the central nervous system. Immunology 141: 302-313

Pekny M, Johansson CB, Eliasson C, Stakeberg J, Wallen A, et al. (1999). Abnormal reaction to central nervous system injury in mice lacking glial fibrillary acidic protein and vimentin. J Cell Biol 145: 503-514

Pekny M, Leveen P, Pekna M, Eliasson C, Berthold CH, et al. (1995). Mice lacking glial fibrillary acidic protein display astrocytes devoid of intermediate filaments but develop and reproduce normally. EMBO journal 14: 1590-1598

Pekny M, Nilsson M. (2005). Astrocyte activation and reactive gliosis. Glia 50: 427434

Pekny M, Pekna M. (2014). Astrocyte reactivity and reactive astrogliosis: costs and benefits. Physiol Rev 94: 1077-1098

Pekny M, Wilhelmsson U, Pekna M. (2014). The dual role of astrocyte activation and reactive gliosis. Neuroscience Letters 565: 30-38

Pfeifenbring S, Bunyan RF, Metz I, Rover C, Huppke P, et al. (2015). Extensive acute axonal damage in pediatric multiple sclerosis lesions. Ann Neurol 77: 655-667

Pförtner R. (2013). Astroglial and therapeutic factors affect demyelination in murine models with toxic demyelination. Georg August University Göttingen, Göttingen. 127 pp.

Premack BA, Schall TJ. (1996). Chemokine receptors: Gateways to inflammation and infection. Nat Med 2: 1174-1178 
Qian L, Gao X, Pei Z, Wu X, Block M, et al. (2007). NADPH oxidase inhibitor DPI is neuroprotective at femtomolar concentrations through inhibition of microglia over-activation. Parkinsonism Relat Disord 13 Suppl 3: S316-320

Quarles RH. (2007). Myelin-associated glycoprotein (MAG): past, present and beyond. Journal of Neurochemistry 100: 1431-1448

Raasch J, Zeller N, van Loo G, Merkler D, Mildner A, et al. (2011). IkB kinase 2 determines oligodendrocyte loss by non-cell-autonomous activation of NF$\mathrm{KB}$ in the central nervous system. Brain 134: 1184-1198

Ransohoff RM, Hamilton TA, Tani M, Stoler MH, Shick HE, et al. (1993). Astrocyte expression of mRNA encoding cytokines IP-10 and JE/MCP-1 in experimental autoimmune encephalomyelitis. Faseb j 7: 592-600

Remington LT, Babcock AA, Zehntner SP, Owens T. (2007). Microglial Recruitment, Activation, and Proliferation in Response to Primary Demyelination. The American Journal of Pathology 170: 1713-1724

Richardson KC, Jarett L, Finke EH. (1960). Embedding in epoxy resins for ultrathin sectioning in electron microscopy. Stain Technol 35: 313-323

Roessmann U, Gambetti P. (1986). Astrocytes in the developing human brain. An immunohistochemical study. Acta Neuropathologica 70: 308-313

Rushton WAH. (1951). A theory of the effects of fibre size in medullated nerve. The Journal of Physiology 115: 101-122

Saab AS, Tzvetanova ID, Nave K-A. (2013). The role of myelin and oligodendrocytes in axonal energy metabolism. Current Opinion in Neurobiology 23: 1065-1072

Scheiber IF, Dringen R. (2013). Astrocyte functions in the copper homeostasis of the brain. Neurochemistry International 62: 556-565

Schmidt-Ullrich R, Memet S, Lilienbaum A, Feuillard J, Raphael M, Israel A. (1996). NF-kappaB activity in transgenic mice: developmental regulation and tissue specificity. Development 122: 2117-2128

Schönrock L, Kuhlmann T, Adler S, Bitsch A, Brück W. (1998). Identification of glial cell proliferation in early multiple sclerosis lesions. Neuropathology and Applied Neurobiology 24: 320-330

Seger R, Krebs EG. (1995). The MAPK signaling cascade. The FASEB Journal 9: 726-735

Selmaj KW, Raine CS. (1988). Tumor necrosis factor mediates myelin and oligodendrocyte damage in vitro. Ann Neurol 23: 339-346

Sharma K, Schmitt S, Bergner CG, Tyanova S, Kannaiyan N, et al. (2015). Cell typeand brain region-resolved mouse brain proteome. Nat Neurosci 18: 18191831

Sheng WS, Hu S, Feng A, Rock RB. (2013). Reactive Oxygen Species from Human Astrocytes Induced Functional Impairment and Oxidative Damage. Neurochemical Research 38: 2148-2159

Simons M, Nave K-A. (2015). Oligodendrocytes: Myelination and Axonal Support. Cold Spring Harbor Perspectives in Biology

Simpson J, Rezaie P, Newcombe J, Cuzner ML, Male D, Woodroofe MN. (2000a). Expression of the $\beta$-chemokine receptors CCR2, CCR3 and CCR5 in multiple sclerosis central nervous system tissue. Journal of Neuroimmunology 108: 192-200

Simpson JE, Newcombe J, Cuzner ML, Woodroofe MN. (2000b). Expression of the interferon- $\gamma$-inducible chemokines IP-10 and Mig and their receptor, CXCR3, in multiple sclerosis lesions. Neuropathology and Applied Neurobiology 26: 133-142 
Skripuletz T, Hackstette D, Bauer K, Gudi V, Pul R, et al. (2012). Astrocytes regulate myelin clearance through recruitment of microglia during cuprizone-induced demyelination. Brain

Sofroniew MV. (2009). Molecular dissection of reactive astrogliosis and glial scar formation. Trends in Neurosciences 32: 638-647

Sofroniew MV. (2015). Astrocyte barriers to neurotoxic inflammation. Nat Rev Neurosci 16: 249-263

Sorensen TL, Tani M, Jensen J, Pierce V, Lucchinetti C, et al. (1999). Expression of specific chemokines and chemokine receptors in the central nervous system of multiple sclerosis patients. J Clin Invest 103: 807-815

Sospedra M, Martin R. (2005). Immunology of multiple sclerosis. Annu Rev Immunol 23: $683-747$

Srinivasan M, Lahiri DK. (2015). Significance of NF-KB as a pivotal therapeutic target in the neurodegenerative pathologies of Alzheimer's disease and multiple sclerosis. Expert Opinion on Therapeutic Targets 19: 471-487

Ståhlberg A, Andersson D, Aurelius J, Faiz M, Pekna M, et al. (2011). Defining cell populations with single-cell gene expression profiling: correlations and identification of astrocyte subpopulations. Nucleic Acids Research 39: e24

Tanuma N, Sakuma H, Sasaki A, Matsumoto Y. (2006). Chemokine expression by astrocytes plays a role in microglia/macrophage activation and subsequent neurodegeneration in secondary progressive multiple sclerosis. Acta Neuropathologica 112: 195-204

Tirotta E, Ransohoff RM, Lane TE. (2011). CXCR2 signaling protects oligodendrocyte progenitor cells from IFN-gamma/CXCL10-mediated apoptosis. Glia 59: 1518-1528

Toft-Hansen H, Füchtbauer L, Owens T. (2011). Inhibition of reactive astrocytosis in established experimental autoimmune encephalomyelitis favors infiltration by myeloid cells over T cells and enhances severity of disease. Glia 59: 166176

Ueda A, Okuda K, Ohno S, Shirai A, Igarashi T, et al. (1994). NF-kappa B and Sp1 regulate transcription of the human monocyte chemoattractant protein-1 gene. The Journal of Immunology 153: 2052-2063

Ullian EM, Sapperstein SK, Christopherson KS, Barres BA. (2001). Control of Synapse Number by Glia. Science 291: 657-661

Uyeda CT, Eng LF, Bignami A. (1972). Immunological study of the glial fibrillary acidic protein. Brain Research 37: 81-89

Van Den Berg CJ, Garfinkel D. (1971). A simulation study of brain compartments. Metabolism of glutamate and related substances in mouse brain. Biochemical Journal 123: 211-218

Voskuhl RR, Peterson RS, Song B, Ao Y, Morales LB, et al. (2009). Reactive astrocytes form scar-like perivascular barriers to leukocytes during adaptive immune inflammation of the CNS. J Neurosci 29: 11511-11522

Voß EV, Škuljec J, Gudi V, Skripuletz T, Pul R, et al. (2012). Characterisation of microglia during de- and remyelination: Can they create a repair promoting environment? Neurobiology of Disease 45: 519-528

Werner S, Saha J, Broderick C, Zhen E, Higgs R, et al. (2010). Proteomic Analysis of Demyelinated and Remyelinating Brain Tissue following Dietary Cuprizone Administration. Journal of Molecular Neuroscience 42: 210-225

Wilhelmsson U, Bushong EA, Price DL, Smarr BL, Phung V, et al. (2006). Redefining the concept of reactive astrocytes as cells that remain within their 
unique domains upon reaction to injury. Proceedings of the National Academy of Sciences 103: 17513-17518

Williams A, Piaton G, Lubetzki C. (2007). Astrocytes-Friends or foes in multiple sclerosis? Glia 55: 1300-1312

Wong Ee T, Tergaonkar V. (2009). Roles of NF-kB in health and disease: mechanisms and therapeutic potential. Clinical Science 116: 451-465

Woodruff RH, Franklin RJM. (1999). Demyelination and remyelination of the caudal cerebellar peduncle of adult rats following stereotaxic injections of lysolecithin, ethidium bromide, and complement/anti-galactocerebroside: A comparative study. Glia 25: 216-228

Woodruff RH, Fruttiger M, Richardson WD, Franklin RJM. (2004). Platelet-derived growth factor regulates oligodendrocyte progenitor numbers in adult CNS and their response following CNS demyelination. Molecular and Cellular Neuroscience 25: 252-262

Wu D, LaRosa GJ, Simon MI. (1993). G protein-coupled signal transduction pathways for interleukin-8. Science 261: 101-103

Yamamoto Y, Gaynor RB. (2001). Therapeutic potential of inhibition of the NFkappaB pathway in the treatment of inflammation and cancer. $J$ Clin Invest 107: $135-142$

Yan J, Greer JM. (2008). NF-kB, a Potential Therapeutic Target for the Treatment of Multiple Sclerosis. CNS \& Neurological Disorders - Drug Targets (Formerly Current Drug Targets 7: 536-557

Yeh TH, Lee da Y, Gianino SM, Gutmann DH. (2009). Microarray analyses reveal regional astrocyte heterogeneity with implications for neurofibromatosis type 1 (NF1)-regulated glial proliferation. Glia 57: 1239-1249

Zamanian JL, Xu L, Foo LC, Nouri N, Zhou L, et al. (2012). Genomic analysis of reactive astrogliosis. The Journal of Neuroscience 32: 6391-6410

Zeis T, Enz L, Schaeren-Wiemers N. (2015). The immunomodulatory oligodendrocyte. Brain Res

Zhang J, Shi XQ, Echeverry S, Mogil JS, De Koninck Y, Rivest S. (2007). Expression of CCR2 in both resident and bone marrow-derived microglia plays a critical role in neuropathic pain. J Neurosci 27: 12396-12406

Zhang Y, Sloan Steven A, Clarke Laura E, Caneda C, Plaza Colton A, et al. (2016). Purification and Characterization of Progenitor and Mature Human Astrocytes Reveals Transcriptional and Functional Differences with Mouse. Neuron 89: 37-53 